\title{
Consolidation of parental monitoring variables and scales: Preliminary evidence for construct validity
}

\author{
Ryan J. Anderson \\ West Virginia University
}

Follow this and additional works at: https://researchrepository.wvu.edu/etd

\section{Recommended Citation}

Anderson, Ryan J., "Consolidation of parental monitoring variables and scales: Preliminary evidence for construct validity" (2009). Graduate Theses, Dissertations, and Problem Reports. 4438.

https://researchrepository.wvu.edu/etd/4438

This Thesis is protected by copyright and/or related rights. It has been brought to you by the The Research Repository @ WVU with permission from the rights-holder(s). You are free to use this Thesis in any way that is permitted by the copyright and related rights legislation that applies to your use. For other uses you must obtain permission from the rights-holder(s) directly, unless additional rights are indicated by a Creative Commons license in the record and/ or on the work itself. This Thesis has been accepted for inclusion in WVU Graduate Theses, Dissertations, and Problem Reports collection by an authorized administrator of The Research Repository @ WVU. For more information, please contact researchrepository@mail.wvu.edu. 
Consolidation of Parental Monitoring Variables and Scales: Preliminary Evidence for Construct Validity

Ryan J. Anderson, M.A.

Thesis submitted to the Eberly College of Arts and Sciences at West Virginia University in partial fulfillment of the requirements

for the degree of

\author{
Master of Science \\ in \\ Psychology
}

Cheryl B. McNeil, Ph.D., Chair

William J. Fremouw, Ph.D.

JoNell Strough, Ph.D.

Department of Psychology

Morgantown, West Virginia

2009

Keywords: parent-adolescent relationships, parental monitoring, parenting, parenting style, monitoring, self-disclosure 


\author{
Abstract \\ Consolidation of Parental Monitoring Variables and Scales: Preliminary \\ Evidence for Construct Validity
}

Ryan J. Anderson

The aim of the present study was to improve definitions of parental monitoring constructs by reducing the domain of content from which researchers have sampled in previous investigations. For example, between the years of 1991 and 2007 researchers developed at least 49 different parental monitoring scales comprised of a total of 310 questions or items. Visual inspection of these scales as well as thorough review of the parental monitoring literature suggested that researchers primarily were interested in assessing five domains of content (the sum of which is described as parental monitoring). These five domains of content are 1) adolescent perceptions of parental monitoring knowledge, 2) parental behavioral control, 3) parental psychological control, 4) parent-adolescent relationship quality, and 5) parent-adolescent communication. Three exploratory hypotheses were posited for the present investigation. First, it was hypothesized that five empirically derived factors would adequately represent the five domains of content. Second, it was hypothesized that the factors would be conceptually distinct, yet moderately correlated. Third, it was hypothesized that the adolescent-driven practice of self-disclosure to parents would be subsumed by a parent-adolescent communication factor. To test these hypotheses, a sample of 320 college undergraduate students provided retrospective accounts of their parental monitoring experiences as assessed by the pool of 310 parental monitoring questions. Results of exploratory factor analysis showed that seven factors accounted for $66 \%$ of the variance in the observed data. In spite of identifying seven factors instead of five, inspection of the questions subsumed by the seven factors showed that the seven factors mapped onto the five domains of content. The seven factors did show moderate intercorrelations as well as a pattern of convergent correlations with a well-validated measure of parent-adolescent communication. Contrary to expectations, adolescent self-disclosure to parents was subsumed by a parental monitoring knowledge factor rather than a parent-adolescent communication factor. The partial support for the three exploratory hypotheses was discussed according to models of human development that emphasize research strategies sensitive to person, process, context, and time. 


\section{Acknowledgements}

I would like to thank the members of my thesis committee for their flexibility over the course of this project. Thanks to Steven Branstetter for remaining committed to the study in spite of geographical distance. Thanks to Cheryl McNeil for chairing the committee and maintaining that critical ratio of labeled praise to positively-stated direct commands. Thanks to JoNell Strough and Bill Fremouw, who on short notice agreed to be a part of the reconfigured thesis committee. Surely the length of this document caused the latter member at least a small amount of grief. (I promise to be more concise for the dissertation). Finally, thanks to Lesley Cottrell for her input in the early stages of this project. 
Title Page

$\begin{array}{ll}\text { Abstract } & \text { ii }\end{array}$

$\begin{array}{ll}\text { Acknowledgments } & \text { iii }\end{array}$

Table of Contents $\quad$ iv

List of Tables $\quad$ vi

Introduction $\quad 1$

$\begin{array}{ll}\text { Literature Review } & 4\end{array}$

$\begin{array}{ll}\text { Present Study } & 36\end{array}$

$\begin{array}{ll}\text { Method } & 39\end{array}$

$\begin{array}{ll}\text { Participants } & 39\end{array}$

$\begin{array}{ll}\text { Procedure } & 40\end{array}$

$\begin{array}{ll}\text { Measures } & 43\end{array}$

$\begin{array}{ll}\text { Results } & 48\end{array}$

$\begin{array}{ll}\text { Preliminary Analyses } & 48\end{array}$

$\begin{array}{ll}\text { Primary Analyses } & 58\end{array}$

$\begin{array}{ll}\text { Discussion } & 68\end{array}$

$\begin{array}{ll}\text { Factor Labels } & 70\end{array}$

$\begin{array}{ll}\text { Limitations } & 83\end{array}$

$\begin{array}{ll}\text { Implications and Future Directions } & 87\end{array}$

$\begin{array}{ll}\text { Conclusion } & 91\end{array}$

$\begin{array}{ll}\text { References } & 92\end{array}$

$\begin{array}{ll}\text { Appendixes } & 104\end{array}$ 
Tables 


\section{List of Tables}

1. Number of Unique Scales Used to Measure Parental Monitoring Constructs Across 29 Core Studies

2. Participant Demographics

3. Descriptive Statistics for the Parental Monitoring Variables

4. Factor Loadings for the Parental Monitoring Variables

5. Correlations Among Parental Monitoring Factors

6. Correlations Among Parental Monitoring Factors and the Parent-Adolescent Communication Scale 


\section{Consolidation of Parental Monitoring Variables and Scales: Preliminary \\ Evidence for Construct Validity}

It is late in the evening and your teenage son or daughter is out with friends. Before your teen left the house, you asked about where he or she would be and with whom. This is somewhat reassuring information, yet you are aware of the seriousness of the pressures facing teenagers and cannot help being concerned. You ask yourself: "Have I done everything to ensure my child's safety? Did I make my expectations clear? Is there anything else I should have done or said?"

These types of questions are common among the parents of adolescents - and rightly so. For example, the Youth Risk Behavior Surveillance reported by the Centers for Disease Control (CDC; 2008) revealed that over $20 \%$ of adolescents reported current cigarette use. Additionally, over one-quarter of all adolescents reported drinking five or more alcoholic beverages on one occasion within the past 30 days, and nearly as many reported using marijuana at least once in the past 30 days. Furthermore, nearly half (46.7\%) of adolescents reported ever engaging in sexual intercourse; $14.4 \%$ reported having had four or more partners, and among the $34.3 \%$ who had been sexually active within the past three months, $37 \%$ had not used condoms.

The cause for concern is evident. Parents are left to consider what role they can possibly play in equipping their adolescents to face a set of complex decisions regarding substance use, delinquent behavior, sexual activity, and a range of other problem behaviors. Popular media messages such as the National Youth Anti-Drug Media Campaign offer seemingly viable solutions: "Be a better listener," "Don't react in a way that will cut off further discussion," and "Encourage your child to feel comfortable telling you about problems they may be having and asking you for help" (Office of National Drug Control Policy [ONDCP], 2008). Such advice is 
aimed at facilitation of parent-adolescent relationships with the goal of helping parents monitor their adolescent's activities. This advice is consistent with traditional interpretations of parentactive strategies for the monitoring of adolescents. For instance, Dishion and McMahon (1998) defined parental monitoring of youth risk behavior as "a set of correlated parenting behaviors involving attention to and tracking of the child's whereabouts, activities, and adaptations" (p. 61). This definition makes apparent the longstanding assertion that monitoring is an activity in which parents actively engage (see Dishion, 1990; Dornbusch et al., 1985; Patterson \& Stouthamer-Loeber, 1984). Yet within the past decade, other researchers have challenged the notion that monitoring is exclusively parent-active behavior. This latter contingent of researchers has noted that monitoring is also knowledge that parents obtain, often by no tangible efforts of their own. In fact, Stattin and Kerr (2000) found that monitoring knowledge was best predicted by adolescent self-disclosure. That is, parents come to know information not by actively seeking it; rather, parents receive knowledge through their adolescent's voluntary disclosure of information. These findings have implications for parent-adolescent interactions. The best empirical evidence to date suggests that parent-adolescent interaction is a transactional, dynamic process of socialization where both parent and adolescent behaviors are associated with outcomes such as adolescent decisions to use alcohol, tobacco, and other drugs; engage in sexual intercourse; or become involved in delinquent activity.

Subsequent to reports of findings that support the primacy of adolescent-driven processes to parental monitoring, researchers have begun to study variables thought to measure the transactional or bidirectional socialization that occurs between parents and adolescents and its relation to the aforementioned problematic outcomes. For example, researchers have investigated parent-adolescent communication (Cottrell, Yu et al., 2007; Huebner \& Howell, 2003; Miller- 
Day, 2008; Yu et al., 2006), family composition (Fisher, Leve, O’Leary, \& Leve, 2003), adolescent perceptions of family functioning (Henry, Ronbinson, Neal, \& Huey, 2006), adolescent beliefs about the legitimacy of parental authority (Darling, Cumsille, \& Martinez, 2007; Laird, Pettit, Dodge, \& Bates, 2003; Smetana \& Daddis, 2002), and adolescent perceptions of parenting practices (Borawski, Ievers-Landis, Lovegreen, \& Trapl, 2003). These studies reflect the increased emphasis on adolescents as active agents in their own monitoring - a focus that is less obvious in popular media campaigns or even in common sense attempts to deal with the day-to-day stress of being the parent of an adolescent.

The accumulating evidence in support of the role of adolescents as active agents in their own monitoring, leads to a new set of research questions such as how to define new variables of interest, which variables of interest show the strongest relations with adolescent outcomes, and how the variables of interest are related to one another. Unfortunately, the development of measures to advance a more balanced study of parent-adolescent socialization within the context of parental monitoring is not well established. For example, researchers operationalize constructs such as parental behavioral control in qualitatively different ways, using many different scales and items. For instance, Barber (2002) has conceptualized parental behavioral control as overt parental expectations for behavior, enforcement of such expectations, and direct monitoring behavior to ensure those expectations are met. As such, parental behavioral control is believed to be a beneficial, protective parenting practice. Findings reported by Soenens, Vansteenkiste, Luyckx, and Goossens (2006) support this assertion. Stattin and Kerr (2000), however, have conceptualized parental behavioral control as more intrusive, overlapping to some degree with parental psychological control. Other inconsistencies in assessing behavioral control (as well as other core parental monitoring constructs) are found throughout the parental monitoring 
literature. In fact, in the 29 core parental monitoring articles that were reviewed for the present study, more than 10 distinct measures of parental behavioral control were identified. Therefore, the present study is concerned with identifying a core of empirically supported variables most commonly used to tap the constructs thought to underlie parental monitoring processes - whether the processes are parent-driven, adolescent-driven, or the result of some combination of parentand adolescent-driven processes. Such findings will serve to better inform future investigations and, perhaps, permit greater attention to the troubling questions parents face in the hours after their adolescent sons and daughters have gone out for the evening.

\section{Literature Review}

Twenty-nine core parental monitoring articles published over the course of the past 25 years describe a set of parent- and adolescent-driven behaviors that are directly related to parents' knowledge of their adolescents' whereabouts, activities, and adjustment. These parent and adolescent behaviors, in turn, are most commonly shown to be related to problem outcomes, either by direct means or indirectly through parental knowledge (e.g., Fletcher, Steinberg, \& Williams-Wheeler, 2004; Soenens et al., 2006). Consider the following representative example: A mother and her adolescent son spend a few minutes just talking each day. The mother is not intrusive; rather, she just wants to let her son know that she is interested in things that are important to him. If the son does not wish to talk, his mother respects his privacy. Over time, the son begins to seek out his mother outside of these casual conversations to discuss weightier issues. Through this latter type of discussion, the mother beings to learn more about the pressures her son faces to smoke, use substances, and engage in sexual behavior. Subsequently, the mother is able to adjust her parenting approach in a manner that is sensitive to these concerns and is founded on an open pattern of communication. 
The preceding practical example demonstrates a complex set of parent-adolescent interactions; therefore, parental monitoring may not be the most apt label as it implies only parent-driven behaviors. Throughout this review, parenting behavior will be the generic terminology used to describe parent-driven strategies. When the focus of discussion is on adolescent-driven processes, it will be labeled as such. Parental monitoring will be used in reference to the research literature as a whole. Finally, when the focus of discussion is on the give-and-take between parents and adolescents, it will be described as "interactive monitoring." It is believed that this new phraseology best captures processes that depend on what both parents and adolescents do.

In addition to specifying terminology to describe various monitoring processes, the present study is concerned with defining these processes. That is, parental monitoring researchers have used many different items and scales to assess the constructs of interest (see Table 1). To what extent do these different measures share common variance? To what extent do they account for unique variance? Do newer scales such as those designed to assess adolescent self-disclosure (e.g., Stattin and Kerr, 2000) as well as more general measures of parent-adolescent communication (e.g., Huebner and Howell, 2003) represent new, distinct constructs, or do they share the majority of their variances with well-established relationship-oriented variables such as family support (Barnes, Farrell, \& Banerjee, 1994) and parental warmth and involvement (Lamborn, Mounts, Steinberg, \& Dornbusch, 1991)? These questions point to the complexity of the parental monitoring literature and the importance of defining a parsimonious measurement model. 


\section{Types of Validity}

In order to provide a frame of reference for the present literature review and subsequent empirical study, it is necessary to define several types of validity. Content and construct validity have thus far been alluded to, yet it is important to provide a more precise denotation of different types of validity.

Cronbach and Meehl (1955) noted that content validity is foundational to construct validity and "is established by showing that the test items are a sample of a universe in which the investigator is interested" (p. 282). More specifically, the content validity of tests is "established by defining a universe of items and sampling systematically within this universe to establish the test" (p. 282). The universe of content is established deductively; that is, by making many observations and subsequently generalizing these observations to individual cases. Thus, the universe of content is the set of all observations of the phenomenon of interest. Most areas of scientific investigation fail at sampling all observations, and ultimately are restricted (by a number of real-world constraints) to sampling many observations.

Cronbach and Meehl (1955) defined construct validity as "some postulated attribute of people, assumed to be reflected in test performance" (p. 282). For example, a person who responded in the affirmative to test questions about feeling sad, empty, or worthless; having reduced interest in enjoyable activity; having reduced levels of energy; experiencing changes in weight; and experiencing changes in sleep is described as depressed or experiencing depression. Depression itself is not directly observable; however, some of the postulated facets of depression are directly observable. For instance, a person who has lost interest in an enjoyable activity could be observed participating in that activity at a reduced rate. 
To establish construct validity, at least two procedures are required. First, a "numerical estimate of construct validity" (Cronbach \& Meehl, 1955, p. 289), such as factor analysis must be provided. Second, the lawful relations of the construct to other well-established constructs must be shown. Given preliminary evidence for construct validity, researchers posit labels that are brief statements about the essential facet of the construct. Construct labels are similar to concepts or classes of closely related stimuli. Constructs have practical value in the sense that they afford people the opportunity to identify common thoughts, feelings, and experiences. Construct labels have practical value to scientists in much the same manner given that a wellestablished construct allows researchers to conduct investigations in a stepwise manner so as to accumulate information about a particular phenomenon.

In subsections of the present literature review, the parental monitoring literature was organized according to five commonly investigated constructs: 1) parental monitoring knowledge, 2), parental monitoring behavior, 3) parental psychological control, 4) parentadolescent relationship quality, and 5) parent-adolescent communication. This accounts for recent studies that have described monitoring as a parent-adolescent interactive process (e.g., Fletcher et al., 2004; Soenens et al., 2006; Waizenhofer, Buchanan, \& Jackson-Newsom, 2004). Thus, the chief goal of the present review and subsequent empirical study was to summarize the most commonly investigated parental monitoring variables (i.e., items) according to a numerical estimate of their construct validity as well as a numerical estimate of their relations with other previously validated constructs.

\section{Outcomes in Parental Monitoring Studies}

Externalized behaviors in the context of the parental monitoring literature are best described as adolescent behavior that is directly observable and has potentially adverse 
consequences for adolescents and families. In the context of the Diagnostic and Statistical Manual of Mental Disorders (DSM-IV-TR; American Psychiatric Association [APA], 2000), externalized behavior disorders are diagnosed in childhood and adolescence and include Attention-Deficit/Hyperactivity Disorder, Oppositional Defiant Disorder, Conduct Disorder, and Disruptive Behavior Disorder Not Otherwise Specified.

For the purpose of the present review, externalized behaviors are defined specifically as those behaviors related to obtaining, using, or selling substances, including tobacco and alcohol; general delinquency such as skipping school, vandalism, and theft of nontrivial items; and behaviors associated with negative health outcomes such as early initiation of sexual activity or sex with a number of different partners over a short period of time. Many of these more specific externalized behaviors are listed as partial criteria for several of the DSM-IV-TR diagnoses above. However, the individual problem behaviors — not the actual diagnoses—are most commonly assessed in parental monitoring studies.

Adolescent problem behaviors generally are positioned as outcome or criterion variables; however, some researchers have investigated reciprocal associations for adolescent problem outcomes and parental monitoring variables. For example, Laird, Pettit, Dodge, and Bates (2003) specified monitoring knowledge as an outcome variable and regressed it on adolescent antisocial behavior. Monitoring knowledge was defined as what parents know about where their adolescents are, what their adolescents are doing, and whom their adolescents are with. From the statistically significant regression coefficients for the antisocial behavior-monitoring knowledge relation, Laird, Pettit, Dodge, et al. (2003) concluded that adolescent involvement in antisocial behavior may actually lead to reductions in parental monitoring knowledge as opposed to the more commonly held conclusion that reductions in monitoring knowledge lead to increases in 
adolescent problem behavior (e.g., Dishion and McMahon, 1998). Limitations inherent in the study design, however, leave the authors' conclusion about the direction of the association open to debate. That is, the study was conducted with longitudinal data collected on adolescents over the course of grades nine through twelve. The researchers did not control for adolescent-driven processes or parenting behaviors that occurred prior to grade nine. Thus, it is not possible to conclude a causal relation between antisocial behavior and parental monitoring knowledge with any degree of certainty. This criticism also holds for the investigations that have specified the alternative relation where adolescent problem behaviors are regressed on parental monitoring knowledge.

Among the earliest outcomes of interest in the parental monitoring literature were opposition, defiance, and disturbances of conduct (e.g., Patterson \& Stouthamer-Loeber, 1984). Other researchers have investigated parental monitoring as related to adolescent substance use. For example, researchers have described the relation between higher degrees of parental monitoring and decreases in adolescent alcohol use (Web, Bray, Getz, \& Adams, 2002; Beck, Boyle, \& Boekeloo, 2004). Other researchers have investigated similar associations for culturally diverse samples (Barnes, Farrell, \& Banerjee, 1994; Ramirez et al., 2004). Adolescent sexual risk taking also is a well-established outcome in parental monitoring investigations, and generally is defined as early or precocious sexual activity, sexual activity with multiple partners over brief periods of time, or failure to use prophylactics (e.g., Huebner \& Howell, 2003; Wight, Williamson, \& Henderson, 2006).

Various types of adolescent social outcomes also have been specified as criterion variables. In the present review, social outcomes are defined as the quality of relationships that adolescents have within a particular institution (e.g., school, community) or interpersonal context 
(e.g., peer relationships, family relationships). Many of the same parental monitoring variables associated with delinquency, substance use, and precocious sexual activity also have shown relations with social outcomes. For instance, Steinberg (1987) assessed the role of family composition factors as related to antisocial peer pressure (see also Cernkovich \& Girodano, 1987). Other studies extended these findings to include research on deviant peer affiliation as related to parental monitoring knowledge and parenting behaviors (Brown, Mounts, Lamborn, \& Steinberg, 1993; Dishion, Patterson, Stoolmiller, \& Skinner, 1991). More recent investigations have concluded that peer influences are best interpreted as predictors of externalized behaviors rather than legitimate outcomes in their own right (e.g., Jaccard, Blanton, \& Dodge, 2005; Matza, Kupersmidt, \& Glenn, 2001; Miller \& Plant, 2003; Prinstein, Boerger, \& Spirito, 2001; Rai et al., 2003). Studies of adolescent academic achievement, where academic achievement was specified as a social outcome, have shown relations with parenting style (Steinberg, Lamborn, Dornbusch, \& Darling, 1992) and parental involvement (Spera, 2006).

In addition to externalized behaviors and social outcomes, researchers also have explored the association between parental monitoring variables and internalized outcomes, but to a lesser extent. This may be due to the fact that these problems are less salient than those that are externalized or social. In fact, with internalized problems, the adolescent may experience distress privately while adults remain unaware. Revelation of internalized problems, in many instances, may only be realized once problems surface as externalized behavior such as self-harm. In the context of DSM-IV-TR (APA, 2000), internalized outcomes are defined broadly as symptoms (but not necessarily diagnoses) of anxiety and depression. Notable research in this area has been conducted by Barber, Olsen, and Shagle (1994; Barber, 1996) who noted that patterns of parental 
psychological control were strongly associated with child and adolescent reports of internalized problems such as isolation, confusion, and low affect.

Finally, it should be noted that a number of studies have reported relations between parental monitoring variables and positive or strength-based outcomes. For example, studies have shown support for the relation of monitoring knowledge and parental support with mental well being (Hair, Moore, Garrett, Ling, \& Cleveland, 2008) and identity achievement (Sartor \& Youniss, 2002). In the former study, mental well being was defined as how often in the past month adolescents reported being happy and calm or peaceful and not depressed, downhearted, or nervous. In the study conducted by Sartor and Youniss (2002), identity achievement was defined in contrast to identity confusion. Achievement items indicated that adolescents had a clear idea of what they wanted to be, felt that they had their lives together, and were proud of what they stood for. Another study (Graber, Nichols, Lynne, Brooks-Gunn, and Botvin, 2006) showed that parental monitoring knowledge was related to competence for a sample of urban minority youth from seventh to eighth grade. Competence was defined as global self worth, assertiveness, and good grades. Relations between each of these outcomes and monitoring knowledge held for hierarchical regression models of concurrent and longitudinal data. In contrast to the first two studies cited, the study conducted by Graber et al. (2006) did not include parental monitoring variables other than parental monitoring knowledge.

It is interesting to note that the number of studies reporting on the relation of parental monitoring variables and positive outcomes are few compared to the number of studies reporting on the relation of parental monitoring variables to problem outcomes. For example, a PsycINFO search using the keyword combination "parental monitoring and problem outcomes" conducted in June 2009 yielded over 250 hits, whereas a PsycINFO search using the keyword combinations 
"parental monitoring and positive outcomes" and "parental monitoring and well-being" conducted on the same date yielded only 35 hits total. Of the 35 studies, only the three previously cited and one other study specified predictor variables that were related to the parental monitoring literature. The fourth study (Amato \& Fowler, 2002) did not specify a true positive outcome measure. That is, the measure of adolescent adjustment used by Amato and Fowler (2002) contained two negative behaviors (i.e., bullies or is cruel, loses temper easily) and two positive behaviors (i.e., does what is asked, gets along well with other kids). The two positive behavior items were reverse coded so that higher scores on the scale reflected maladjustment.

It is interesting to consider that many problem outcomes commonly investigated by parental monitoring researchers could be reframed as positive outcomes. For example, an item that reads, "How many times in the past month have you smoked marijuana?" could be reworked as, "How many times in the past month have you refused an offer to smoke marijuana?" Items reworked in this manner should not be considered as opposite sides of the same coin, and expanding the focus of outcome measures may offer at least two advantages. First, the study of positive adolescent outcomes may provide insight into what is (versus what is not working) working for parents and adolescents when those adolescents report decreased instances of problem behavior and higher levels of interpersonal and emotional adjustment. Second, positive adolescent outcomes may be more representative of the behavior of the majority of adolescents. Even though the Youth Risk Behavior Surveillance conducted by the Centers for Disease Control (CDC; 2008) reported seemingly high 30-day prevalence rates for the use of alcohol $(25 \%)$, tobacco $(20 \%)$, and marijuana (25\%); these statistics are not reflective of what the vast majority of adolescents are doing. Developing outcome measures that are more representative of the behavior of the majority of adolescents in community samples serves to reduce skew that is 
inevitably present when measuring low-frequency behaviors. Greater measurement variance as well as variables that have univariate normal distributions are related to stronger bivariate correlations between variables and improve the ability to detect hypothesized effects (Tabachnick and Fidell, 2007, chapter 4).

Finally, with regard to studies that have reported positive outcomes for parental monitoring variables, it is interesting to note that the three studies described above reported small effect sizes for the regression models tested. For example, the value of $R^{2}$ for the models reported in the three studies ranged from .07 to .19. For example, in Graber et al. (2006), effect sizes for the positive adolescent outcomes were .07 for assertiveness and .19 for self-esteem, whereas the effect sizes for the adolescent problem behaviors of delinquency and aggression given the same set of predictors were .27 and .29 . This pattern of results suggests that regression models predicting positive outcomes should be more carefully specified. Furthermore, positive outcomes should be evaluated for content, criterion, and construct validity. These goals are beyond the scope of the present study; however, it is believed that by improving evidence for the construct validity of parental monitoring variables, the present study may improve the quality of models used in future investigations of positive adolescent outcomes.

In summary, the parental monitoring literature can be described, in part, on the basis of the relations found between the five commonly investigated constructs (i.e., adolescent perceptions of parental monitoring knowledge, parental monitoring behavior, parental psychological control, parent-adolescent relationship quality, and parent-adolescent communication) and adolescent outcomes; of which, substance use, depression, and decline in academic achievement are just several examples (see Dishion and McMahon, 1998 for a more exhaustive coverage of outcome variables). Yet, even the abbreviated list of outcomes reviewed 
above shows the importance of positive parent-adolescent interactions. Mental health professionals, healthcare professionals, and educators are identified as among those who can potentially utilize these findings. Thus, it is essential that researchers communicate findings in a manner that is comprehensible to those without extensive training in the methodology of the social sciences. Therefore, researchers must make informed decisions about the variables that warrant continued investigation. This calls for balance of parsimony and inclusiveness. We turn our attention now to discussion of the five identified parental monitoring constructs: 1) parental monitoring knowledge, 2) parental monitoring behavior, 3) parental psychological control, 4) parent-adolescent relationship quality, and 5) parent-adolescent communication. The following subsections will describe the origins, definitions, and associations of the constructs. Constructs that are defined broadly, such as parent-adolescent relationship quality and parent-adolescent communication, will be reviewed with the goal of distilling more precise definitions to guide the construct validation procedures that follow the present literature review.

\section{Origin and Present Application of Five Constructs}

The parental monitoring literature has a long and varied history that spans several decades. Within the past 25 years, it has come to occupy its own space in the research enterprise of the social sciences; however, it continues to be adjacent to and frequently overlaps with other active literatures including communications and criminology. Indeed, adolescent socialization is of concern to any family presented with the unique challenges of parenting adolescents. Researchers in the area of parental monitoring have concerned themselves with answering questions directly related to these unique challenges. As such, a number of variables have been shown to guide predictions about adolescent behavior. Thus, researchers have used many different measures of the core constructs. Review of the parental monitoring literature from the 
mid-1960's to the present, however, shows that several recurring measurement themes are evident. Again, these measurement themes are the five core constructs; 1) parental monitoring knowledge, 2) parental monitoring behavior, 3) parental psychological control, 4) parentadolescent relationship quality, and 5) parent-adolescent communication.

Parental monitoring as behavior or knowledge? The origin of parental monitoring is loosely traced (e.g., Barber, 1996; Lamborn, Mounts, Steinberg, \& Dornbusch, 1991; Steinberg, Mounts, Lamborn, \& Dornbusch, 1991) to factor analytic studies of the Children's Reports of Parental Behavior Inventory (CRPBI; Schaefer, 1965a, 1965b). Schaefer (1965b) was interested in developing a conceptual model of parenting behaviors. Items included on the CRPBI were derived from psychologists' ratings of parent behavior and other inductive methods to produce twenty-six discrete components of parent behavior. Ten items were written for each component to develop a 260-item instrument. Factor analyses of the items demonstrated evidence for three orthogonal (i.e., minimally overlapping) factors: 1) Rejection versus Acceptance, 2) Psychological Control versus Psychological Autonomy, and 3) Lax Control versus Firm Control. Rejection versus Acceptance and Lax Control versus Firm Control were later used to support the classification of four parenting styles: authoritative, authoritarian, indulgent, and neglectful (Lamborn et al., 1991). These four parenting styles were found to be related to adolescent outcomes for psychosocial development, school achievement, internalized distress, and problem behavior. Authoritative parenting was associated with well-adjusted, competent adolescents who were less likely than peers from non-authoritative families to report drug and alcohol use, school misconduct, or delinquency. On the other hand, neglectful parenting was associated with negative reports across all four outcomes. Authoritarian parenting was associated with adolescent conformity to parental standards and low levels of problem behavior, but high 
levels of internalized distress and diminished social and academic ability. Indulgent parenting was associated with adolescent involvement in problem behavior and disengagement from school, but high levels of social competence and low levels of internalized distress.

Lamborn et al. (1991) concluded that these results replicated contemporary investigations of parenting style conducted by Diana Baumrind (e.g., Baumrind, 1991). They extended Baumrind's findings through differentiation of permissive parenting into two distinct parenting styles, neglectful and indulgent. This differentiation was considered relevant to the prediction of internalized behavior, but less important to the prediction of externalized behavior. With regard to the specific items used to produce the four parenting styles, Lamborn and colleagues (1991) used nine items labeled Parental Strictness/Supervision and 15 items labeled Parental Warmth/Involvement that were reportedly derivative of the Lax Control versus Firm Control and Rejection versus Acceptance factors of the CRPBI. The Strictness/Supervision items were believed to assess parenting behavior that set boundaries and limits for adolescents. However, visual inspection of the items reveals that they more likely measure parents' knowledge regarding adolescents' whereabouts and activities. For example, one such item reads: "My parents know exactly where I am most afternoons after school." Variations of the Strictness/Supervision items have appeared in other studies that assessed specific monitoring processes as opposed to composite parenting styles (e.g., Dornbusch et al., 1985; Hirschi, 1969; McCord, 1979; Patterson \& Stouthamer-Loeber, 1984).

The difference between measures that combine constructs to afford an overall impression of parenting style versus those that tap single constructs is similar to experimental studies that investigate the effects of a single independent variable versus those that investigate the effects of multiple independent variables. The experiment that assesses change on a single independent 
variable is considered a purer estimate of the effects of that independent variable, whereas an experiment that assesses change on multiple independent variables allows for determining how one independent variable affects an outcome at a given level of another independent variable, commonly called an interaction. Measures that combine constructs are similar to experiments that attempt to interpret multiple interactions. That is, the greater the number of independent variables that interact, the more difficult it is to interpret the interaction. By comparison, the effects of multiple, overlapping constructs included in the same measure are difficult to interpret. However, whereas the factorial experiment is a legitimate design strategy, correlational research that includes more than one construct in a single measure of an independent variable is not a legitimate design strategy because it is difficult to estimate how much variance in outcome is accounted for by each construct.

The solution to this potential confound is to specify and compare several measurement models to determine whether the variable of interest is unidimensional or multidimensional. That is, the researcher must show that the variable represents a single construct. If the results of the tests of measurement models show that the original variable of interest represents multiple constructs (as in a confirmatory factor analysis that shows model fit for two or more latent variables), then the original variable of interest should be treated as multiple variables, the number of which is the same as the number of hypothetical constructs (factors or latent variables) identified in the measurement model.

The fact that the composite measure described in Lamborn and colleagues (1991) crossed Parental Warmth/Involvement with Strictness/Supervision is not itself problematic. In fact, crossing these constructs had a strong theoretical basis. Rather, it was problematic given that Strictness/Supervision may have been a poor label for what was measured. That is, 
Strictness/Supervision was not a measure of parenting behavior. Instead, it was a measure of parental monitoring knowledge, or the extent to which parents know where their adolescents are, whom they are with, and what they are doing.

In a more recent investigation of parental monitoring, Stattin and Kerr (2000) emphasized the importance of distinguishing parental monitoring knowledge from parental monitoring behavior. Other investigators also have shown interest in describing the conceptual and empirical distinction between parental monitoring behavior and parental monitoring knowledge. For example, Barber (2002) developed a measure to sample parental monitoring behavior, labeled Regulation. This measure included overt parental expectations for adolescent behavior, enforcement of such expectations, and direct monitoring behavior to ensure such expectations are met. Sample items from this measure representative of each parent action include: "My mother or father is a person who has clear expectations for how I should behave in and outside the home," "My mother or father is a person who applies consequences to me if I don't behave according to her/his expectations," and "My mother or father is a person who watches to make sure I behave appropriately" (pp. 7-8).

Soenens et al. (2006) used the Regulation scales, Parental Expectations for Behavior and Parental Monitoring of Behavior. These investigators contended that Barber's (2002) Regulation measure of parental monitoring behavior assessed "less domineering" (p. 309) parenting behaviors compared to measures used by other researchers (i.e., Stattin \& Kerr, 2000). Conclusions drawn from the findings reported by Soenens et al. indicate that parental monitoring behavior and parental monitoring knowledge are distinct constructs where parents who engage in monitoring behavior are likely to be more knowledgeable about where their adolescents are, whom their adolescents are with, and what their adolescents are doing. In turn, having more 
knowledge is protective against adolescent problem outcomes. Stattin and Kerr (2000)

established the foundation for the conclusions drawn by Soenens et al. (2006); however, the former investigators differed from the latter with regard to the importance of parent- versus adolescent-driven processes.

Stattin and Kerr (2000) conducted a pivotal study that ameliorated inconsistent reporting of monitoring knowledge versus monitoring behavior by noting that earlier parental monitoring research commonly measured an "end product" (i.e., monitoring knowledge) rather than monitoring behavior (p. 1073). For example, a scale presumed to assess parental monitoring knowledge is found in Brown et al. (1993). Sample items read: "How much do your parents really know about where you go after school?" "How much do your parents really know about what you do in your free time?" and "How much do your parents really know about who your friends are?" This scale (or items sampled from it) has appeared in numerous other investigations, some of which have incorrectly described it as a measure of parental monitoring behavior (e.g., Barber, 1996; Fletcher et al., 2004; Laird, Pettit, Bates, \& Dodge, 2003; Laird, Pettit, Dodge, \& Bates; Mounts, 2001, Mounts, 2002; Pettit, Laird, Dodge, Bates, \& Criss, 2001; Steinberg, Fletcher, \& Darling, 1994).

Another commonly used parental monitoring knowledge scale historically described as a measure of parental monitoring behavior, is attributed to Silverberg and Small (1991; D. M. Gondoli, personal communication, June 5, 2008). Sample items read: "How often does your mom know where you are after school?" "How often do you talk with your mom about things you do with your free time?" and "How often does your mom know whom you're with when you're not at home?" This scale also has appeared in numerous studies (e.g., Beck et al., 2004; 
Borawski et al., 2003; Li et al., 2000; Stanton et al., 2000; Yang et al., 2006), some of which have incorrectly defined it as a measure of parental monitoring behavior.

In addition to incorrectly measuring parental monitoring behavior through improper use of measures of parental monitoring knowledge, other problems exist with regard to the measurement of these two parental monitoring variables. For example, visual inspection of some measures shows a mix of behavior, knowledge, and even communication items, suggesting that such measures are not unidimensional. As previously noted, composite scores from multidimensional measures confound the constructs of interest, making it impossible to determine which construct is accounting for the variance in outcome. For example, a scale attributed to Small and Kerns (1993; as cited in Beck et al., 2004; Huebner \& Howell, 2003) included items: "My parents know where I am after school," "My parents monitor my computer/internet use," and "I tell my parents whom I'm going to be with before I go out." These items seem to measure three conceptually different parental monitoring constructs: knowledge, behavior, and adolescent self-disclosure, respectively. Other examples of multidimensional scales that have been treated unidimensionally are found in Barnes and colleagues (1994; Barnes et al., 2006), Longest and Shanahan (2007), and Wight and colleagues (2006).

In summary, monitoring knowledge and behavior are conceptually distinct constructs within the greater domain of parental monitoring. Monitoring knowledge is most aptly defined as information parents obtain regarding their adolescents' whereabouts, activities, and associates. In spite of previous inaccuracies it continues to be an important variable given its consistent associations with many problem outcome variables as well as its consistent associations with the other four core parental monitoring constructs: 1) parental monitoring behavior, 2) parental 
psychological control, 3) parent-adolescent relationship quality, and 4) parent-adolescent communication (e.g., Fletcher et al., 2004; Soenens et al., 2006).

Monitoring behavior is most aptly defined in a manner consistent with Barber's (2002) Regulation scale: overt parental expectations, enforcement of expectations, and direct monitoring behavior to ensure expectations are met. Both knowledge and behavior, when measured and labeled appropriately, play important roles in describing parental monitoring processes.

Parental psychological control. Parental psychological control is a third construct of interest in the parental monitoring literature. As with parental monitoring knowledge and parental monitoring behavior, its origin is traced to the CRPBI, namely the Psychological Control versus Psychological Autonomy factor that assessed parental intrusiveness, control through guilt, possessiveness, parental direction, and parental protectiveness (Schaefer, 1965b). More recently, researchers have demonstrated renewed interest in psychological control as specifically related to other parental monitoring variables (e.g., Barber et al., 1994; Barber, 1996; Pettit et al., 2001; Smetanan \& Daddis, 2002). Whereas the need for parent-driven limit setting, enforcement of rules, and knowledge-gathering has been of consistent interest to researchers, Barber (1996) has noted that "far less attention ... has been given to the need for personal autonomy and the role that control processes play in inhibiting it" (p. 3299). Subsequent to his observation that psychological control was not well understood, Barber (1996) validated 10 Psychological Control versus Psychological Autonomy items adapted from the CRPBI. He also obtained observer ratings of psychological control in a laboratory setting. From these endeavors, the eight-item Psychological Control Scale-Youth Self Report (PCS-YSR) was developed. Items on this scale are believed to have greater behavioral specificity than those from the CRPBI (Barber, 1996). 
Barber (1996) described parental psychological control as "attempts that intrude into the psychological and emotional development of the child (e.g., thinking processes, self-expression, emotions, and attachment to parents)" (p. 3296). Psychological control was also described as "manipulation and exploitation of the parent-child bond (e.g., love-withdrawal and guilt induction); negative, affect laden expressions and criticisms (e.g., disappointment and shame); and excessive personal control (e.g., possessiveness and protectiveness)" (p. 3297). More recently, Barber et al. (2008) developed the Parental Disrespect scale in an effort to better differentiate monitoring behavior and psychological control by providing behaviorally specific definitions for what they have described as "violations of self." Eight such violations consistently were observed across culturally diverse samples: 1) ridicule, 2) embarrassment, 3) failure to respect person, 4) violations of privacy, 5) guilt induction, 6) unreasonable expectations, 7) unfair comparisons to others, and 8) ignoring.

Other researchers have demonstrated interest in psychological control, including Smetana and Daddis (2002) who posited further evidence for psychological control as distinct from other constructs such as parental monitoring knowledge and parenting behavior. They accomplished this through investigation of the types of acts parents attempted to regulate and the corresponding degree to which adolescents rated such control as psychological or intrusive. They defined moral, social, and personal issues or areas of one's life and obtained adolescents' ratings of parents' legitimate authority to regulate these domains. The study of domains in relation to psychological control is characterized by a social cognitive approach to beliefs adolescents hold about their parents' right to be involved in certain areas of their lives (see Nucci, 1981; Smetana, 1988; see also Smetana, 2000; Smetana \& Asquith, 1994). The personal domain proved to be a source of frequent conflict between parents and adolescents where adolescents' beliefs about the 
legitimacy of parental authority over this domain were associated with adolescents' perceptions of parents as psychologically controlling (Smetana \& Daddis, 2002).

Stimuli from the socially regulated domain included a mix of moral and conventional items such as lying to parents and not doing assigned chores, whereas those from the personal domain included a mix of personal, multifaceted, and friendship items such as choice of music, staying out late, and seeing friends that parents do not like (Smetana \& Daddis, 2002). Stimulus items were rated as to the degree to which they were governed by rules in the family home (i.e., restrictive control) and whether or not adolescents felt it appropriate for parents to make rules about a particular stimulus item (i.e., legitimacy of parental authority). Adolescents who endorsed less legitimate parental authority over personal acts and who rated parents as high in restrictive control also rated parents as more psychologically controlling. This phenomenon also was observed at two-year follow up. Thus, the type of acts parents attempted to regulate influenced adolescents' perceptions of psychological control. Furthermore, what adolescents defined as psychologically controlling increased from early to middle adolescence, which is consistent with adolescents' developmental needs for more autonomy.

Indeed, psychological control is a construct of interest to parental monitoring researchers. Yet, as Barber et al. (2008) have noted, its position in relation to protective modes of parental behavioral control is not as clearly understood as its relation to parental monitoring knowledge. At the item level of measurement, this is an important distinction given that behavioral control and psychological control are presumed to have different associations with adolescent problem behavior. Thus, it is important to make certain that scales do not confound psychological control and behavioral control. This is akin to determining at what point parenting behaviors unreasonably violate adolescents' autonomy needs and contribute to the perception of 
psychological control. Several additional scales not explicitly labeled psychological control contain items thought to reflect parental psychological control, including Indirect Monitoring (Cottrell, Branstetter, Cottrell, Stanton, \& Harris 2007), Perceptions of Parental Prohibiting (Mounts, 2000; 2001), Parental Control (Fletcher et al., 2004; Stattin \& Kerr, 2000), Adolescent Perceptions of Parental Control (Jaccard et al., 2005), and Parental Solicitation (Stattin \& Kerr, 2000).

Given renewed interest in psychological control, the ability to situate it among other parental monitoring constructs is considered important. Psychological control affords insight about parenting practices that are ineffective and even harmful. Such practices should be avoided and replaced by proactive and beneficial parenting behavior. We turn our attention now to several parent-adolescent interactive processes that are considered protective factors.

Parent-adolescent relationship quality. Whereas parental psychological control is described as intrusive, manipulative, and disrespectful, parent-adolescent relationship quality is considered protective and beneficial. It is a fourth construct of interest to parental monitoring researchers. As with psychological control, its history can be traced to the pioneering work of Schaefer (1965a, 1965b) who labeled it Acceptance versus Rejection. This factor was previously described in the present review as related to assessment of parenting styles or typologies where it was crossed with Lax Control versus Firm Control (e.g., Lamborn et al., 1991). A sample Acceptance versus Rejection item reads: "What do you think is usually true or usually false about your parent? I can count on him/her to help me out if I have some kind of problem." According to Schaefer (1965b), Acceptance is characterized by "positive evaluation, sharing, expression of affection, emotional support, and equalitarian treatment" (p. 554). Parents rated high in Acceptance can be described as loving, responsive, and involved. B. K. Barber (2008, 
personal communication, June 3, 2008) evaluated the performance of the items written by Schaefer and developed a related scale labeled Connection. A sample item reads: "How much does your mother/female caregiver do the following things in her relationship with you? Supports and encourages me." Soenens et al. (2006) used Acceptance items re-labeled as Responsiveness, which they defined as "the degree to which adolescents experience a warm and affective relationship with their parents" (p. 307).

Other varieties of the parent-adolescent relationship quality construct include measures of Satisfaction with Parental Relationships (Jaccard et al., 2005; Miller \& Plant, 2003; Ryan et al., 2007), Parental Caring (Miller \& Plant, 2003), Parental Trust (Borawski et al., 2003), Family Support (Barnes et al., 1994; Barnes, Hoffman, Welte, Farrell, \& Dintcheff, 2006), and Household Closeness (Longest \& Shanahan, 2007). In support of assessing the quality of parentadolescent relationship within the context of parental monitoring, Barber, Stolz, and Olsen (2005) have noted that it is well established given its contiguity with "sturdy theories," including attachment and social learning. More recently, Branstetter, Furman, and Cottrell (2009) showed that adolescents' perceptions of attachment relationships with their mothers were related to parental monitoring knowledge; and this relation, in the context of the model the authors tested, was more important than parental support—a facet of parent-adolescent relationship quality.

It remains to be seen, however, which facets of parent-adolescent relationship quality are most pertinent to the investigation of parental monitoring. For example, the broad dimensions of relationship quality may lend itself to a unidimensional scale where items describe closely related facets of satisfaction, caring, trust, support, and closeness. Or it is possible that relationship quality as presently conceptualized subsumes empirically distinct subscales, perhaps 
even separate constructs of interest. That is, researchers have yet to specify the domain of relationship quality according to an empirically-derived measurement model.

The following example shows some of the barriers to the interpretation of findings when constructs are measured differently across studies. In one set of studies that addressed questions about the importance of parental versus adolescent involvement in monitoring processes, relationship quality was measured three different ways by three different groups of researchers. Each group of researchers was attempting to weigh in on the relevance of adolescent selfdisclosure to parental monitoring. As previously noted, Soenens et al. (2006) used a measure of relationship quality thought to assess the degree to which adolescents experience relationships with parents as warm and affective. Stattin and Kerr (2000) were not as explicit in defining their measure of parent-adolescent relationship quality; however, examination of the items showed that some items measured connectedness, whereas other items measured divisiveness or interactions that might force parents and adolescents further apart. Fletcher et al. (2004) used a measure comprised of items thought to tap warmth and engagement written to reflect specific parenting behaviors (as opposed to parent-adolescent interactive processes). All three researchers reported different, and in some cases, contradictory findings for the role of parent-adolescent relationship quality. Were these differences a product of the different ways in which relationship quality was measured? Were they the product of the different ways that the other variables were measured (e.g., parental monitoring behavior)? In spite of the fact that the three groups of researchers were addressing closely related research questions about adolescent-self disclosure, the coherence of the three sets of findings is compromised given the disparate measurement strategies employed in each investigation. A concrete example of what is implied here can be referenced in the work of a prescribing physician who changes a patient's medications one at a 
time in a systematic fashion so as to understand which is creating the desired or undesired effect. This approach avoids confusion caused by interaction effects when more than one medication at a time is changed. In summary, parent-adolescent relationship quality as studied by parental monitoring researchers shows the importance of clearly specifying the construct to be measured.

Providing a context for adolescent self-disclosure. An increasing number of studies have diverged from the tradition of evaluating parenting behaviors alone in an effort to assess adolescents' active roles in their own monitoring. The study of parent-adolescent communication provides the opportunity to examine how constructs such as parental monitoring knowledge, parental behavioral control, parental psychological control, and parent-adolescent relationship quality are transacted. One of the key features of communication is that it is a fundamental aspect of all of the other monitoring processes. For example, communication can be psychologically intrusive and controlling. Communication also is necessary in order for parents to make clear their expectations for their adolescents' home and public behavior. Reciprocal and balanced communication can affect the degree to which the parent-adolescent relationship is characterized by warmth, caring, and concern. Furthermore, communication is an important means of obtaining or offering monitoring knowledge. Thus, communication has unique properties that are worth investigating. Indeed, a number of researchers already have exposed some of its attributes.

For example, Stattin and Kerr (2000) revealed the complex and multifaceted quality of parent-adolescent interactive processes within the context of parental monitoring. Primarily, they found that monitoring knowledge was heavily dependent upon adolescent self-disclosure. That is, parents obtained knowledge only if adolescents chose to disclose that knowledge. As previously noted, their reinterpretation calls into question the validity of prior research that 
confounded knowledge and behavior. Perhaps more importantly, their research establishes the case for adolescents as active agents in the socialization process by way of communication.

In considering the role of communication, Stattin and Kerr (2000) proposed three possible sources of parental monitoring knowledge: 1) self-disclosure where adolescents spontaneously provide parents with information, 2) parental solicitation where parents directly ask adolescents or their friends for information, and 3) parental control where parents impose rules and restrictions to control the amount of freedom adolescents have to engage in behaviors without telling parents. This latter method is not communication; rather, it is a form of parental behavioral control. Stattin and Kerr hypothesized that self-disclosure would emerge as the most important means by which parents obtain knowledge.

To test the hypothesis that self-disclosure was responsible for monitoring knowledge, Stattin and Kerr (2000) regressed monitoring knowledge on adolescent self-disclosure, parental solicitation, and parental control in a sequential regression model. Self-disclosure, entered in the first block, accounted for $44 \%$ of the variance in parents' monitoring knowledge. The combined effects of parental solicitation and parental control accounted for a less impressive, but still statistically significant $3 \%$ of the variance. In all regression models reported, adolescent selfdisclosure was the first predictor entered into the model. Hence, in a sequential analysis, it would be expected to account for a greater amount of variance. With regard to this method, it is essential to note that a parent-driven strategy, parental control, remained a significant predictor of monitoring knowledge in spite of the fact that it was entered into the regression model after adolescent self-disclosure.

Other findings reported by Stattin and Kerr (2000) included a significant negative association for adolescent self-disclosure and normbreaking behavior. They defined 
normbreaking behavior as alcohol or marijuana use, vandalism, theft, bullying, fighting, and contact with police. Parental control also was associated with normbreaking, although much less so than adolescent self-disclosure. Again, the effect of the sequential analysis should be noted.

Further analyses assessed adolescent self-disclosure alongside parent-adolescent relationship quality using a simultaneous entry regression model. Again, self-disclosure emerged as the best predictor of normbreaking behavior; however, quality of the parent-adolescent relationship also attained statistical significance. Stattin and Kerr (2000) concluded that this finding suggested that self-disclosure is more than a proxy for some other measure such as parent-adolescent relationship quality.

In many respects, Stattin and Kerr (2000) provided a much-needed re-evaluation of the parental monitoring literature. Their point that parental monitoring is actually monitoring knowledge is prudent (i.e., knowledge has been misconstrued as behavior). Yet the optimism with which the results for self-disclosure are presented may be premature as well as incomplete. In the various regression models, parental control consistently accounted for additional unique variance in monitoring knowledge and normbreaking behavior, albeit a slight amount. Again, it should be noted that this slight amount may, to some extent, be an artifact of the sequential method of entering model predictors. Furthermore, what cannot be inferred from these findings is the relative importance of knowledge parents gain through their own efforts. For example, adolescents may reveal a great deal of information to parents. In fact, they may even alert parents to deviant peers or experimentation with substances of abuse. Yet what cannot be accounted for is the impact of parent-driven monitoring strategies. This is akin to small effect sizes in extremely large randomized clinical control trials of the effects of a potentially life-saving 
medication. If even a small number of participants live, the small effect size is justified. Similarly, if even a small bit of essential information is gained, parents' own efforts are justified.

In addition to evaluating the overall impact of Stattin and Kerr (2000) on parental monitoring, examination of their measurement strategy is especially relevant to the present review and subsequent investigation. Each of three variables (i.e., adolescent self-disclosure, parental control, and parental solicitation) that were tested for relative contributions to parental monitoring knowledge can be further assessed on a qualitative, item-by-item basis to generate hypotheses as to how these individual items would fair in an exploratory quantitative analysis. Some researchers may consider this to be picayune and would not want their own measures subject to such scrutiny. However, in the case of a study with as profound an impact on a literature as that of Stattin and Kerr (2000) on parental monitoring, thorough evaluation is warranted. In particular, self-disclosure must be carefully evaluated.

In a related study, Kerr and Stattin (2000) replicated the above findings using an urban sample of adolescents. They extended their findings by subjecting their 15 -item measure of sources of parental knowledge to a principal-components analysis that demonstrated three distinct components: 1) adolescent self-disclosure, 2) parental solicitation, and 3) parental control. Several new outcome measures also were employed, including school problems, poor teacher relations, depressed mood, low self-esteem, failure expectations, deviant friends, and poor relationship with mother or father. As was the case in Stattin and Kerr (2000), statistically significant effects for parental control were not fully removed from the various regression models tested, even with the prior sequential entry of adolescent self-disclosure.

When considering these results, it is worthwhile to note that Kerr and Stattin (2000) undertook substantial revision of their scales, including item wordings. What might ordinarily be 
glossed over is considered noteworthy given the far-reaching impact of this set of studies and the manner in which they have shaped subsequent investigation. Examples of the various revisions are as follows: In Kerr and Stattin (2000), a representative adolescent self-disclosure item read, "If you are out at night, when you get home, do you tell what you have done that evening?" The comparable item in Stattin and Kerr (2000) read, "Do you like to tell your parents about what you did and where you went during the evening?" Two items were used to assess adolescent selfdisclosure of school related-behavior in Kerr and Stattin (2000) versus only one item in Stattin and Kerr (2000). To achieve this using only five items, the item "Do you spontaneously tell your parents about your friends (which friends you hang out with and how they think and feel about various things)?" was dropped. The item that assessed adolescent disclosure about peer relationships also was dropped. With only two items left unchanged, this was a considerably different measure of self-disclosure than the one reported in Stattin and Kerr (2000).

The two items that remained unchanged were those that asked about keeping a lot of secrets and hiding a lot from parents: "Do you keep a lot of secrets from your parents about what you do during your free time?" and "Do you hide a lot from your parents about what you do during nights and weekends?" Actively hiding or keeping secrets may or may not be a pure measure of adolescent self-disclosure as such items suggest subversive activity in which adolescents may engage as part of active attempts to deceive parents.

The foregoing criticism is qualitative in nature and susceptible to bias. Criticisms of face validity are certainly subject to flaws of personal perception, and when discussed too readily in relation to construct validity, are susceptible to the error of reification. Yet, in spite of a landmark reinterpretation of the literature, research by Stattin and Kerr (2000; Kerr \& Stattin, 2000) invites criticism regarding measurement strategy and its effect on construct validity. The 
measures obtained on the scales in question yielded results highly relevant to the research enterprise and to the consumers of such research. Thus, it is believed that further empirical investigation is warranted to provide objective interpretation of self-disclosure as an adolescentdriven process as well as its relation to other measures of parent-adolescent communication.

Given the controversial nature of the findings reported by Stattin and Kerr (2000; Kerr and Sattin, 2000), other researchers have posited their own models to weigh in on the relative importance of self-disclosure. Fletcher et al. (2004) were among the first to take issue with the exclusively adolescent-centered reinterpretation of parental monitoring. They specified a path model to test the effects of parenting behavior above and beyond the effects of adolescent selfdisclosure alone. Soenens and colleagues (2006) conducted a subsequent investigation that reconciled findings from Stattin and Kerr (2000; Kerr \& Stattin) and Fletcher et al. (2004). Soenens et al. (2006) specified a path model to test both direct and indirect paths for three parenting variables (responsiveness, behavioral control, and psychological control) to parental monitoring knowledge. Indirect paths from these three variables were hypothesized through adolescent self-disclosure. This was an important consideration that permitted the researchers to test the degree to which behavioral control was associated with self-disclosure, which was untested by Stattin and Kerr (2000; Kerr \& Stattin, 2000). In fact, Soenens et al. (2006) hypothesized that parents high in behavioral control might actually elicit self-disclosure from adolescents.

To be consistent with prior studies, Soenens et al. 2006) conducted analyses separately for mothers and fathers. Results demonstrated that the model with both direct and indirect effects for the three parenting styles on monitoring knowledge was the best fit for both adolescentreported and father-reported parenting. Monitoring knowledge was then inversely related to 
adolescent problem outcomes. A similar model was fit to adolescent reports for mothers with significant direct and indirect paths for the three parenting variables. However, the model for mother-reported parenting produced an additional direct, negative association between psychological control and affiliation with substance abusing peers. Aside from this unique path, the model was similar to those described by adolescents and fathers in all other respects. Additionally, it should be noted that responsiveness — a facet of parent-adolescent relationship quality - showed the strongest positive association with adolescent self-disclosure across mother, father, and adolescent reports.

At least three strengths of the Soenens et al. (2006) study are apparent. First, the behavioral control measure was thought to be more sensitive to parental protective processes than the parental control and parental solicitation measures employed by Stattin and Kerr (2000; Kerr \& Stattin, 2000). When this key distinction was made, parenting behavior once again demonstrated convincing associations with monitoring knowledge. Second, Soenens et al. (2006) demonstrated the importance of parental responsiveness, a variable that has long been touted as highly relevant to the study of parent-adolescent socialization processes (e.g., Hirschi, 1969), and is considered qualitatively similar to relationship quality. Third, the direct path form behavioral control to monitoring knowledge in addition to the indirect path through self-disclosure shows the importance of both parent and adolescent behavior to parental monitoring.

Adolescent self-disclosure is reviewed herein as a facet of parent-adolescent communication given what self-disclosure purports to measure rather than what it may actually measure (consider the mixed content of the two self-disclosure scales reviewed above). To expand the findings for self-disclosure, research in the broader domain of parent-adolescent 
communication has the potential to provide unique information about the interactive quality of parental monitoring.

Whereas, some investigations have generated mixed results for the role of parentadolescent communication in conceptual models of parental monitoring (e.g., Huebner \& Howell, 2003; Wight et al., 2006), other investigations have shown associations for parentadolescent communication with both externalized and internalized adolescent outcomes (e.g., Caughlin \& Malis, 2004). Investigation of deficits in parent-adolescent communication (Guilamo-Ramos, Jaccard, Dittus, and Bouris, 2006) as well as how parents can communicate effectively with adolescents about alcohol tobacco and other drug use (ATOD; Miller-Day, 2002, 2008) also have provided information as to how other key processes such as monitoring behavior and monitoring knowledge are transacted between parents and adolescents. Perhaps the most compelling reason to continue to study parent-adolescent communication is evidenced in descriptive analyses reported by Miller-Day (2002) where $56.7 \%$ of adolescents surveyed stated they had not conversed with parents about ATOD use. Furthermore, when such communication did take place, adolescents perceived that parents were merely asserting that drugs are "bad" ( $p$. 609), which suggests that adolescents tended to perceive the communication as serving parents' own agendas. This is problematic in light of the recent emphasis on adolescent-driven processes such as self-disclosure.

In a study of parent-adolescent conflict and adolescent problem outcomes such as low self-esteem and substance use, Caughlin and Malis (2004) described a style of demand-withdraw communication in which parents and adolescents engaged in a characteristic pattern of nagging and criticizing each other about the topic of discussion. These patterns of conflict commonly led to the withdrawal of one of the parties from the discussion and were associated with low self- 
esteem as well as alcohol and drug use - outcomes observed for both parents and adolescents. Even common topics of discussion such as allowance and cleaning one's bedroom were associated with problem communication. This finding provides a tenable reason as to why parents and adolescents infrequently discuss ATOD use. More importantly, such patterns of communication are likely to preclude adolescent self-disclosure. In contrast to the sit-down conversations about substantial life issues (e.g., substance use, human sexuality) advocated by popular media, it may first be necessary for parents to create a climate conducive to such discussions via success with issues that are perceived as less threatening and void of any dominant parental agenda. This balance of parent and adolescent roles in the parental monitoring process is believed to mesh with findings reported by Soenens et al. (2006).

Whereas some investigations have reported on the quality of parent-adolescent communication, others have assessed factors that optimize parent-adolescent communication. For example, Guilamo-Ramos, Jaccard, Dittus, and Bouris (2006) assessed source characteristics of parents that influenced adolescent risk behavior using a "framework of persuasion and attitude change" (p. 1230). The source characteristics under consideration were parental expertise, or the degree to which adolescents perceived their parents to give good advice; parental trustworthiness, or the degree to which adolescents perceived their parents to be honest and genuinely looking out for the adolescents' best interests; and accessibility, or the degree to which adolescents perceived their parents to be available in times of need. Results suggested that adolescents who rated their parents positively on source characteristics were less likely to be involved in health-risk behaviors such as cigarette smoking and sexual intercourse. Further indirect effects for the source characteristics were demonstrated through frequency of communication, which in turn was negatively associated with both health-risk behaviors. Thus 
the extent to which parents are perceived as giving good advice and the frequency with which parents talk to their adolescents were considered protective factors in relation to certain health risk behaviors.

The investigation conducted by Guilamo-Ramos et al. (2006) was not part of the immediate parental monitoring literature (i.e., monitoring knowledge was not assessed); however, the findings are potentially useful in further defining factors that may influence selfdisclosure. In fact, the researchers noted: "Positive attribution of parental expertise, trustworthiness, and accessibility are . . likely to affect an adolescent's motivation to communicate with parents and to behave in accordance with parents' values" (p. 1232). This, too, is consistent with the model reported by Soenens et al. (2006). That is, parental responsiveness and behavioral control enhanced adolescent self-disclosure and was related to greater parental monitoring knowledge. In fact, findings reported by Guilamo-Ramos et al. (2006) reflect the importance of accurately defining adolescent self-disclosure so as to better understand the nature of its relationship with parenting variables such as responsiveness.

Research in the area of parent-adolescent communication as related to parental monitoring is still in its nascent stage; however, it has advanced the understanding of parentadolescent socialization as a bidirectional process.

\section{The Present Study}

In spite of its status as a mature research literature, parental monitoring research does not always agree with regard to how constructs of longstanding interest should be measured. It is interesting to note that lack of agreement rarely centers on theoretical concerns. Furthermore, there is evidence of little active dispute over the domain of content. Content validity is based on precedent. However, in some instances, when assembling their scales, researchers appear to have 
constructed multidimensional scales, written redundant items, or written new items that are ambiguous in terms of the construct to which they may relate.

It is possible to dismiss the importance of construct validity to parental monitoring on the grounds that the accumulation of evidence for criterion validities such as predictive and concurrent validity and the ubiquitous reporting of coefficient alpha are sufficient indicators of validity and reliability. Here, the "accumulation of evidence" refers to the parental monitoring literature as a whole. For example, one might be tempted to say that if parental monitoring behavior is inversely related to adolescent problem outcomes, then monitoring behavior is a valid measure given that it showed predictive associations with the criterion variable (e.g., adolescent substance use). However, criterion validity alone does not provide sufficient insight into why the variables are related. It is believed that why questions are best formulated and investigated using theory as a guide. For example, a recent investigation conducted by Smetana and Daddis (2002) invoked theory (i.e., social control theory) to answer questions about adolescents' perceptions of parental intrusions into various areas of their life as psychologically controlling. Hence, these investigators established a theory-based referent for understanding the parental psychological control construct. It is believed that such theory-based investigations provide a detailed guide for understanding the complex processes that are transacted between parents and adolescents. Furthermore, such investigations may increase the likelihood of identifying points of intervention within the processes.

The aim of the present study was to conduct an empirical test of the construct validity and related psychometric characteristics of the parental monitoring literature. Failure to attend to measurement of the core constructs already has led to confusion (e.g., confounding parental monitoring knowledge with parental monitoring behavior), and other as-yet-to-be identified 
instances may exist (e.g., the role of adolescent self-disclosure as related to parent-adolescent communication). Hence, the present study assembled a representative pool of items most commonly used in investigations of parental monitoring. Data collected from the administration of the item pool was subjected to exploratory factor analysis, the goal of which was to identify correlated factors that showed empirical as well as conceptual relevance based on review of the research literature and the construct definitions posited therein. Conclusions were drawn with regard to advancing theory-based investigation of parental monitoring processes that account for parenting behaviors as well as the active roles adolescents play in their own monitoring.

\section{Research Questions and Hypotheses}

On the basis of the rich history of content in the parental monitoring literature, it was possible to formulate questions and hypotheses to inform decisions about the research methods of the present study. Three questions were posited: 1) How many conceptually distinct constructs are necessary to adequately describe parental monitoring, 2) in what ways are they related, and 3) which variables (items) provide the best approximations of these hypothetical constructs? These three questions were thought to be inter-related in the sense that any decision made on the basis of one would directly affect the others.

Hypothesis 1: Number of factors. Review of the parental monitoring literature suggested that five factors would account for the majority of the variance in the raw data from the large pool of items assembled for the present study. The five factors were expected to be consistent with the definitions posited for 1) parental monitoring knowledge, 2) parental behavioral control, 3) parental psychological control, 4) parent-adolescent relationship quality, and 5) parentadolescent communication. The five factors will be further interpreted with regard to how well they account for parenting behaviors, adolescent-driven processes, and interactive monitoring. 
Hypothesis 2: Relations among factors. Whereas the preceding hypothesis proposes the number of factors, the second hypothesis proposes how the factors are related. Based on previous literature (Stattin \& Kerr, 2000; Soenens et al., 2006; Fletcher et al., 2004; Nunnally \& Bernstein, 1994), it was expected that five factors or core parental monitoring constructs would be conceptually distinct, yet demonstrate some degree of statistically significant correlation.

Hypothesis 3: Communication. Communication is one of the five hypothesized factors in the present study, and it is believed to interface with the other four factors. The third hypothesis of interest to the present study held that the adolescent-driven process of self-disclosure would be subsumed by the communication factor. That is, it was hypothesized that the parent-adolescent communication factor would load on items that were written to measure adolescent selfdisclosure to parents.

\section{Method}

\section{Participants}

A convenience sample of 360 West Virginia University students was recruited from undergraduate psychology courses between January and March of the spring 2009 academic semester. Data was available for 355 of the participants; five participants withdrew prior to completing the investigation. After assessing for outliers, missing data, and nonnormality, 320 participants were retained for the main analyses (see the Results section of the present study for a detailed report of data screening and imputation).

Table 2 shows the demographic profile of the 320 participants grouped by sex whose data was used in the main analyses of the present investigation. Participants were 18 to 22 years old, with a mean age of 19.01 years $(S D=0.93)$. The majority of participants were freshman $(N=$ $162)$ or sophomores $(N=97)$ in college. Participants were queried as to when they last lived with 
an adult guardian (e.g., mother, father, stepmother, stepfather, aunt, uncle, grandparent, or other guardian) on a full-time basis. Full-time basis was defined as "your regular place of residence over a period of at least four months." These restrictions yielded a sample composed predominantly of emerging adults (Arnett, 2000; 2007) in their first or second year of college who had lived with an adult caregiver on a full-time basis within the past three years.

It is acknowledged that the present sample is not an adolescent sample; however, it is argued that the current experiences of the majority of the participants are consistent with developmental processes first begun in adolescence. For example, Arnett (2000) has reported that emerging adults_-persons age 18 to 25 years old — commonly report experiencing a mix of dependence on and autonomy from parental figures.

A further consideration in selecting the present sample was that participant accounts of parenting practices would necessarily be retrospective. Brewin, Andrews, and Gotlib (1993) conducted a comprehensive review of the use of retrospective accounts in research studies. These authors concluded that as long as participants were old enough and were asked about the occurrence of specific events, their accounts were not adversely affected by the passage of time. Furthermore, they noted that retrospective accounts of parenting practices have been found to be one of the most accurate types of retrospective accounts.

\section{Procedure}

The Institutional Review Board at West Virginia University approved this study. Information was provided to subjects to introduce the purpose of the project, procedures, and consent forms. Extra credit for participation was granted regardless of whether participants completed the study or answered every question. 
The item pool was sampled from a total of 29 parental monitoring (or closely related) studies that employed 49 unique scales for a total pool of 310 items. The primary investigator classified all items on the basis of face validity according to the five proposed factors. The primary investigator also undertook revision of items to improve syntax and grammar for the purposes of clarity and fit with regard to response format. Items were not revised for content, except when an item was thought to be double-barreled; that is, when a single item was written using conjunctions (e.g., and, but, or) to connect phrases or clauses that represented separate facets of the construct of interest.

The revised item pool was administered to 360 psychology undergraduate students. The sample size was selected according to absolute size requirements recommended by Nunnally and Bernstein (1994) among others (e.g., Comrey, 1973). Participants accessed the present study via a web-based interface maintained by the department of psychology at West Virginia University. Sona (version 2.67; Sona Systems Ltd., 2007) is an experiment management system that allows users to sign up for and participate in approved research through a secure web-based interface. The program can be accessed at any time from computers equipped with a standard web browser and Internet connection.

In the first section of the survey, following the consent procedures, participants provided demographic information. In the subsequent sections of the survey, participants were presented with the following prompt:

You will be asked to answer some questions about your relationship with your parents or other adult guardian(s) with whom you lived the majority of the time from ages 12 to 18 . As you answer the questions, please think back to your junior year in high school. You were probably about 16 or 17 years old. This may have been the year you took the SAT's 
or ACT's and started thinking about college. Answer all of the following questions based on what you experienced at that time in your life. For example if a question were to ask, "My parents and I talk about my plans to attend college," you would think back to when you were a junior in high school and answer accordingly.

Following the prompt, participants were presented with the pool of 310 parental monitoring items, eight items designed to detect socially desirable responding, and 33 items from validated measures to be used in analyses demonstrating convergent validity. The Sona experiment management system recommends displaying no more than 25 to 30 items to participants on the computer screen at a given time to accommodate slower Internet connections (Sona Systems Ltd., 2007). Fifteen sections were used to present all items used in the present study, including the items from the demographics form. A number identifying each of the 310 parental monitoring items was written on 3 -inch by 5 -inch index cards and shuffled. The numbered cards were then drawn from the top of the pile, and the item corresponding to the number written on the index card was typed into the Sona experiment management system. No more than 26 items were entered into a given section. The eight items used to detect socially desirable responding were dispersed across sections $2,4,6,8,10,12,14$, and 15 . The 20-item demographics form always appeared in the first section of the questionnaire, the 310 parental monitoring items always appeared in sections 2 through 13, and the 33 convergent validity items always appeared in sections 14 and 15 . The two convergent validity scales were originally developed to assess adolescent and young adult ratings of several parenting variables and showed adequate psychometric properties and evidence of construct validity. The 310 parental monitoring items were presented randomly within sections 2 through 13 to each participant using one of the randomization features of the Sona Experiment Management 
System. Randomization was used to reduce systematic error variance that may occur due to participant perceptions and biases that commonly occur when the same items are consistently presented together. The two convergent validity scales always were presented in the same order. Measures

Parental Monitoring Items The pool of 310 parental monitoring items was generated via thorough review of the parental monitoring literature. ${ }^{1}$ First, the prinicipal investigator conducted several keyword searches during January 2008 using the PsycINFO database. Broad searches such as "parent-adolescent relations", "parenting," and "adolescent and parent communication" yielded over 1,000 articles per keyword. Therefore, more targeted searches were conducted. For example, "parental monitoring" returned 647 peer-reviewed, English-language articles. To further reduce the number of articles, the search on "parental monitoring" was restricted to the years 2000 to 20008 . This restriction was a justifiable starting point given that one of the most influential parental monitoring investigations (Stattin and Kerr, 2000) to date provided an extensive reinterpretation of the conceptual and empirical understanding of parental monitoring, reflecting a departure from investigations conducted prior to its publication. As of January 2008, Stattin and Kerr (2000) had been cited 221 times in the PsycINFO database. Restricting the range of years yielded 442 peer-reviewed, English-language journals.

Next, these 442 article titles or abstracts were reviewed for their relevance to parental monitoring. If a title clearly indicated that an article was not relevant, the abstract was not reviewed. For example, some titles contained the keyword "monitoring"; however, its use was not related to parent-adolescent relationships. For instance, numerous titles contained "monitoring" as related to neuroimaging (e.g., functional magnetic resonance imaging or fMRI). When it was not immediately clear whether or not a title related to parental monitoring, the 
article abstract was reviewed. To qualify as relevant to the present investigation, the abstract of the article had to show that the article investigated parenting practices or adolescents' perceptions of parenting practices, parent-adolescent relationships, or parent-adolescent communication as related to an externalizing adolescent problem behavior. Externalizing was defined as overt behaviors that potentially could be observed such as substance use, general delinquency (e.g., theft, truancy, vandalism), and high risk sexual behavior (e.g., not using condoms). Externalizing behavior is contrasted with internalizing behavior, which refers to feelings and emotions that are not readily observable.

Review of titles and abstracts reduced the number of relevant articles to approximately 100. The next step, then, was to identify and peruse the most frequently cited articles (per statistics provided in the PsycINFO search results list). For example, Fletcher et al. (2004) was cited 40 times in the database; Laird, Pettit, Bates, and Dodge (2003) was cited 41 times in the database; and Kerr and Stattin (2000) was cited 184 times in the database. In the process of reviewing the reference lists of these articles, a number of older articles (1984 to 1999) were identified, including Lamborn et al. (1991), which had 420 citations in the database; Brown et al. (1993), which had 188 citations in the database; Barber (1996), which had 263 citations in the database; and Dishion and McMahon (1998), which had 166 citations in the database. The cumulative review of parental monitoring articles showed that approximately four constructs were most commonly invoked by parental monitoring researchers. These constructs, as described in the literature review portion of the present investigation were: 1) parental monitoring knowledge, 2) parental monitoring behavior, 3) parental psychological control, and 4) parentadolescent relationship quality. Parent-adolescent communication initially was not an obvious, 
important area of investigation; however, further review of the literature led the primary investigator to conclude that it was relevant to the goals of the present investigation.

An additional keyword search of the PsycINFO database returned 62 results for "parental monitoring and communication" and four results for "parental monitoring and self-disclosure." Again, titles and abstracts were used to cull the irrelevant studies. During this process, the study conducted by Soenens et al. (2006) was identified. It addressed several unresolved research questions raised by Stattin and Kerr (2000) and Fletcher et al. (2004) and provided a comprehensive model of parental monitoring.

During the next step in the series of steps conducted to generate the item pool, the principal investigator read the measures subsection of each article to identify relevant scales. Scales were relevant and included in the item pool if they were adolescent self-report measures that appeared to tap one of the five core parental monitoring constructs: 1) parental monitoring knowledge, 2) parental monitoring behavior, 3) parental psychological control, 4) parentadolescent relationship quality, and 5) parent-adolescent communication. Scales also were excluded on two criteria: 1) if they were part of a measure with an extensive validation history; for example, the Parent-Adolescent Communication Scale (PACS; Barnes and Olson, 1985), and 2) if they were scales that extended one of the five constructs by examining a very narrow facet of the construct, such as the Computer Monitoring scale developed by Cottrell, Branstetter, et al. (2007). The reason for this latter exclusion criterion was twofold. First, the principal investigator proposed to validate the most common facets of the five constructs. Second, it was important to keep an already large item pool to a manageable size so as to reduce measurement error related to participant fatigue. 
When a scale met inclusion criteria, but was not published, the corresponding investigator was contacted by email, and a copy of the items was requested. Six such persons were contacted, including Drs. Brian Barber, Grace Barnes, Dawn Gondoli, Michelle Miller-Day, Susan Silverberg-Koerner, and Mr. Kyle Longest. These researchers graciously provided their scales and any additional, unpublished information about the reliability and validity of their measures. Furthermore, they granted permission for their measures to be used in the present investigation.

Finally, studies using measures that were reported earlier in the parental monitoring literature were accounted for. That is, the pool of items was reviewed thoroughly to ensure that there were no duplicate items. The result of this process led to a validation pool of 310 parental monitoring items adapted from 29 separate investigations spanning the years 1991 to 2007. Internal consistencies for the measures as reported in the original investigations ranged from .46 to .90 with the majority of internal consistencies in the range of .70 to .90 . Several investigations briefly reported results for measurement models that were the basis for variables used in their primary analyses (e.g., Guilamo-Ramos et al., 2005; Kerr and Stattin, 2000; Lamborn et al., 1991).

Parental Monitoring Item Response Formats. (Appendix A). For the 310 parental monitoring items, fifteen qualitatively different response formats were used. All response formats were five-, six-, seven-, or eight-point Likert type. Only one question from the item pool required the 8-point response format.

Four of the response formats allowed respondents to estimate quantity, such as how much effort parents put into obtaining monitoring knowledge or how much monitoring knowledge adolescents freely disclosed to parents. Four additional response formats assessed quality; for example, to what degree adolescents experienced understanding, satisfaction, or closeness in 
their relationships with parents. One response format had respondents rate how they made decisions in relation to parents; for example, "My parents and I make the decision together" versus "My parents decide this without discussing it with me." Two time-related response formats were used on two separate items so that respondents selected a window of time during which parents expected them to return home on week nights and weekend nights, respectively. Finally, two response formats allowed respondents to estimate agreement, one response format assessed the frequency with which particular events occurred, and one response format assessed certainty.

Demographic information. (Appendix B) Participants were asked to report on basic demographic information such as age, sex, race/ethnicity, and composition of their family of origin.

Marlowe-Crowne Personal Reaction Inventory. The Marlowe-Crowne scale (Crowne \& Marlowe, 1964) is an eight-item self-report measure that asks participants to report on opinions and behaviors related to how the participant attempts to present him or herself to others. Each question is answered true or false, and half of the questions are reverse-coded. The MarloweCrowne Social Desirability Scale has demonstrated good internal consistency, $(\alpha=.77$; Ray, 1984) and a strong convergent correlation to other measures of social desirability, $r=.68$ (Stober, 2001).

Family Intrusiveness Scale. The Family Intrusiveness Scale (FIS; Gavazzi, Reese, and Sabatelli, 1998) is a 13-item self-report measure that evaluates the extent to which adolescents and young adults perceive that family members are involved in their lives in ways that interfere with developmentally appropriate autonomy (Touliatos, Perlmutter, and Holden, 2001). Each item is answered on a seven-point Likert scale $(1=$ never, $4=$ sometimes, $7=$ always $)$. The FIS 
has yielded a one-factor solution with items loading .30 or higher on the single factor, and has demonstrated good internal consistency ( $\alpha=.89$; Gavazzi et al., 1998).

Parent-Adolescent Communication Scale. The Parent-Adolescent Communication ScaleAdolescent Form (PACS-A; Barnes and Olson, 1985) is a 20-item self-report measure developed with regard to empirical and theoretical considerations about how parents and adolescents interact. Items were written to measure positive and negative aspects of parent-adolescent communication as well as the process and content of such communication. Early validation of the PACS showed a three-factor solution: Open Family Communication, Problems in Family Communication, and Selective Family Communication (Barnes \& Olson, 1985, p. 55). Given that one of the goals of scale development was to produce a measure that was valid for adult and adolescent perceptions of family communication, further validation was conducted on a sample of 1,841 parents and adolescents. Based on this subsequent work, the PACS-A should be interpreted according to a two factor solution: Open Family Communication and Problems in Family Communication (p. 56). The two-factor solution showed factors loading on items in the range of .45 to .71 . Two items had loadings of .26 and .29 . Coefficient alpha was .87 for Open Family Communication, .78 for Problems in Family Communication, and .88 for the total scale (p. 57). Items are answered on a five-point Likert scale $(1=$ strongly disagree, $3=$ neither agree nor disagree, $5=$ strongly agree).

Results

\section{Preliminary Analyses}

Outliers, missing data, and nonnormality. Prior to conducting the main analyses, the pool of 310 parental monitoring items was examined through PASW (version 17.0; SPSS Inc., 2009) 
and SPSS (version 16.0; SPSS Inc., 2008) for accuracy of data entry, missing values, and fit between their distributions and the assumptions of exploratory factor analysis.

Survey data was available for 355 of 360 participants. Five participants withdrew prior to completing the investigation. For participants who withdrew, the Sona Experiment Management System produced only the participants' study identification number. No other information such as responses to demographic variables or partially completed surveys was available for these five participants. The primary investigator granted the five participants full credit for having participated in the investigation as is consistent with the policies of the Institutional Review Board at West Virginia University.

Of the 355 participants who completed the investigation, a number of participants were identified as outliers on age and on the amount of time required to complete the survey. Eight participants were older than 22 years of age and were deleted from further analysis. To estimate a reasonable completion time for the full survey, the principal investigator sampled completion time data from three laboratory assistants who were instructed to complete 25 sample questions as quickly and accurately as possible. Timed results showed that the assistants averaged foursecond completion times for each question. At this rate, a participant could complete the entire survey of 362 items in 25 minutes. Subsequently, all participants who required 24 minutes or less were deleted from further analyses. Deleted durations ranged from 11 to 24 minutes. Thus, data for a total of 31 participants were deleted given outlying values on age, completion time, or, in two instances, both age and completion time.

SPSS Missing Values Analysis was used to estimate the amount and pattern of missing data. Results showed that the variable with the greatest amount of missing data, "My parents make it clear that I have to pay for my own substances," had $4.6 \%$ missing data. The next highest 
value was 2.8\%: "My parents are people who believe that parents have the right to set rules and regulations for how children should behave." Examination of the number of cases with missing data showed that 53 participants were missing data on at least one of the 343 variables. Six participants had more than $10 \%$ missing data, and four of the six participants had more than $20 \%$ missing data. These latter four cases were deleted from further analyses, reducing the total number of participants included in the main analyses to 320 .

With these four participants deleted from further analyses, 49 of 320 participants were missing data on at least one of the 343 variables, which translated to $14.3 \%$ of the data missing listwise. Tabachnick and Fidell (2007) have noted that 5\% of data missing listwise and a pattern of data classified as missing at random is an acceptable justification for deletion of cases with missing data. The present investigation fell outside these parameters with regard to the amount of missing data (i.e., $14.3 \%$ is greater than the criterion of $5 \%$ ). With regard to the pattern of missing data, Little's test of the data missing completely at random (MCAR) was not significant, $\chi^{2}=14,026.963, d f=14,404, p=.987$. A statistically nonsignificant value for Little's MCAR test is desired and indicates that the probability that the observed pattern of missing data differs from randomness is less than .05 (Tabachnick \& Fidell, 2007, p. 63). Thus, results of Little's MCAR test and the small amount of data missing for each variable (less than 5\%) suggested that imputation of missing data points was appropriate.

The chosen method of imputation was expectation maximization (EM). Tabachnick and Fidell (2007) have noted that this method of imputation is appropriate for exploratory data analyses when inferential statistical tests will not be used (p. 68). The present investigation was exploratory and no inferential statistical tests were conducted. 
In the first attempt to impute data for the present investigation, the EM algorithm failed to converge. This algorithm is based on an iterative process similar to maximum likelihood estimation (see McKnight, McKnight, Sidani, and Figueredo, 2007, pp. 164-166; Tabachnick \& Fidell chapters $4,10,13$, and 14). The latter procedure is used commonly in exploratory factor analysis, logistic regression, and structural equation modeling and is sensitive to singularity and multicollinearity; that is, redundant information in the dataset (Tabachnick \& Fidell, 2007, p. 90). Therefore it was necessary to perform an item-by-item analysis to determine which variables, if any, had content that was redundant. Examination of the correlation matrix revealed 24 pairs of variables that correlated .80 to .89 . Inspection of the content of these variables revealed subtle differences in wording such as "If I have been out very late one night, my parents require that I explain whom I was with" versus "If I have been out very late one night, my parents require that I explain what I did.” Thus, it was decided to further examine the content of all of the parental monitoring variables in the dataset for wordings that were nearly identical across multiple items. Sixty-four such variables were identified and deleted from further analyses.

Criteria for selecting which redundant variables to drop were as follows: 1) simplicity of phrasing, and 2) prestige of the study from which the item was sampled. The former generally was prioritized over the latter. For example, a variable that was published in an article that was cited frequently in the PsycINFO database and published in a high-impact journal would not be retained if its phrasing was more complicated than a nearly identical item from a less prestigious publication.

After deleting the 64 redundant items, data was imputed for missing values on the 246 remaining parental monitoring variables, the 13 Family Intrusiveness Scale (FIS; Gavazzi, et al., 
1998) variables, and the 20 Parent-Adolescent Communication Scale (PACS; Barnes \& Olson, $1985)$ variables. The EM algorithm converged, but showed a number of imputed values that were out of range, negative, or out of range and negative. Given that this imputation was unacceptable, the imputed results were discarded and additional univariate data screening was conducted.

First, items in the dataset that were worded negatively were reverse coded. For example, participants responded to the item, "My parents go back and forth between being warm and critical to me" on a response format from 6 (exactly like my parents) to 1 (nothing like my parents). This item and other similarly worded items were recoded so that higher values on the response format related to positive behaviors.

Next, the 279 variables were screened for univariate outliers. Outliers were identified as participants whose standardized score on a given variable exceeded a cutoff of \pm 3.29 . This value was chosen given that only 1 of 1000 participants would be expected to have produced a score of that value. Given that the present dataset was comprised of 320 participants, it was not probable that standard scores greater than \pm 3.29 should be observed. In fact, scores greater or less than \pm 3.29 indicated that the observed response on a given variable might be part of a set of responses belonging to a population different from the one sampled. Thus, univariate outliers with standardized scores greater or less than \pm 3.29 on a given variable were recoded by subtracting 3.29 times the standard deviation of that variable from the mean of that variable when negative skew was present. When positive skew was present, the recoded value was equal to the mean of the variable added to 3.29 times the standard deviation of the variable.

Last, the 279 variables were examined for nonnormality, which was assessed according to five criteria: mean, standard deviation, standardized skew greater or less than \pm 3.29 , standardized kurtosis greater or less than \pm 3.29 , and visual inspection of the histogram with a 
normal curve imposed. Seventy-eight items were identified as problematic according to at least three of five criteria. These items were further examined for content and the caliber of the original investigation from which they were sampled. After considering these two additional criteria, the 20 worst items according to standard deviations greater than 1.5 (in addition to problem values on at least two of the other five original criteria) were deleted from further analyses.

It should be noted that during screening for outliers and examination of univariate normality, the FIS (Gavazzi, et al., 1998) showed deviations from normality on three of the five criteria mentioned above for 9 of 13 items. The PACS (Barnes \& Olson, 1985), however, had no items meeting more than two of five criteria. Visual inspection of the distribution of scores for each PACS item approximated a normal curve. Thus, it was decided that the FIS would be dropped as a measure of convergent validity, whereas the PACS would be retained as a measure of convergent validity. The final pool of items after inspection for univariate outliers and nonnormality was 246 items: 226 parental monitoring items and 20 PACS items.

Using the pool of 246 items, the EM algorithm converged and produced a stable imputation with no out of range or negative values. The imputed dataset was rechecked for univariate outliers, and none were identified according to the criteria of standard scores greater or less than \pm 3.29 . Visual inspection of the distribution of scores for each of the parental monitoring items (226 items) revealed 24 items with skewed distributions and standard deviations greater than 1.5. These items were not deleted, but were marked for further examination when conducting checks of linearity and homoscedasticity.

Prior to evaluating pairwise plots of items for linearity and homoscedasticity, the dataset was screened for the presence of multivariate outliers according to the procedure described by 
Tabachnick and Fidell (2007, p. 99) and using PASW Regression (version 17.0; 2009). Participant identification code was selected as the outcome variable and the 226 parental monitoring items were entered into the multiple regression equation as predictors using the backward stepwise method. Regression diagnostics for Mahalanobis distance, leverage, and Cook's distance were requested. The critical value for evaluating Mahalobis distance was, $\chi^{2}=$ 297.4, $d f=226, p<.001$. The highest value in the observed data was 290.33 and was below the critical value. Furthermore, there were no multivariate outliers using Lunneborg's (1994) criterion for leverage: $h_{\mathrm{ii}} \geq 2(k / N)$. In this equation, $k$ is the number of predictors in the regression equation (i.e., 226) and $N$ is the number of participants (i.e., 320). The critical value for the present dataset was 1.41 , whereas the highest leverage value produced by the regression diagnostics was .24. Finally, the highest value for Cook's distance was .91, which is less than the criterion of 1.00 that is associated with a given case having excessive influence on the regression model (Cook \& Weisberg, 1982). Results of these analyses showed that no cases in the dataset were multivariate outliers; therefore, it was not necessary to conduct further regression analyses to identify the combinations of variables producing outlying cases.

Following examination of cases for multivariate outliers, checks of linearity and homoscedasticity were conducted using 15 pairs of randomly drawn items from the 24 items with visibly skewed distributions and standard deviations greater than 1.5 . These 24 items showed the greatest violations of univariate normality, and, among the 226 parental monitoring items, were most likely to evidence departures from linearity and the presence of heteroskedasticity.

PASW Regression (version 17.0; 2009) was used to generate residual plots for the 15 item pairs (Tabachnick \& Fidell, 2007, p. 126). Visual inspection of the normal probability plots 
of the observed residuals versus the predicted residuals showed that 5 of 15 plots deviated from linearity as evidenced by the plot of observed residuals falling above and below the diagonal line that represents the predicted or expected value for normally distributed residuals. Visual inspection of the scatterplots of the observed residuals versus the predicted residuals showed similar departures from linearity. However, these plots did not reveal any instances of true curviliearity; rather, they showed instances of linearity plus curvilinearity (see Tabachnick \& Fidell, 2007, p. 84). The former is associated with near-total absence of linear relationships, whereas the latter is associated with reductions in the magnitude of linear relationships between variables (p. 83).

Further inspection of the scatterplots showed that the plots of the observed data generally were homoscedastistic, meaning that plots of the residuals for item pairs had similar variance or spread of scores across the continuum of observed values (Tabachnick \& Fidell, 2007, pp. 125127).

In summary, checks of linearity and homoscedasticity did not reveal any departures that would pose a threat to the primary analyses of the present study. That is, pairs of variables generally were homoscedastistic and departures from linearity were not extreme. For instance, given that there were 25,312 possible combinations of item pairs from the 226 parental monitoring items, it was expected that not all variable pairs would show perfectly linear relationships. Therefore, given the absence of true curvilinearity in the pairs of items sampled and tolerance for the presence of pairs of items showing some degree of linearity plus curvilinearity, no transformations were performed and all items were retained.

Appropriateness of the data for factor analysis. After addressing the problem of missing data and examining the dataset for outliers and nonnormality, it was necessary to evaluate the 
appropriateness of the correlation matrix for factor analysis. An unrotated principal components analysis (PCA) was conducted to evaluate singularity and multicollinearity. Singularity is present in a dataset when variables are redundant; that is, variables are perfectly related and do not make a unique contribution to the amount of variance accounted for in the observed data (Tabachnick \& Fidell, 2007, p. 88). Multicollinearity differs from singularity in that variables that are multicollinear are not perfectly related, but are highly correlated in the order of .90 or higher (p. $88)$.

One method of screening for multicollinearity is to evaluate the determinant of the correlation matrix, which, along with other diagnostic tests, was obtained through the PASW (version 17.0; 2009) factor analysis descriptives option. Values for the determinant that are less than .00001 may indicate the presence of multicollinearity (Field, 2005, p. 648). A determinant that approaches zero is problematic given that the matrix algebra used in factor analysis requires that matrices be inverted, which is analogous to the problem of carrying out division with a denominator of zero (Tabachnick \& Fidell, 2007, p. 683). The determinant of the correlation matrix for the 226 parental monitoring items was less than .00001 . To further diagnose the extent of the problem, the correlation matrix was scanned for values .90 or higher. No such values were found. Furthermore, four additional diagnostic criteria indicated that the data were appropriate for factor analysis in spite of having a determinant that approached zero.

First, the Kaiser-Myer-Olkin (KMO) measure of sampling adequacy was .86. The KMO statistic varies from zero to one and is a ratio of the squared correlations between variables to the squared partial correlations between variables (Kaiser, 1970). Values close to zero indicate that the value for the squared partial correlations is large compared to the value of the squared correlations, which indicates that the pattern or correlations is diffuse and the data may not be 
appropriate for factor analysis (Kaiser, 1974). That is, when the KMO statistic reaches a low value, it may be the case that only a small number of variables correlate well, which will cause factors to load poorly on the full set of variables included in the analysis. The KMO value obtained for the present study was .86 , which is considered a "great" value according to Hutcheson and Sofroniou's (1999, as cited in Field, 2005, p. 640) extension of Kaiser's (1974) minimal criteria of values greater than .5 .

Second, the KMO criteria also can be applied to the correlations for pairs of variables produced in the anti-image correlation matrix. For the present study, only 4 of 226 variables had values below the cutoff of .5. However, these items were not deleted.

Third, in addition to problems encountered when the correlations between variables are too high or too diffuse, correlations between variables that are too low can likewise be problematic. Bartlett's test of sphericity tests for correlations that are too low. That is, Bartlett's test evaluates the null hypothesis that the correlation matrix is an identity matrix. In an identity matrix, correlations are zero (Field, 2005, p. 652). For the present study, Bartlett's test showed that the correlation matrix was significantly different from an identity matrix $[\chi 2=69,514.87, d f$ $=25,425, p<.0001]$, and thus appropriate for factor analysis.

Fourth, the reproduced correlation matrix was generated to evaluate the pattern of residuals where the majority of values should be less than .05 (Field, 2005, p. 642, 655). In the present study, only 195 of 25,425 (i.e., $0.77 \%$ ) residuals were greater than .05 .

In summary, four of five data screening procedures indicated that the data collected for the present study was appropriate for factor analysis. The fact that the determinant of the correlation matrix approached zero was not considered a deterrent. For example, it was expected that the primary analyses for the present study would require approximately 10 to 20 separate 
factor analyses to arrive at an interpretable final factor solution. Over the course of this many analyses, problems related to the determinant would be apparent if factor extractions such as maximum likelihood failed to converge or if factors loaded on different combinations of variables from one analysis to the next. Such indicators of unstable factor solutions were not encountered in any of the analyses reported in the Primary Analyses section below.

\section{Primary Analyses}

Three data analysis strategies guided the main analyses. First, the measurement model for the pool of parental monitoring items was estimated using exploratory factor analysis. Second, the resultant scales were subjected to reliability analysis to estimate the amount of variance attributable to true score variance versus error variance. Third, the pattern of correlations for the resultant scales were calculated, which included convergent validity with the PACS.

Measurement model. Maximum likelihood extraction with varimax orthogonal rotation was used to estimate the number of factors and the manner in which they loaded on the 226 parental monitoring variables. Using the extraction criterion of eigenvalues greater than 1.00 (Kaiser, 1960), 12 factors were indicated that accounted for approximately 55\% of the variance in the observed data. In this first factor analysis, 7 variables were complex (i.e., there was more than one factor loading greater than .45 on the variable). Sixty-eight variables had factor loadings less than .45. That is, the overlapping variance between variable and factor was less than $20 \%$. Inspection of the content of the 68 variables showed that they were very specific in scope or very general in scope.

In the second factor analysis, maximum likelihood extraction again was used with the 226 parental monitoring items; however, promax rotation was used. Inspection of the factor correlation matrix showed that each of the 12 factors correlated .32 or greater with at least one 
other factor, and there were several correlations between factors in the .40 's and .50 's. Thus, a number of factors had at least $10 \%$ of their variance in common, which suggested that a promax rotation was appropriate (Nunnally \& Bernstein, 1994, p. 501; Tabachnick \& Fidell, 2007, p. 646). Furthermore, there were 94 variables with factor loadings less than .45 , and 57 of these variables also had not loaded in the first factor analysis with varimax rotation. Thus, these 57 variables were deleted from further analyses.

The third factor analysis on the reduced pool of 169 variables yielded 13 factors with eigenvalues greater than 1.00 that explained slightly more than $61 \%$ of the variance in the observed data. Comparison of this analysis to the previous analysis showed that 120 of 169 variables attained the same loading pattern and magnitudes of loadings. Another 21 variables did not load in the third analysis and were deleted from further analyses.

Analyses four and five also were conducted using maximum likelihood extraction and promax rotation. Across these analyses, another 14 variables had factor loadings less than .45 and were deleted from further analyses. Again, the pattern and magnitudes of loadings were consistent when compared to the pattern and magnitudes of previous analyses. Given that one of the goals of the present investigation was to reduce the number of parental monitoring variables to a parsimonious set of interpretable factors, it was decided that the criterion for factors loading on variables would be increased from .45 to .55 , or $30 \%$ shared variance between variable and factor. With the new loading criterion, 26 variables were deleted from further analyses following the fifth analysis.

The sixth analysis was conducted on the reduced pool of 108 variables and yielded 14 factors that explained $68 \%$ of the variance in the observed data. Eight variables did not load .55 or greater. Inspection of variables with factor loadings for Factor 8 and Factor 12 also were 
problematic. First, Factor 8 loaded on three of the variables from the six-item scale developed by Fletcher et al. (2004). The content of the three items reflected parent-adolescent decision making with regard to spending time with friends, spending money, and when the adolescent could start dating. Given that it was difficult to identify any unitary dimension that defined factor eight, it was thought that the unique response format was accounting for the pattern of factor loadings. Thus, the three items were deleted from further analyses. Second, Factor 12 loaded on only two variables from Barber's Parental Regulation scale (Barber, 2002). The fact that these two items had not shown this pattern of loadings in previous analyses combined with the fact that they correlated less than .70 in the correlation matrix suggested that they constituted an unstable or unreliable factor. Thus, following the sixth factor analysis, an additional 12 items were deleted from further analyses.

The seventh analysis was conducted on the reduced pool of 96 variables and yielded nine factors with eigenvalues greater than 1.00 that explained $65.4 \%$ of the variance in the observed data. Factors were not loading on five of the variables when using the .55 criterion; however, when using the .45 criterion, factors were loading on these five variables. At this point in the analyses, a stable factor solution was achieved as evidenced by the consistent pattern and magnitude of factor loadings observed across seven separate factor analyses. Thus, the adequacy of the factor solution was inspected via examination of variable content for each of the nine factors.

Inspection of the nine factors loading on variables showed that the first factor was defined by variables with content consistent with parent-adolescent relationship quality, such as "My parents are people who make me feel like I am the most important person in their lives." The second factor was defined by variables with content consistent with adolescent perceptions 
of parental monitoring knowledge, such as "How often do your parents know where you are when you go out at night?" The third factor was defined by variables with content consistent with parental requirements for adolescents about sharing of knowledge-related information, such as "If I have been out very late one night, my parents require that I explain whom I was with." The fourth factor was defined by variables with content consistent with parental psychological control, such as "My parents are people who go back and forth between being warm and critical of me." The fifth factor was defined by variables with content consistent with parental implementation of consequences for adolescent rule-breaking behavior (i.e., a form of parental behavioral control), such as "My parents are people who will take action if I don't follow the rules." The sixth factor was defined by variables with content consistent with parent-adolescent communication about drugs and alcohol, such as "At least one of my parents asks about my thoughts and opinions about drinking alcohol." The seventh factor was defined by variables with content consistent with lax parental behavioral control, such as "My parents are people who are very unclear as to what they expect of me." The eighth factor contained the three variables from the Adolescent Demand-Parent Withdraw Communication scale developed by Caughlin and Malis (2004); for example, "During a discussion of a problem, how often do you criticize while your parents try to ignore you." The ninth factor was defined by variables with content consistent with specific parenting behaviors considered psychologically controlling, such as "In the past four months, how often have your parents read your personal notes or diary/journal?"

In the course of interpreting the solution, subtle redundancy of variables content was observed. For example, "My parents are people who are able to make me feel better when I am upset" and "My parents are people who make me feel better after talking over my worries with them." One of the research goals that guided the hypotheses of the present study was the goal of 
consolidating the number of variables and scales required to explain parental monitoring behaviors, processes, and outcomes. With this goal in mind, 17 variables showing redundancy comparable to the preceding example were deleted from further analysis.

The eighth analysis was conducted on the reduced pool of 79 variables and yielded nine factors with eigenvalues greater than 1.00 that explained $65.2 \%$ of the variance in the observed data. The pattern of factors loading on variables was consistent with the results from the seventh analysis; however, no factors were loading .45 or greater on three variables that assessed perceptions of school-related monitoring knowledge. These three variables were deleted from further analyses.

The ninth and tenth analyses were conducted to further test the viability of the preliminary solution identified in analysis seven. In analysis seven, the second factor and the third factor were defined according to content related to perceptions of parental monitoring knowledge. To test whether or not the second factor and the third factor were distinct, an eightfactor solution was imposed with the intent of collapsing the second factor and the third factor into a single perceptions of parental monitoring knowledge factor. Results of the ninth analysis did not support an eight-factor solution. The two knowledge-related factors remained distinct and problems were observed with variables and factors related to psychological control and behavioral control.

To further test the preliminary solution identified in analysis seven, a six-factor solution was imposed with the intent of collapsing the second factor and the third factor, as described above, as well as the fifth factor and the seventh factor. In analysis seven, the fifth factor and the seventh factor were defined according to content related to parental monitoring behavior. Results of the tenth analysis did not support a six-factor solution. Again, the knowledge-related factors 
remained distinct and problems were observed with variables and factors related to psychological control and behavioral control.

The eleventh analysis was conducted to provide a direct test of the hypothesis that five factors would account for the relations among variables in the observed data. This imposed fivefactor solution on 76 variables yielded a solution that accounted for $56.2 \%$ of the variance in the observed data. The solution showed a pattern of factor loadings that were different from all prior analyses, including analyses nine and ten. For example, the pattern of factor loadings for analysis eleven showed several heterogeneous factors; that is, factors that subsumed content that was mixed with regard to knowledge, behavior, psychological control, communication, and relationship quality. Due to mixed content, the five-factor solution could not be interpreted.

In spite of the interpretation problems for analyses nine through eleven, factors continued to load on 68 of the 76 remaining parental monitoring variables. The eight items that did not load were from two scales: Restrictive Monitoring as developed by Cottrell, Branstetter, et al. (2007) and Parental Regulation as developed by Barber (2002). The Restrictive Monitoring scale consists of three variables. Prior to analyses nine through eleven, the Restrictive Monitoring scale variables comprised the ninth factor (see the results of analysis seven described above). The Parental Regulation scale consists of 30 variables. Prior to analyses nine through eleven, five variables from the Parental Regulation scale comprised the fifth factor (see the results of analysis seven described above).

The decision to delete the five Parental Regulation variables from further analyses was informed by the following considerations. First, six other variables from the Parental Regulation scale consistently loaded on a single factor in analyses seven through ten. Second, other researchers have reported difficulty developing a clear measurement model when using all 30 
Parental Regulation variables (e.g., Soenens et al., 2006). Third, visual inspection of the five problem variables showed content that was not clearly indicative of parental behavioral control versus parental psychological control.

To decide whether to delete or retain the three Restrictive Monitoring variables, a twelfth analysis was conducted on the 71 remaining parental monitoring variables. Again, factor loadings for the three Restrictive Monitoring variables did not reach .45. Thus, these three items were deleted from further analyses.

The thirteenth analysis was conducted on the reduced pool of 68 variables and yielded seven factors with eigenvalues greater than 1.00 that explained $66.2 \%$ of the variance in the observed data. Results showed that factors loaded higher than .55 on 66 of 68 variables. All 68 factor loadings were higher than .45 . The table of factor loadings and communalities is shown in Table 4. Inspection of the seven factors loading on variables showed that the first factor was defined by variables with content consistent with parent-adolescent relationship quality. The second factor was defined by variables with content consistent with adolescent perceptions of parental monitoring knowledge. The third factor was defined by variables with content consistent with monitoring knowledge that was required by parents. The fourth factor was defined by variables with content consistent with adolescent perceptions that parents were psychologically controlling. The fifth factor was defined by variables with content consistent with parental implementation of consequences for adolescent rule-breaking behavior (i.e., a form of parental behavioral control). The sixth factor was defined by variables with content consistent with parent-adolescent communication about drugs and alcohol. The seventh factor contained the three variables from the Demand-Withdraw Communication scale developed by Caughlin and Malis (2004). Internal consistencies for the seven factors were calculated and showed values for 
Cronbach's alpha in the range of .78 to .97 with six of seven factors showing values of alpha that were greater than .85 (see Table 4).

To further test the solution identified in analysis thirteen, a six-factor solution was imposed with the intent of collapsing Factor 2 and Factor 3. Results of this analysis did not support a six-factor solution. To test the hypothesis that five factors would account for the relations among variables in the observed data, a five-factor solution was imposed. Results of this analysis did not support a five-factor solution. Thus, the seven-factor solution was retained. The factors are interpreted further in the Discussion section of the present study.

Correlations among factors. The correlations of the seven factors with one another are reported in Table 5. The correlations were calculated to test the hypothesis that constructs commonly invoked in the parental monitoring literature are qualitatively distinct, but quantitatively related. Of the 21 unique correlations possible, 18 were significantly correlated, $p$ $<.01$. Nine correlations were higher than .30 , and no correlation was higher than .60 . Nunnally and Bernstein (1994) have suggested that correlations in the range of .30 to .70 support the adequacy of an oblique rotation in factor analysis (p. 501).

Parent-adolescent relationship quality correlated .34 with parent-adolescent communication about drugs and alcohol and .60 with adolescent perceptions of monitoring knowledge. Inverse correlations were observed for parent-adolescent relationship quality and psychological control (-.47) and demand-withdraw communication (-.39). Adolescent perceptions of parental monitoring knowledge was correlated .50 with monitoring knowledge that was required by parents. Monitoring knowledge that was required by parents was correlated with parental implementation of consequences for adolescent rule-breaking behavior (.37) and parent-adolescent communication about drugs and alcohol (.36). Parental implementation of 
consequences for adolescent rule-breaking behavior was correlated .33 with parent-adolescent communication about drugs and alcohol. Parental psychological control correlated .42 with demand-withdraw communication.

Correlations of factors with the PACS. The correlations of the total score for the 68 parental monitoring variables as well as the correlations of the seven parental monitoring factors with the PACS total scale score, the PACS Problem Communication scale score, and the PACS Open Communication scale score are reported in Table 6. Factor scores were calculated using a method described by Comrey (1973, p. 233). First, the variables subsumed by the parental psychological control factor, the demand-withdraw communication factor, and the Problem Communication scale were reverse coded. Second, the 68 parental monitoring variables and the 30 PACS variables were converted to standard scores to account for inter- and intrascale differences in response format. Third, the standardized variables were summed for each of the seven parental monitoring factors to produce seven factor scores. Fourth, the standardized scores for all 68 parental monitoring variables were summed to produce a parental monitoring total scale score. Fifth, the standardized variables were summed for both the PACS Problem Communication subscale and the Open Communication subscale to produce two factor scores. Sixth, the standardized scores for all 20 PACS variables were summed to produce a PACS total scale score. It should be note that more sophisticated methods of calculating factor scores are available (e.g., regression, Bartlett, Anderson-Rubin). However, the present method was chosen given that the goal of the preset study was to provide preliminary evidence for construct validity such that it is not clear whether or not the present results will generalize to other populations of interest (i.e., adolescents of varying ages). Both Tabachnick and Fidell (2007) and Comrey 
(1973) have noted the adequacy of this method of calculating factor scores when conducting preliminary investigations.

The pattern of Pearson product-moment correlation coefficients for the parental monitoring factors and the parental monitoring total score with the PACS Open Communication scale, the PACS Problem Communication scale, and the PACS total scale score ranged from .00 to .83 . The PACS total scale score was correlated .49 with the parental monitoring total scale score. Inverse relations ranging from -.05 to -.56 were observed for the PACS Problem Communication scale with parent-adolescent communication about drugs and alcohol, adolescent perceptions of parental monitoring knowledge, and parent-adolescent relationship quality. Parental psychological control and demand-withdraw communication were correlated .73 and .47 respectively with the PACS Problem Communication scale.

Positive relations ranging from .05 to .83 were observed for the PACS Open Communication scale with parental implementation of consequences for adolescent rulebreaking behavior, monitoring knowledge required by parents, parent-adolescent communication about drugs and alcohol, adolescent perceptions of parental monitoring knowledge, and parentadolescent relationship quality. Parental psychological control and demand-withdraw communication were correlated -.53 and -.37 respectively, with the PACS Open Communication scale.

Socially-desirable responding. To estimate the degree to which participants may have responded to items in an uncommonly positive manner, the Pearson product-moment correlation for the parental monitoring total score with the eight-item Marlowe-Crowne Personal Reaction Inventory (Crowne \& Marlowe, 1964) was calculated. A sample item from the Marlowe-Crowne Personal Reaction Inventory reads, "Have there been occasions where you took advantage of 
someone?" Responses were coded 0 (yes) and 1 (no). The four uncommonly positive items (e.g., sample item above) were reverse coded so that higher total scores on the scale reflected a higher degree of socially desirable responding. Scores on the Marlowe-Crowne Personal Reaction Inventory were converted to standardized scores before calculating the correlation coefficient with the parental monitoring standardized total score. Results showed that the Marlowe-Crowne Personal Reaction Inventory correlated, $r(309)=.17, p<.01$, with the parental monitoring total score. The correlation coefficient was statistically significant; however, this result was likely due to the size of the sample. Furthermore, the correlation coefficient is interpreted as "small" according to the conventions prescribed by Cohen (1988).

\section{Discussion}

The present study was concerned with reducing the number of dimensions and variables or items used to describe the set of processes commonly referred to as parental monitoring. A pool of 226 items was factor analyzed and reduced to a set of 68 items defined by seven conceptually distinct, but correlated factors. The seven factors were consistent with constructs commonly investigated by parental monitoring researchers (e.g., Barber, 1996; Fletcher et al., 2004; Soenens et al., 2006; Stattin \& Kerr, 2000). These constructs are: 1) parental monitoring knowledge, 2) parental behavioral control, 3) parental psychological control, 4) parentadolescent relationship quality, and 5) parent-adolescent communication.

\section{Examination of the Proposed Hypotheses}

The present study hypothesized that five factors would explain the majority of variance in a sample of observed scores obtained on a reduced set of the original 226 parental monitoring items. As previously noted, seven factors (not five) were identified. However, all seven factors were consistent with the domains of content of the five hypothesized factors. 
The key difference between the hypothesized five factors and the resultant seven factors was with regard to the number of factors necessary to define each content area. For example, the present study showed results in support of two distinct knowledge factors as well as two distinct communication factors. Thus, the number of factors was greater than five, but the content domains were equal to five. Furthermore, the hypothesis that proposed a distinct communication factor was supported. Again, the hypothesis proposed that one of five factors would be related to parent-adolescent communication, whereas two communication factors were identified.

The present study further hypothesized that the parental monitoring factors would be moderately correlated in the order of .30 to .70 (Nunnally and Bernstein, 1994, p. 501). This hypothesis was largely supported given that the majority of correlations between factors ranged from .23 to .60 . Furthermore, the pattern of correlations that were positive and negative was as expected. For example, parental psychological control—an intrusive, controlling, and disrespectful style of parenting — was negatively correlated with positive qualities of parentadolescent relationships. Parent-adolescent relationship quality was, in turn, correlated with higher levels of perceived parental monitoring knowledge. Several correlations between factors showed minimal (i.e., less than 5\% shared variance) association. For example, parent-child communication about alcohol and drugs was not related to psychological control.

Demand/withdraw communication was not related to monitoring knowledge required by parents, parental implementation of consequences for adolescent rule-breaking behavior, or parentadolescent communication about alcohol or drugs.

To obtain further information about the validity of the seven parental monitoring factors, correlations between the factors and the Parent-Adolescent Communication Scale (PACS; Barnes \& Olson, 1985) and its subscales were calculated. The resultant pattern of 
correlations was as expected. For example, parental psychological control correlated highly and positively with PACS Problem Communication. Parental psychological control correlated highly and negatively with PACS Open Communication. Thus, the convergent pattern of correlations for the parental monitoring factors with the PACS and its subscales provided further evidence for the construct validity of the parental monitoring factors (The first evidence of construct validity was the results of the factor analysis).

Finally, it should be noted that the participants' responding to parental monitoring items was not influenced by socially desirable responding. That is, participants did not endorse items in a manner that suggested they were trying to give a more favorable impression of themselves.

In summary, the obtained results generally supported the three exploratory hypotheses. In the subsequent section, the findings of the present study are further interpreted according to the content of the seven parental monitoring factors. First, each factor is operationalized according to its content, taking into consideration the intent of the investigation from which the items were derived. Second, limitations are considered. Third, the findings are interpreted generally according to person-in-context models of human development (e.g., Bronfenbrenner \& Morris, 2006) with possibilities for future investigation as guided by these models.

\section{Factor Labels}

The purpose of the present section was to derive more effective factor labels through examination of item content for each factor, taking into account the origin of the items and the research context within which the items were first tested.

Parent-adolescent relationship quality. The largest factor identified in the present investigation was parent-adolescent relationship quality. This factor was defined by 23 items taken from seven different scales that were developed to sample the overall or general quality of parent-adolescent relationships. Parent-adolescent relationship quality was of interest to early 
investigators of parental monitoring and commonly was crossed with other content domains such as parental firmness or control (e.g., Lamborn et al., 1991; Steinberg et al., 1992) to approximate Baumrind's (1991) parenting typologies. For example the Parental Warmth/Involvement scale (Lamborn et al., 1991) was developed to "measure the extent to which the adolescent perceives his or her parents as loving, responsive, and involved" (p. 1053). For instance, the item "I can count on my parents to help me out if I have some kind of problem" has content related to these three parenting characteristics indicative of high quality parent-adolescent relationships as perceived by adolescents. Factor 1 of the present study loaded on this item and others like it.

Scales developed by Stattin and Kerr (2000) and Ryan et al. (2007) also have been used to measure parent-adolescent relationship quality. Whereas the program of research conducted by Lamborn and Steinberg and their colleagues was related to broader parenting typologies, Stattin and Kerr disaggregated parenting into component behaviors. That is, Stattin and Kerr were interested in determining the relative contribution of adolescent behavior and parent behavior, to adolescent problem outcomes. In spite of these differences in research design, the items developed by Stattin and Kerr are similar to those developed by Lamborn et al. (1991). One subtle difference, however, is that the scale developed by Stattin and Kerr included items that assessed adolescent perceptions of their parents as loving, responsive, and involved as well as adolescents' reciprocation. For example, Factor 1 of the present study loaded on two such items derived from Stattin and Kerr's Parent-Child Relationships scale. For instance, "I accept my parents the way they are." This finding is consistent with the contention that valid measures of parental monitoring must assess parenting style as well as adolescents' willingness to be socialized (Darling \& Steinberg, 1993). 
Factor 1 of the present study also subsumed items related to parental support (Barber et al., 2008; Barnes, 1994). In their respective measures of parent-adolescent relationship quality, both of these researchers have emphasized parenting style. For example, Barber et al. (2008) have proposed that adolescents who perceive their parents as supportive are "more socially competent and less depressed" (p. 2) compared to adolescents who do not perceive their parents as supportive. For instance, "My parents are people who make me feel like I am the most important person in their lives" (Barber et al., 2008) broadly reflects parental supportiveness. As with the measures developed by parenting typology researchers, measures developed by Barber and Barnes and her colleagues were more heavily weighted by items related to parenting style versus adolescent willingness to be socialized. Factor 1 of the present study yielded a sample of both types of content. This is considered a strength given the prominence of person-in-context models that theorize complex reciprocal interactions between persons and environments (e.g., Bronfenbrenner \& Morris, 2006; see also Magnusson \& Stattin, 2006).

In summary, Factor 1 of the present study was defined by items that reflected adolescents' perceptions of their parents as attentive, affectionate, guiding, encouraging, comforting, loving, close, and dependable. Two items also reflected adolescents' attempts to reciprocate these markers of high quality relationships. Thus, Factor 1 is interpreted as a general measure of relationships that are characterized by love, responsiveness, involvement, and support. As such, Factor 1 is given the label Quality Parent-Adolescent Relationships. Quality appears first to distinguish this type of relationship from other types of parent-adolescent relationships characterized by problem interactions. "Parent" precedes "Adolescent" to acknowledge that the present measure, while subsuming some adolescent-driven content, 
primarily is a measure of adolescent perceptions of what parents do to foster love, responsiveness, involvement, and support.

Parental Monitoring Knowledge. The origins of this construct are traced to Social Control Theory (Hirschi, 1969) and subsequent investigations conducted by McCord (1979) and Patterson and Stouthamer-Loeber (1984). More recently, Stattin and Kerr (2000) cautioned researchers against casual interpretation of the construct as a measure of parenting behavior or direct control. That is, they defined monitoring knowledge as a product of specific parent- and adolescent-driven processes, placing greatest emphasis on adolescent-driven processes such as self-disclosure. Thus, monitoring knowledge is an outcome, not a behavior.

In addition to being a product or outcome, monitoring knowledge often is measured according to adolescents' self reports of how much knowledge they think their parents possess. That is, monitoring knowledge often is based on adolescents" "perceptions" and says nothing about whether such perceptions are accurate or inaccurate. Fletcher et al. (2004) have noted: “Regarding concerns over adolescents' abilities to perceive accurately their parents' behaviors, we subscribe to the view that parental behaviors are largely meaningful in that they are filtered through the perceptions of the individuals being parented" (p. 794). Thus, any parenting behavior likely will be interpreted according to a given adolescent's subjective experience of his parents and their parenting practices. This inevitably will be true any time that adolescent self-report data is collected and analyzed. However, self-report data collected for the monitoring knowledge construct may be of even greater interest to researchers given that its protective effects are not well understood.

Indeed, perhaps the most perplexing feature of parental monitoring knowledge is that no clear psychological mechanism has been posited to account for its role as a protective factor in 
models of parental monitoring. Measures of monitoring knowledge such as the scale developed by Susan Silverberg-Koerner and Stephen Small presented during a paper symposium at the 1991 meeting of the Society for Research in Child Development (Gondoli, personal communication, June 5, 2008), assess adolescents' perceptions of parental knowledge on the basis of three elements: where, with whom, and doing what. These three elements are then given temporal referents such as when you go out at night, after school, when not at home, during the evening, and during your free time. Factor 2 of the present study contained 16 items, 11 of which were consistent with conventional where/with-whom/what measures of parental monitoring (Barnes et al., 2006; Brown et al., 1993; Lamborn et al., 1991; Ramirez et al., 2004; Stattin \& Kerr, 2000). However, five additional items subsumed by Factor 2 showed departures from this convention.

The observed departures were threefold. First, Factor 2 loaded on one item from the Child-Disclosure scale developed by Stattin and Kerr (2000), "I tell my parents about where I went during the evening," and another item from the Self-Disclosure scale developed by Kerr and Stattin (2000), "When I get home after being out at night, I tell my parents about what I did." As with the two items observed on the Quality of Parent-Adolescent Relationships Factor, these two items were thought to reflect the importance of adolescents' willingness to be socialized. That is, adolescents are forthcoming with information as evidenced by voluntary disclosures to parents. Second, Factor 2 loaded on one additional item from the Child-Disclosure scale, "I hide a lot from my parents about what I do when I am out at night and on the weekends.” Third, Factor 2 loaded on two items form the Adolescent Beliefs About Parental Knowledge scale (Laird, Pettit, Dodge, et al., 2003); for example, "My parents should have knowledge about what things I do with my friends." 
It is believed that these five items are not in direct conflict with the 11 conventional monitoring knowledge items. In fact, these five items may afford some insight into the mechanism(s) that produce the protective effects of monitoring knowledge. Consider the following interpretation based on the contextual model of parenting proposed by Darling and Steinberg (1993). In the contextual model, parenting practices (e.g., behavioral control) are theorized to be directly related to adolescent outcomes. Parenting style (e.g., authoritative parenting) and adolescents' willingness to be socialized were theorized to moderate the relation of parenting practices and adolescent outcomes. In the context of the present study, participants' beliefs about parental monitoring knowledge and adolescents' willingness to volunteer monitoring information to parents are interpreted according to the contextual model of parenting style as evidence of adolescents' openness to parental influence. Thus, it may be the case that parental monitoring knowledge is a proxy for one or many reciprocal processes that take place between parents and their children that ultimately affect the degree to which adolescents conform to parental goals and values. These reciprocal processes may have very different topographies and functions depending on the specific period of childhood or adolescence (e.g., toddlerhood versus early adolescence) investigated. It should be noted that the present study did not provide any empirical test of plausible alternatives to the monitoring knowledge construct; rather, findings are extended here for the purpose of identifying problems and questions for future investigation. At present, monitoring knowledge is theorized to be the end result of these earlier reciprocal processes.

In summary, Factor 2 of the present study was defined by items that reflect adolescents' perceptions of their parents as knowledgeable as well as items that reflect adolescents' willingness to be sources of parental knowledge. Thus, Factor 2 is interpreted as a measure of the 
content, context, and source facets of monitoring knowledge. Absent any tests of the unique predictive validity of these facets and absent longitudinal data describing the development of adolescents' willingness/unwillingness to be socialized, the traditional construct label of Parental Monitoring Knowledge is retained.

Parental control. Factor 3 loaded on all six items from the Parental Control scale developed by Stattin and Kerr (2000). A sample item reads, "Before I go out on a Saturday night, my parents require that I tell them whom I going out with.” In some respects, Parental Control is similar to Parental Monitoring Knowledge. For example, both factors subsume items that measure knowledge-content and knowledge-context. The key difference is that Parental Control is just as it sounds - a parental requirement. Thus, in terms of the Contextual Model of Parenting (Darling \& Steinberg, 1993), Parental Control is considered a parenting practice and does not provide any information about adolescents' willingness to comply with the requirement.

Further inspection of the items that comprise Parental Control showed that they have a temporal facet. That is, one type of item has parents requiring information before their adolescent is allowed to go out (prospective knowledge), a second type of item has parents requiring information while the adolescent is out (concurrent knowledge), and a third type of item has parents requiring knowledge after the adolescent returns home (retrospective knowledge). Certainly time-sensitive knowledge is advantageous to parents. For example, a parent could require that his or her adolescent provide knowledge details of where, who, and what prior to the adolescent leaving the house. Then, the parent could have the adolescent call home while he or she is out. Last, the parent could review the details of the evening with the adolescent. This temporally-sensitive method of actively seeking monitoring knowledge allows the parent to test the consistency of his or her adolescents' plans across the course of an evening out. In scientific 
terms, this is akin to test-retest reliability. Of course, reliability will be useful only to the extent that the adolescent provides a transparent accounts of where, who, and what. This latter point again raises the importance of balance between adolescent-driven and parent-driven processes.

In summary, Factor 3 of the present study was defined by items that reflected parents' rules about adolescent disclosure of monitoring knowledge. Thus, Factor 3 is interpreted as subsuming content that includes parental knowledge, parenting behavior, and parent-adolescent communication. Thus, it may be the case that disaggregation of parental monitoring constructs may not always be possible or desirable. That is, attempts to disaggregate the constructs ignore the fact that parental monitoring is a process that takes place in a given context over a given period of time. Furthermore, the extent to which the communication yields information with protective value is determined by a number of factors (e.g., parenting style), the most important of which is the adolescent's decision to comply with the parental requirement (Stattin \& Kerr, 2000). In light of these considerations, Parental Knowledge Requirements is thought to be a better label of the construct.

Psychological control. Factor 4 was indicated by nine items, six of which were derived from Barber's (Barber, 1996; Barber et al., 2008) ongoing validation of the psychological control construct. Two additional items were derived from the Feeling Controlled by Parents scale developed by Stattin and Kerr (2000). These two items showed the highest factor loadings of the nine items and were qualitatively similar to the items developed by Barber. A sample Feeling Controlled by Parents item reads, "I think that my parents interfere too much in my free time activities." One additional item was derived from Barber's (2002) Parental Regulation: Parental Monitoring of Behavior scale, "My parents are people who go overboard in checking on my behavior." 
As with Quality Parent-Adolescent Relationships and Parental Monitoring Knowledge, measurement of Factor 4 of the present study was influenced by adolescent perceptions. Yet, psychological control differs from the other two constructs in the sense that it is a parent-driven process that likely depends very little on what dispositions or behaviors the adolescent contributes to the context of parenting. As such Factor 4 was defined by parenting practices of interference, privacy violations, unreasonable expectations, coercion, ambivalence, unfair criticism, and lack of empathy. Psychological Control (Barber, 1996) and, more recently, Parental Disrespect (Barber et al., 2008) are apt labels. Yet, the meaning of Psychological Control is perhaps too general and implies meaning that may not be warranted given the outcomes with which it has been associated (see Barber, 1996; Barber et al., 1994). Furthermore, all Factor 4 items show elements of Parental Disrespect; yet, in the greater context of adolescent development, Parental Disrespect may not fully describe the scope of this problem parenting style. For example, a parent may behave disrespectfully by cracking a joke about his or her adolescents' body odor in front of friends or family; however, an ongoing pattern of bringing up an adolescent's shortcomings or past mistakes to maintain a position of parental control surpasses mere disrespect. Thus, Feeling Controlled by Parents is taken from Stattin and Kerr (2000) as a label that is neither too inclusive nor too restrictive when used to describe the present set of nine items.

Behavioral control. Factor 5 was indicated by six items, all of which were derived from Barber's (2002) 30-item Parental Regulation scale. More specifically, the six items were taken from the Parental Enforcement of Expectations subscale. As with Feeling Controlled by Parents, Regulation is considered to be a construct weighted in favor of parent-driven processes. The content of the six items included parental action taken to restrict privileges, apply consequences, 
and enforce consequences when adolescents are found in violation of parental rules or expectations. Studies have shown that parental behavioral control affords protection against adolescent problem outcomes such as delinquency and aggression (Barber, 1996; Barber et al., 1994; Dornbusch et al., 1985; Gray \& Steinberg, 1999). The present study showed a small to moderate (Cohen, 1988) positive, concurrent correlation for parental behavioral control with Feeling Controlled by Parents. Furthermore, parental behavioral control was not correlated with either the PACS Open Communication scale or the PACS Problem Communication scale. It was, however, moderately and positively correlated with Parental Knowledge Requirements.

Clearly, the correlation between parental behavioral control and Feeling Controlled by Parents raises concerns about the validity of one or both factors. However, the pattern of observed correlations is not considered a plausible threat to construct validity. First the amount of shared variance is small (approximately 5\%). It may be the case that parents who are overly controlling and parents who provide legitimate control in response to their adolescents' rule breaking share characteristics (as perceived by adolescents) of attentiveness or high expectations. It is perhaps the more extreme manifestations that differentiate problematic control from control that is protective. Second, the present study did not test the criterion validity of the two constructs to determine their differential pattern of relations with adolescent outcomes such as internalizing or externalizing problems. Third, and related to the second point, the Parental Enforcement of Expectations items identified in the present investigation previously were used to distinguish psychological control from behavioral control (Barber, 1996). The second and third points are qualified by noting that whether or not this distinction holds for the subset of items identified in the present study remains to be tested. 
In summary, Factor 5 of the present study was defined by items that reflect parents' enforcement of rules and expectations for adolescent behavior. The items did not specify specific behavioral expectations or specific punishing contingencies; thus, it is considered a general measure of a parenting practice. Given that Factor 5 loaded on 6 of 10 items from Barber's (2002) Parental Enforcement of Expectations subscale, that label is retained.

Communication factors. The present study hypothesized parent-adolescent communication as a fifth construct relevant to parental monitoring processes. Furthermore, it was hypothesized that items developed by Stattin and Kerr (2000; Kerr \& Stattin, 2000) to operationalize adolescent self-disclosure would be subsumed by that communication factor. The latter part of this exploratory hypothesis was incorrect. Self-disclosure items were subsumed by Parental Monitoring Knowledge and the implication of this finding already has been discussed. The former part of this exploratory hypothesis - the legitimacy of a conceptually distinct communication factor-showed mixed results.

As previously discussed, not all of the factors identified in the present investigation were found to assess single facets of a given domain of content. For example, Parental Monitoring Knowledge subsumed the conventional where, who, and what information as well as several items that indicated the directional flow of such information via parent-adolescent communication. Similarly, Parental Knowledge Requirements was defined by content that was multifaceted, including parental monitoring knowledge, parental behavioral control, and parentadolescent communication. In each instance, parent-adolescent communication was conceptualized as a general process that occurred within the same context as parenting style, parenting practices, and adolescents' willingness to be socialized (i.e., Darling \& Steinberg, 1993). 
With regard to Factor 6 of the present study, however, the communication component was unitary. That is, its content was defined by a specific type of parent-adolescent communication—communication about alcohol and other drugs.

Factor 6 of the present study subsumed five items from the 10-item Parent-Child Communication about Alcohol scale developed by M. Miller-Day (personal communication, June 4, 2008). A sample item reads, "At least one of my parents has lectured me or given me a speech about drinking alcohol." This item and other similarly worded items do not necessarily give the impression (i.e., face validity) of effective parental communication. Rather, the items seem to reflect what Miller-Day (2002) previously described as mere parental assertion that drugs are bad (p. 609). Yet, the five items from the Parent-Child Communication about Alcohol scale showed moderate, positive correlations with factors such as Quality Parent-Adolescent Relationships, Parental Monitoring Knowledge, Parental Knowledge Requirements, and Parental Enforcement of Expectations. It also was moderately and positively correlated with the PACS total score and the PACS Open Communication scale. It was not correlated with Feeling Controlled by Parents, Adolescent-Demand/Parent-Withdraw Communication, or the PACS Problem Communication scale.

The fact that the Parent-Child Communication about Alcohol Scale added substantially to the amount of variance explained by the factor solution and showed a plausible pattern of correlations with other factors and other measures indicate that further tests of its utility are warranted. The label given to Factor 6 is adjusted to provide a more specific and accurate description: Parent-Adolescent Communication about Alcohol and Other Drugs.

Factor 7 of the present study subsumed three of three items from the AdolescentDemand/Parent-Withdraw Communication scale used by Caughlin and Malis (2004). A sample 
item reads, "During a discussion of a problem, how often do you criticize while your parents try to ignore you?" In the study conducted by Caughlin and Malis, demand/withdraw patterns were observed for mundane topics of discussion as well as more serious topics such as adolescent alcohol and drug use.

The Adolescent-Demand/Parent-Withdraw items used in the present study potentially provide a unique vantage point for assessing parent-adolescent conflict as related to parental monitoring. Whereas global measures of parental psychological control assess problem parenting behaviors, the Adolescent-Demand/Parent Withdraw scale assesses a problem interaction that likely depends on what both parents and adolescents do when faced with issues about which they disagree.

A key difference between Factor 6 and Factor 7 is that the former assessed communication about a specific topic, whereas the latter assessed a general style of communication that could be used to measure parent-adolescent conflict across a number of different domains. Thus, Factor 7 is a multifaceted construct as it subsumes facets of communication, behavior, and psychological control. Furthermore, it balances parent- and adolescent-driven processes taking place within a given context.

Factor 7 correlated negatively and moderately with Quality Parent-Adolescent Relationships, Parental Monitoring Knowledge, and PACS Open Communication. It was positively and moderately associated with Feeling Controlled by Parents and PACS Problem Communication.

In summary, Factor 7 of the present study was defined by items that reflect problem communication patterns between adolescents and parents. The content of the items suggested that this may be an adolescent-driven or adolescent-initiated process whereby adolescents initiate 
discussion of a given topic with forcefulness and demands directed at parents. The parental response may then add to the overall level of dysfunction of the interaction. Caughlin and Malis (2004) described this type of communication as Adolescent-Demand/Parent-Withdraw communication, which is considered an apt label and is retained for the present study.

\section{Limitations}

The findings from the present study were, in many ways, consistent with the findings of previous studies of parental monitoring. That is, the measurement model reported in the present study showed factors with content comparable to the core constructs of interest to parental monitoring investigators: 1) parental monitoring knowledge, 2) parental behavioral control, 3) parental psychological control, 4) parental-adolescent relationship quality, and 5) parentadolescent communication. When interpreting and extending the findings of the present study, however, several limitations must be considered.

Two of the limitations are related. First, the present study was conducted with a sample of emerging adults. Second, given that the sample was older and comprised of college students, few participants were actively experiencing any parental monitoring on a day-to-day basis. That is, participant accounts of parental monitoring were retrospective.

With regard to the age of the sample, Arnett (2000) has defined persons age 18 to 25 years old as emerging adults on the basis of demographic and subjective distinctions when compared to adolescents or young adults. For example, emerging adults experience a mix of both dependence on and independence from adults. Furthermore, approximately $60 \%$ of 18 - to 25 year-olds that Arnett surveyed did not see themselves as persons who consistently evidenced personal responsibility and independent decision making (p. 473). Thus, in some respects (e.g., demographic changes), emerging adult development is qualitatively different from adolescence; 
however, in other respects (e.g., continued dependence on parents), it is qualitatively similar to adolescence.

These similarities suggest that certain developmental tasks first begun in adolescence extend into emerging adulthood. Consider, for example, the importance of increased autonomy to adolescent development (Soenens, Vansteenkiste, Lens, Luyckx, Gossens, et al., 2007). Based on emerging adults own perceptions of their developmental status, it would appear that autonomy-seeking is still a salient characteristic for those who are 18 to 25 years old. In the case of the present study, it is acknowledged that the sample chosen is not an adolescent sample; however, it is argued that the current experiences (i.e., mixed dependence on adults and autonomy-seeking) of the majority of the participants are consistent with developmental processes that first began during adolescence.

With regard to the use of retrospective accounts, Brewin, Andrews, and Gotlib (1993) noted: "provided that individuals are questioned about the occurrence of specific events or facts that they were sufficiently old and well placed to know about, the central features of their accounts are likely to be reasonably accurate" (p. 94). Participants in the present study were asked to recall events that took place when they were approximately 17 years of age. Furthermore, these events were not isolated occurrences; rather, they were ongoing processes.

Brewin et al. (1993) specifically noted the high degree of accuracy obtained when collecting retrospective accounts of parenting. In fact, they referenced the Children's Report of Parental Behavior Inventory (CRPBI; Schaefer, 1965a) as yielding consistent results over time. The present study included some questions from the CRPBI, and many, if not all, of the questions included in the present study were similar in content and structure to CRPBI questions. Thus, it would appear that the use of retrospective accounts does not pose a plausible threat to 
the external validity of the present study given the characteristics of and the time frame for the events recalled.

The third limitation also is related to the composition of the sample. Specifically, over three quarters of the sample was female. Prior investigations of parental monitoring have shown that parents often report higher levels of monitoring knowledge for female versus male adolescents (Smetana \& Daddis, 2002; Stattin \& Kerr, 2000; Waizenhofer et al., 2004). However, when full models that include other parental monitoring constructs such as psychological control, behavioral control, and relationship quality, sex differences have not been shown to moderate the structural relations between constructs (Soenens et al., 2006), nor have sex differences been identified when testing the factorial invariance of measurement models (Pettit et al., 2001). Unfortunately, the relatively small sample of male participants $(N=71)$ in the present study did not allow for a legitimate test of factorial invariance. Yet, the pattern of results observed in prior studies suggests that the results of the present study are not adversely affected by the imbalance of male and female participants.

The fourth limitation of the present study is defined by the lack of cultural diversity observed among the participants. Nearly $94 \%$ of the 320 participants whose data was used in the primary analyses described themselves as Caucasian. Other investigators also have reported findings obtained from narrow sampling procedures. Consider that influential studies conducted by Stattin and Kerr (2000) and Soenens et al. (2006) were carried out with predominantly white European youth. Similar limitations are observed for parental monitoring research conducted on U.S. samples (e.g., Cottrell, Yu, et al., 2007). Other researchers have recruited samples cultural minorities; for example, Smetana and Daddis (2002) investigated middle class African American adolescents' domain-specific beliefs about parenting practices as related to the parental 
monitoring constructs of psychological control and parental monitoring knowledge. Darling et al. (2007) investigated Chilean adolescents' beliefs about the legitimacy of parental authority and obligation to obey parental authority. Their findings upheld the importance of parental monitoring knowledge in distinguishing differences between adolescents with regard to obedience.

At least two recent studies have made commendable efforts with regard to recruiting samples that are representative of the U.S. population (e.g., Barnes et al., 2006; Branstetter et al., 2009). These investigators have reported on the utility of parental monitoring knowledge and parent-adolescent relationship quality or support as factors that are protective against adolescent involvement in risk behavior. Thus, it would appear that many of the constructs investigated and validated in the present study have demonstrated some degree of cross-cultural validity. However, it will be important to recruit culturally diverse samples when attempting to cross validate the measurement model identified in the present investigations. In accord with the tenets of bioecological theory (Bronfenbrenner \& Morris, 2006), parental monitoring constructs should be tested across multiple contexts to address relations between two or more settings (i.e., mesosystem) as well as indirect influences (i.e., exosystem) on adolescents and their families as such contexts may differentially affect the validity of parental monitoring constructs for different cultural and socioeconomic groups.

The fifth consideration when interpreting the findings of the present study is with regard to potential differences between adolescents' perceptions of maternal versus paternal monitoring. The present investigation did not distinguish between paternal and maternal monitoring. Some investigators have reported minimal to no difference with regard to models of parental monitoring when adolescents are asked to rate their perceptions of maternal versus paternal 
parenting (e.g., Soenens et al., 2006). However, other investigations have reported variations in parenting as a function of parent gender, especially with regard to the amount of monitoring knowledge a given parent is thought to possess (e.g., Waizenhofer et al., 2004). Thus, the measurement model reported in the present investigations should be validated separately for adolescents' perceptions of mothers versus fathers and the resultant models should be tested for factorial invariance across parent gender.

In summary, potential threats to the validity of the results reported for the present study included concerns related to participant age, the use of retrospective reports, the imbalance of the ratio of male to female participants, cultural homogeneity, and the lack of distinction between participants' perceptions of maternal versus paternal parenting. Based on prior research, it was argued that these threats were not sufficient to invalidate the results of the present study. However, it should be noted that the present study is only the first step in the ongoing process of validating a measurement model for parental monitoring constructs. Thus, confidence in the present findings will increase with systematic replication across diverse samples and contexts.

\section{Implications and Future Directions}

Validation of measurement models is an important goal for any active research literature. Consistent measurement of constructs helps to ensure that researchers are investigating the same items from one study to the next - a practice that in spite of its obvious good sense is not always practiced. For instance, validation of measures is a time consuming process that often yields scant results. Consider the fact that the present study required 18 months to complete. Consider as further evidence that in the course of conducting the present study, the primary investigator received the equivalent of three unpublished manuscripts from B. K. Barber that documented his efforts to validate measures of parental behavioral control, parent-adolescent relationship quality, 
and parental psychological control/disrespect. Validation of measurement models is a pursuit maintained on a lean schedule of reinforcement.

Unfortunately, it would seem that investigators give little attention to measurement models for the constructs in which they are interested. The magnitude of this problem is most apparent when one considers the divergence of research and theory. Early investigators of parental monitoring (e.g., Lamborn et al., 1991) used theory to inform their investigations and operationalized their constructs accordingly. More recent investigations (post Stattin \& Kerr, 2000) have moved away from theory-based investigations of parent-adolescent socialization in favor of increasingly molecular accounts of parental monitoring. This trend has contributed to the development of nearly 50 different ways of measuring core parental monitoring constructs.

Smetana and Daddis (2002) conducted an investigation that is a notable exception to the recent trend of atheoretical accounts of parental monitoring. They showed that parents' involvement in various domains of their adolescents' lives was differentially related to adolescents' perceptions of parental psychological control versus parental monitoring knowledge. Thus, these researchers used a theory-based account of parental monitoring that afforded information about process and context.

The preceding overview of the atheoretical problem is not intended to favor process accounts over disaggregation accounts. Both approaches are useful, and both approaches have limitations. In fact, it is argued that theoretical frameworks can be used to inform both research strategies. For example, person-in-context models of human development are inclusive theories that are well known to developmental researchers. The bioecological model of human development (Bronfenbrenner \& Morris, 2006) and the holistic-interactionistic approach (Magnusson \& Stattin, 2006) are prototypical inclusive theories. In fact, Magnusson and Stattin 
have provided an apt assessment of the "fragmentation" of psychology research in general: "More and more psychologists are becoming aware of the need for a general theoretical framework for designing, implementing, and interpreting studies of specific issues” (p. 401). Therefore, these inclusive theories can be thought of as metatheoretical accounts of human development that aid the interpretation of findings from specific investigations and subsume smaller, less comprehensive theories (e.g., social domain theory, parenting styles).

Bronfenbrenner and Morris (2006) define the bioecological model of human development according to properties of process, person, context, and time (p. 795). For example:

Human development takes place through processes of progressively more complex reciprocal interaction between an active, evolving biopsychological human organism and the persons, objects, and symbols in its immediate external environment. To be effective, the interaction must occur on a fairly regular basis over extended periods of time. Such enduring forms of interaction in the immediate environment are referred to as proximal processes. (p. 797)

This proposition fits well with current conceptualizations of parental monitoring. Earlier manifestations of the Bioecological Model are evidenced in Darling and Steinberg's (1993) Conceptual Model of Parenting, which was referenced throughout preceding sections of the present discussion. The model proposed by Darling and Steinberg is consistent with Bronfenbrenner and Morris' definition of a proximal process. Close examination of the Contextual Model of Parenting shows that it is an inclusive model that permits tests of theory as well as tests of targeted parent or adolescent behaviors. It is inclusive of parent- and adolescentdriven processes as well as their interaction. Findings from the present study indicate the need to attend to these levels of analysis by conducting investigations that are multifaceted and 
multilevel. Several suggestions for future investigation are offered given findings of the present study and their implications for future investigation within the Bioecological framework.

First, the measurement model proposed in the present study should be replicated with representative samples of adolescents and outcome measures should be included so that the criterion validity of the constructs can be assessed. Sufficiently large samples should be obtained to permit tests of age and sex moderators.

Second, several factors in the present study such as Parental Monitoring Knowledge and Parental Knowledge Requirements subsumed multifaceted content. The trend in parental monitoring research has been to disaggregate constructs that appear to sample more than one facet of a content domain so as to identify the component parenting practices or adolescent behaviors. This practice provides a concrete example of what is meant by levels of analysis. Disaggregation is a legitimate method of breaking down parenting processes and adolescent behavior; however, the utility of disaggregating parental monitoring constructs can be improved by selecting the appropriate point in time and duration of time to study the item of interest. It is believed that investigations that are sensitive to these requirements of contextual models will yield findings that explain phenomena that at present continue to perplex researchers; for example, the mechanism(s) related to the protective effects of parental monitoring knowledge.

At a different level of analysis, it may also be important to add content to the smaller factors identified in the present study. For example, focus groups conducted with adolescents could be used to validate the content of the Parent-Child Communication about Alcohol and Other Drugs factor. Other than the pattern of concurrent associations with other factors and measures, little is known about the role of this specific type of parent-to-adolescent 
communication. Indeed, this is of concern given that there is no shortage of advice given to parents via popular media channels.

\section{Conclusion}

The present study showed preliminary evidence for the construct validity of 68 parental monitoring items subsumed by seven factors: 1) Quality Parent-Adolescent Relationships, 2) Parental Monitoring Knowledge, 3) Parental Knowledge Requirements, 4) Feeling Controlled by Parents, 5) Parental Enforcement of Expectations, 6) Parent-Adolescent Communication about Alcohol and Other Drugs, and 7) Adolescent-Demand/Parent-Withdraw Communication. The purpose of conducting the present study was not to develop more or better parental monitoring measures. In fact, no new items were written. Rather, the purpose of the present study was to provide preliminary evidence for a measurement model that summarizes the most important dimensions of parent-adolescent socialization as related to parental monitoring. Thus, it is hoped that greater awareness of measurement concerns will promote consensus among researchers who share the common goal of advancing the research literature by answering perplexing questions such as the mechanisms responsible for the protective effects of monitoring knowledge and by attending to newly emerging areas of importance such as the contexts and processes associated with effective parent-adolescent communication. 


\section{References}

Amato, P., \& Fowler, F. (2002). Parenting practices, child adjustment, and family diversity. Journal of Marriage and Family, 64, 703-716.

American Psychiatric Association (2000). Diagnostic and statistical manual of mental disorders (4th ed., text revision). Washington, DC: Author.

Arnett, J. J. (2000). Emerging adulthood: A conception of development from the late teens through the twenties. American Psychologist, 55, 469-480.

Arnett, J. J. (2007). Emerging adulthood: What is it, and what is it good for? Child Development Perspectives, 1, 68-73.

Barber, B. K. (1996). Parental psychological control: Revisiting a neglected construct. Child Development, 67, 3296-3319.

Barber, B. K. (2002). Regulation as a multicultural concept and construct for adolescent health and development. Unpublished manuscript.

Barber, B. K., Olsen, J. E., \& Shagle, S. C. (1994). Associations between parental psychological and behavioral control and youth internalized and externalized behaviors. Child Development, 65, 1120-1136.

Barber, B. K., Olsen, J. A., Xia, M., McNeely, C., Bose, K., Kritiyapichatkul, C., Krauskopf, D. R., \& Ward, C., L. (2008). Examining the essence of parental psychological control: Exploring parental disrespect. Paper presented at the European Association for Research on Adolescence, Torino, Italy.

Barber, B. K., Stoltz, H. E., \& Olsen, J. A. (2005). Parental support, psychological control, and behavioral control: Assessing relevance across time, method, and culture. Monographs of the Society for Research in Child Development 70, No. 4. 
Barnes, G. M., Farrell, M. P., \& Banerjee, S. (1994). Family influences on alcohol abuse and other problem behaviors among black and white adolescents in a general population sample. Journal of Research on Adolescence, 4, 183-201.

Barnes, G. M., Hoffman, J. H., Welte, J. W., Farrell, M. P., \& Dintcheff, B.A. (2006). Effects of parental monitoring and peer deviance on substance use and delinquency. Journal of Marriage and Family, 68, 1084-1104.

Barnes, H. L., \& Olson, D. H. (1982). Parent-adolescent communication scale. In D. H. Olson, Family inventories: Inventories used in a national survey of families across the family life cycle (pp. 33-48). St. Paul, MN: University of Minnesota.

Baumrind, D. (1991). The influence of parenting style on adolescent competence and substance use. The Journal of Early Adolescence, 11, 56-95.

Beck, K. H., Boyle, J. R., \& Boekeloo, B. O. (2004). Parental monitoring and adolescent drinking: Results of a 12-month follow-up. American Journal of Health Behavior, 28, 272-279.

Borawski, E A., Ievers-Landis, C. E., Lovegreen, L. D., \& Trapl, E. S. (2003). Parental monitoring, negotiated unsupervised time, and parental trust: The role of perceived parenting practices in adolescent health risk behaviors. Journal of Adolescent Health, 33, 60-70.

Branstetter, S. A., Furman, W., \& Cottrell, L. (2009). The influence of representations of attachment, maternal-adolescent relationship quality, and maternal monitoring on adolescent substance use: A 2-year longitudinal examination. Child Development, 80, 1448-1462. 
Brewin, C. R., Andrews, B., \& Gotlib, I. H. (1993). Psychopathology and early experience: A reappraisal of retrospective reports. Psychological Bulletin, 113, 82-98.

Bronfenbrenner, U., \& Morris, P. A. (2006). The bioecological model of human development. In R. M. Lerner \& W. Damon (Eds.), Handbook of child psychology: Vol. 1. Theoretical models of human development (6th ed., pp. 793-828). Hoboken, NJ: John Wiley and Sons.

Brown, B. B., Mounts, N., Lamborn, S. D., \& Steinberg, L. (1993). Parenting practices and peer group affiliation in adolescence. Child Development, 64, 467-482.

Caughlin, J. P., \& Malis, R. S. (2004). Demand/withdraw communication between parents and adolescents: Connections with self-esteem and substance use. Journal of Social and Personal Relationships, 21, 125-148.

Centers for Disease Control \& Prevention (2008). National youth risk behavior surveillanceUnited States, 2007. Morbidity \& Mortality Weekly Report, 57(SS-4), 1-131. Retrieved August 25, 2008, from http://www.cdc.gov/HealthyYouth/yrbs/pdf/yrbss07_mmwr.pdf

Cernkovich, S. A., \& Giordano, P. C. (1987). Family relationships and delinquency. Criminology, 25, 295-321.

Cohen, J. (1988). Statistical power analysis for the behavioral sciences (2nd ed.). New York: Academic Press.

Comrey, A. L. (1973). A first course in factor analysis. New York: Academic Press.

Cook, R. D., \& Weisberg, S. (1982). Residuals and influence in regression. New York: Chapman \& Hall. 
Cottrell, L., Yu, S., Liu, H., Deveaux, L., Lunn, S., Bain, R. M., \& Stanton, B. (2007). Genderbased model comparisons of maternal values, monitoring, communication, and early adolescent risk behavior. Journal of Adolescent Health, 41, 371-379.

Cottrell, S. A., Branstetter, S. A., Cottrell, L., Stanton, B. F., \& Harris, C. V. (2007).

Development and validation of a parental monitoring instrument: Measuring how parents monitor adolescents' activities and risk behaviors. The Family Journal, 15, 328-335.

Cronbach, L. J., \& Meehl, P. E. (1955). Construct validity in psychological tests. Psychological Bulletin, 52, 281-302.

Crowne, D. P., \& Marlowe, D. (1964). The approval motive. New York: John Wiley \& Sons.

Darling, N., Cumsille, P., \& Martinez, M. L. (2007). Adolescents' as active agents in the socialization process: Legitimacy of parental authority and obligation to obey as predictors of obedience. Journal of Adolescence, 30, 297-311.

Darling, N., \& Steinberg, L. (1993). Parenting style as context: An integrative model. Psychological Bulletin, 113, 487-496.

Dishion, T. J., \& McMahon, R. J. (1998). Parental monitoring and the prevention of child and adolescent problem behavior: A conceptual and empirical formulation. Clinical Child and Family Psychology Review, 1, 61-75.

Dishion, T. J., Patterson, G. R., Stoolmiller, M., \& Skinner, M. L. (1991). Family, school, and behavioral antecedents to early adolescent involvement with antisocial peers. Developmental Psychology, 27, 172-180.

Dornbusch, S. M., Merrill, C., Bushwall, S. J., Ritter, P. L., Leiderman, H., Hastorf, A. H., \& Gros, R. T. (1985). Single parents, extended households, and the control of adolescents. Child Development, 56, 326-341. 
Field, A. (2005). Discovering statistics using SPSS (2nd ed.). Thousand Oaks, CA: Sage Publications.

Fisher, P. A., Leve, L. D., O'Leary, C. C., \& Leve, C. (2003). Parental monitoring of children's behavior: Variation across stepmother, stepfather, and two-parent biological families. Family Relations, 52, 45-52.

Fletcher, A.C., Steinberg, L., \& Williams-Wheeler, M. (2004). Parental influences on adolescent problem behavior: Revisiting Stattin and Kerr. Child Development, 75, 781-796.

Gavazzi, S. M., Reese, M. J., \& Sabatelli, R. M. (1998). Conceptual development and empirical use of the Family Intrusiveness Scale. Journal of Family Issues, 19, 65-74.

Graber, J. A., Nichols, T., Lynne, S. D., Brooks-Gunn, J., \& Botvin, G. J. (2006). A longitudinal examination of family, friend, and media influences on competent versus problem behaviors among urban minority youth. Applied Developmental Science, 10, 75-85.

Gray, M. R., \& Steinberg, L. (1999). Unpacking authoritative parenting: Reassessing a multidimensional construct. Journal of Marriage and the Family, 61, 574-587.

Guilamo-Ramos, V., Jaccard, J., Dittus, P., \& Bouris, A. M. (2006). Parent expertise, trustworthiness, and accessibility: Parent-adolescent communication and adolescent risk behavior. Journal of Marriage and Family, 68, 1229-1246.

Hair, E. C., Moore, K. A., Garrett, S. B., Ling, T., \& Cleveland, K. (2008). The continued importance of quality parent-adolescent relationships during late adolescence. Journal of Research on Adolescence, 18, 187-200.

Henry, C. S., Robinson, L. C., Neal, R. A., \& Huey, E. L. (2006). Adolescent perceptions of overall family system functioning and parental behaviors. Journal of Child Family Studies, 15, 319-329. 
Hirschi, T. (1969). Causes of delinquency. Berkley: University of California Press.

Huebner, A. J., \& Howell, L. W. (2003). Examining the relationship between adolescent sexual risk-taking and perceptions of monitoring, communication, and parenting style. Journal of Adolescent Health, 33, 71-78.

Jaccard, J., Blanton, H., \& Dodge, T. (2005). Peer influences on risk behavior: An analysis of the effects of a close friend. Developmental Psychology, 41, 135-147.

Kaiser, H. F. (1960). The application of electronic computers to factor analysis. Educational and Psychological Measurement, 20, 141-151.

Kaiser, H. F. (1970). A second-generation little jiffy. Psychometrika, 35, 401-415.

Kaiser, H. F. (1974). An index of factorial simplicity. Psychometrika, 39, 31-36.

Kerr, M., \& Stattin, H. (2000). What parents know, how they know it, and several forms of adolescent adjustment: Further support for a reinterpretation of monitoring. Developmental Psychology, 36, 366-380.

Laird, R. D., Pettit, G. S., Bates, J. F., \& Dodge, K. A. (2003). Parents' monitoring-relevant knowledge and adolescents' delinquent behavior: Evidence of correlated developmental changes and reciprocal influences. Child Development, 74, 752-768.

Laird, R. D., Pettit, G. S., Dodge, K. A., \& Bates, J. F. (2003). Change in parents' monitoring knowledge: Links with parenting, relationship quality, adolescent beliefs, and antisocial behavior. Social Development, 12, 401-419.

Lamborn, S. D., Mounts, N. S., Steinberg, L., \& Dornbusch, S. M. (1991). Patterns of competence and adjustment among adolescents from authoritative, authoritarian, indulgent, and neglectful families. Child Development, 62, 1049-1065. 
Longest, K. C., \& Shanahan, M. J. (2007). Adolescent work intensity and substance use: The mediational and moderational roles of parenting. Journal of Marriage and Family, 69, $703-720$.

Lunneborg, C. E. (1994). Modeling experimental and observational data. Belmont, CA: Duxbury Press.

Magnusson, D., \& Stattin, H. (2006). The person in context: A holistic-interactionistic approach. In R. M. Lerner \& W. Damon (Eds.), Handbook of child psychology: Vol. 1. Theoretical models of human development (6th ed., pp. 400-464). Hoboken, NJ: John Wiley and Sons.

Matza, L. S., Kupersmidt, J. B., \& Glenn, D. M. (2001). Adolescents' perceptions and standards of their relationships with their parents as a function of sociometric status. Journal of Research on Adolescence, 11, 245-272.

McCord, J. (1979). Some child-rearing antecedents of criminal behavior in adult men. Journal of Personality and Social Psychology, 37, 1477-1486.

McKnight, P. E., McKnight, K. M., Sidani, S., \& Figueredo, A. J. (2007). Missing data: A gentle introduction. New York: The Guilford Press.

Miller-Day, M. A. (2002). Parent-adolescent communication about alcohol, tobacco, and other drug use. Journal of Adolescent Research, 17, 604-616.

Miller-Day, M. A. (2008). Talking to youth about drugs: What do late adolescents say about parental strategies? Family Relations, 57, 1-12.

Miller, P., \& Plant, M. (2003). The family, peer influences and substance use: Findings from a study of UK teenagers. Journal of Substance Use, 8, 19-26. 
Mounts, N. S. (2001). Young adolescents' perceptions of parental management of peer relationships. Journal of Early Adolescence, 21, 92-122.

Mounts, N. S. (2002). Parental management of adolescent peer relationships in context: The role of parenting style. Journal of Family Psychology, 16, 58-69.

Nucci, L. (1981). Conceptions of personal issues: A domain distinct from moral or societal concepts. Child Development, 52, 114-121.

Nunnally, J. C., \& Bernstein, I. H. (1994). Psychometric theory (3rd ed.). New York: McGrawHill.

Office of National Drug Control Policy (2008). National youth anti-drug media campaign. Retrieved November 15, 2008, from http://www.mediacampaign.org/

Patterson, G. R., \& Stouthamer-Loeber, M. (1984). The correlation of family management practices and delinquency. Child Development, 55, 1299-1307.

Pettit, G. S., Laird, R. D., Dodge, K. A., Bates, J. E., \& Criss, M. M. (2001). Antecedents and behavior-problem outcomes of parental monitoring and psychological control in early adolescence. Child Development, 72, 583-598.

Prinstein, M. J., Boergers, J, \& Spirito, A. (2001). Adolescents' and their friends' health-risk behavior: Factors that alter or add to peer influence. Journal of Pediatric Psychology, 26, 287-298.

Rai, A. A., Stanton, B., Wu, Y., Li, X., Galbraith, J., Cottrel, L., Pack, R., Harris, C., D’Alessandri, D., \& Burns, J. (2003). Relative influences of perceived parental monitoring and perceived peer involvement on adolescent risk behaviors: An analysis of six cross-sectional data sets. Journal of Adolescent Health, 33, 108-118. 
Ramirez, J. R., Crano, W. D., Quist, R., Burgoon, M., Alvaro, E. M., \& Grandpre, J. (2004). Acculturation, familism, parental monitoring, and knowledge as predictors of marijuana and inhalant use in adolescents. Psychology of Addictive Behaviors, 18, 3-11.

Ray, J. J. (1984). The reliability of short social desirability scales. The Journal of Social Psychology, 123, 133-134.

Ryan, L. G., Miler-Loessi, K., \& Nieri, T. (2007). Relationships with adults as predictors of substance use, gang involvement, and threats to safety among disadvantaged urban high school adolescents. Journal of Community Psychology, 35, 1053-1071.

Sartor, C. E., \& Youniss, J. (2002). The relationship between positive parental involvement and identity achievement during adolescence. Adolescence, 37, 221-234.

Schaefer, E. S. (1965a). A configurational analysis of children's reports of parent behavior. Journal of Consulting Psychology, 29, 552-557.

Schaefer, E. S. (1965b). Children's reports of parental behavior: An inventory. Child Development, 36, 413-424.

Smetana, J. G. (1988). Adolescents' and parents' conceptions of parental authority. Child Development, 59, 321-335.

Smetana, J. G. (2000). Middle-class African American adolescents' and parents' conceptions of parental authority and parenting practices: A longitudinal investigation. Child Development, 71, 1672-1686.

Smetana, J. G., \& Asquith, P. (1994). Adolescents' and parents' conceptions of parental authority and adolescent autonomy. Child Development, 65, 1147-1162. 
Smetana, J. G., \& Daddis, C. (2002). Domain-specific antecedents of parental psychological control and monitoring: The role of parenting beliefs and practices. Child Development, 73, 563-580.

Soenens, B., Vansteenkiste, M., Lens, W., Luyckx, Goossens, L., Beyers, W., \& Ryan, R. (2007). Conceptualizing parental autonomy support: Adolescent perceptions of promotion of independence versus promotion of volitional functioning. Developmental Psychology, 43, 633-646.

Soenens, B., Vansteenkiste, M., Luyckx, K., \& Goossens, L. (2006). Parenting and adolescent problem behavior: An integrated model with adolescent self-disclosure and perceived parental knowledge as intervening variables. Developmental Psychology, 42, 305-318.

Sona Systems, Ltd. (2007). Sona Experiment Management System (Version 2.67) [Computer software and manual]. Talinn, Estonia: Author.

Spera, C. (2006). Adolescents' perceptions of parental goals, practices, and styles in relation to their motivation and achievement. Journal of Early Adolescence, 26, 456-490.

SPSS, Inc. (2008). Statistical Package for the Social Sciences (Version 16.0) [Computer software]. Chicago, IL: Author.

SPSS, Inc. (2009). Predictive Analytic SoftWare (Version 17.0) [Computer software]. Chicago, IL: Author.

Stanton, B. F., Li, X., Galbraith, J., Cornick, G., Feigelman, S., Kaljee, L., \& Zhou, Y. (2000). Parental underestimates of adolescent risk behavior: A randomized, controlled trial of a parental monitoring intervention. Journal of Adolescent Health, 26, 18-26.

Stattin, H., \& Kerr, M. (2000). Parental monitoring: A reinterpretation. Child Development, 71, 1072-1085. 
Steinberg, L. (1987). Single parents, stepparents, and the susceptibility of adolescents to antisocial peer pressure. Child Development, 58, 269-275.

Steinberg, L., Fletcher, A., \& Darling, N. (1994). Parental monitoring and peer influences on adolescent substance use. Pediatrics, 93, 1-5.

Steinberg, L., Lamborn, S. D., Dornbusch, S. M., \& Darling N. (1992). Impact of parenting practices on adolescent achievement: Authoritative parenting, school involvement, and encouragement to succeed. Child Development, 63, 1266-1281.

Steinberg, L. Mounts, N. S., Lamborn, S. D., \& Dornbusch, S. M. (1991). Authoritative parenting and adolescent adjustment across varied ecological niches. Journal of Research on Adolescence, 1, 19-36.

Tabachnick, B. G., \& Fidell, L. S. (2007). Using multivariate statistics (5th ed.). New York: Pearson.

Waizenhofer, R. N., Buchanan, C. M., \& Jackson-Newsom, J. (2004). Mothers' and fathers' knowledge of adolescents' daily activities: Its sources and its links with adolescent adjustment. Journal of Family Psychology, 18, 348-360.

Webb, J. A., Bray, J. H., Getz, G. J., \& Adams, G. (2002). Gender, perceived parental monitoring, and behavioral adjustment: Influences on adolescent alcohol use. American Journal of Orthopsychiatry, 72, 392-400.

Wight, D., Williamson, L., \& Henderson, M. (2006). Parental influences on young people's sexual behavior: A longitudinal analysis. Journal of Adolescence, 29, 473-494.

Yang, H., Stanton, B., Cottrell, L., Kaljee, L., Galbraith, J., Li, X., Cole, M., Harris, C., \& Wu, Y. (2006). Parental awareness of adolescent risk involvement : Implications of overestimates and underestimates. Journal of Adolescent Health, 39, 353-361. 
Yu, S., Clemens, R., Yang, H., Li, X., \& Stanton, B. (2006). Youth and parental perceptions of parental monitoring and parent-adolescent communication, youth depression, and youth risk behaviors. Social Behavior and Personality, 34, 1297-1310. 
Appendix A

Response Formats for Parental Monitoring Variables

\begin{tabular}{|c|c|c|c|c|c|c|c|}
\hline \multicolumn{7}{|c|}{ Response Format } & \multirow[t]{2}{*}{ Label } \\
\hline & & & Agreement & & & & \\
\hline 7 & 6 & 5 & 4 & 3 & 2 & 1 & Agree/disagre \\
\hline $\begin{array}{l}\text { Entirely } \\
\text { agree }\end{array}$ & $\begin{array}{l}\text { Strongly } \\
\text { agree }\end{array}$ & Agree & $\begin{array}{l}\text { Neither agree } \\
\text { nor disagree }\end{array}$ & Disagree & $\begin{array}{l}\text { Strongly } \\
\text { disagree }\end{array}$ & $\begin{array}{l}\text { Entirely } \\
\text { disagree }\end{array}$ & \\
\hline 6 & 5 & 4 & 3 & 2 & 1 & & Like/unlike \\
\hline \multirow[t]{2}{*}{$\begin{array}{l}\text { Exactly } \\
\text { like my } \\
\text { parents }\end{array}$} & $\begin{array}{c}\text { A lot } \\
\text { like } \\
\text { my parents }\end{array}$ & $\begin{array}{l}\text { Somewhat } \\
\text { like my } \\
\text { parents }\end{array}$ & $\begin{array}{c}\text { Somewhat } \\
\text { unlike my } \\
\text { parents }\end{array}$ & $\begin{array}{l}\text { Very } \\
\text { unlike my } \\
\text { parents }\end{array}$ & $\begin{array}{l}\text { Nothing } \\
\text { like my } \\
\text { parents }\end{array}$ & & \\
\hline & & & Certainty & & & & \\
\hline 7 & 6 & 5 & 4 & 3 & 2 & 1 & Certainty \\
\hline \multirow[t]{2}{*}{ Definitely } & $\begin{array}{c}\text { Very } \\
\text { probably }\end{array}$ & Probably & Possibly & $\begin{array}{c}\text { Probably } \\
\text { not }\end{array}$ & $\begin{array}{c}\text { Very } \\
\text { probably not }\end{array}$ & $\begin{array}{c}\text { Definitely } \\
\text { not }\end{array}$ & \\
\hline & & Decisions & & & & & \\
\hline 5 & 4 & 3 & 2 & 1 & & & Decide \\
\hline $\begin{array}{l}\text { I decide } \\
\text { this without } \\
\text { discussing } \\
\text { it with my } \\
\text { parents }\end{array}$ & $\begin{array}{l}\text { I make } \\
\text { the final } \\
\text { decision } \\
\text { after discussing } \\
\text { it with my } \\
\text { parents }\end{array}$ & $\begin{array}{l}\text { My parents } \\
\text { and I make } \\
\text { the decision } \\
\text { together }\end{array}$ & $\begin{array}{l}\text { My parents } \\
\text { make the } \\
\text { final decision } \\
\text { after discussing } \\
\text { it with me }\end{array}$ & $\begin{array}{l}\text { My parents } \\
\text { decide without } \\
\text { discussing } \\
\text { it with me }\end{array}$ & & & \\
\hline
\end{tabular}

(Appendix A continues) 
(Appendix A continued)

\begin{tabular}{|c|c|c|c|c|c|c|c|}
\hline \multicolumn{7}{|l|}{ Response Format } & \multirow[t]{2}{*}{ Label } \\
\hline \multicolumn{7}{|c|}{ Frequency } & \\
\hline 6 & 5 & 4 & 3 & 2 & 1 & & \multirow[t]{2}{*}{ Frequency } \\
\hline Very frequently & Frequently & Occasionally & Rarely & Very rarely & Never & & \\
\hline \multicolumn{8}{|c|}{ Quality } \\
\hline 7 & 6 & 5 & 4 & 3 & 2 & 1 & Close/distant \\
\hline $\begin{array}{l}\text { As close } \\
\text { as possible }\end{array}$ & $\begin{array}{l}\text { Very } \\
\text { close }\end{array}$ & Close & $\begin{array}{l}\text { Neither close } \\
\text { nor distant }\end{array}$ & Distant & $\begin{array}{l}\text { Very } \\
\text { distant }\end{array}$ & $\begin{array}{l}\text { As distant } \\
\text { as possible }\end{array}$ & \multirow{3}{*}{ Satisfied } \\
\hline 7 & 6 & 5 & 4 & 3 & 2 & 1 & \\
\hline $\begin{array}{l}\text { Perfectly } \\
\text { satisfied }\end{array}$ & $\begin{array}{c}\text { Very } \\
\text { satisfied }\end{array}$ & $\begin{array}{c}\text { Well } \\
\text { satisfied }\end{array}$ & $\begin{array}{l}\text { Partly } \\
\text { satisfied }\end{array}$ & $\begin{array}{l}\text { Poorly } \\
\text { satisfied }\end{array}$ & $\begin{array}{l}\text { Very poorly } \\
\text { satisfied }\end{array}$ & $\begin{array}{l}\text { Not at all } \\
\text { satisfied }\end{array}$ & \\
\hline 7 & 6 & 5 & 4 & 3 & 2 & 1 & \multirow[t]{2}{*}{ Well/poor } \\
\hline $\begin{array}{l}\text { Perfectly } \\
\text { well }\end{array}$ & $\begin{array}{l}\text { Very } \\
\text { well }\end{array}$ & Well & $\begin{array}{l}\text { Neither well } \\
\text { nor poorly }\end{array}$ & Poorly & $\begin{array}{l}\text { Very } \\
\text { poorly }\end{array}$ & $\begin{array}{l}\text { As poorly } \\
\text { as possible }\end{array}$ & \\
\hline 7 & 6 & 5 & 4 & 3 & 2 & 1 & Understand \\
\hline \multirow[t]{2}{*}{$\begin{array}{l}\text { Understand } \\
\text { perfectly } \\
\text { well }\end{array}$} & $\begin{array}{l}\text { Understand } \\
\text { very well }\end{array}$ & $\begin{array}{l}\text { Understand } \\
\text { well }\end{array}$ & $\begin{array}{l}\text { Understand } \\
\text { partly }\end{array}$ & $\begin{array}{l}\text { Understand } \\
\text { poorly }\end{array}$ & $\begin{array}{l}\text { Understand } \\
\text { very poorly }\end{array}$ & $\begin{array}{c}\text { Don't } \\
\text { understand } \\
\text { at all }\end{array}$ & \\
\hline & & Quantity & & & & & \multirow{3}{*}{ Quantity 2} \\
\hline 5 & 4 & 3 & 2 & 1 & & & \\
\hline $\begin{array}{l}\text { As much } \\
\text { as I want }\end{array}$ & A lot & Some & Very little & None & & & \\
\hline
\end{tabular}


(Appendix A continued)

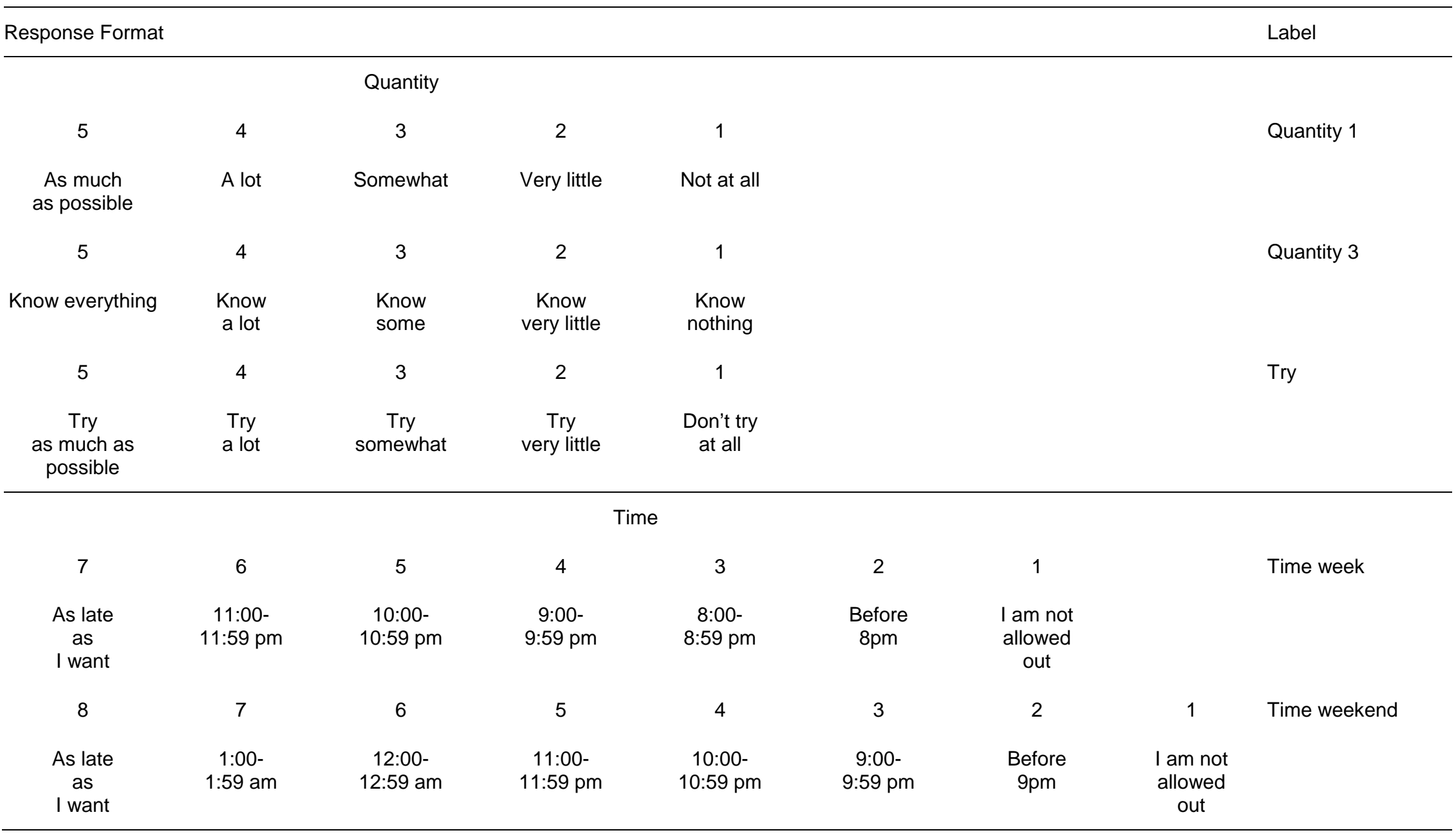


Appendix B

Demographics Form

Please complete the following questions based on your family. We realize that all families are unique and that caregivers may not necessarily be biologically related, and that some individuals split time between two or more households. For these questions, please think of family, primary male guardian, primary female guardian, or siblings as the persons whom you lived with for the majority of the week, month, or year. Please answer to the best of your ability.

1. Your current age

2. Your sex
a) Female
b) Male

3. Your racial background (please select one)
a) American Indian / Alaskan Native
b) Asian
c) Black / African American
d) More than one race
e) Native Hawaiian / Other Pacific Islander
f) White / Caucasian
g) Unknown
h) Other

4. Your current year in college
a) 1
b) 2
c) 3
d) 4
e) 5
f) More than 5 
5. Your current class in college
a) Freshman
b) Sophomore
c) Junior
d) Senior
e) Beyond senior

6. Your current place of residence while attending college
a) University residence hall
b) University apartment
c) Greek housing
d) International house
e) Off-campus housing, live alone
f) Off-campus housing, live with family
g) Off-campus housing, live with roommate(s)
h) Other

7. Please indicate the month / day / year you last lived with your parent(s) or guardian(s) the majority of the time (majority $=$ of the week, month, or year). Estimate day to the best of your ability.

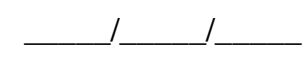

8. Relationship to your primary male guardian
a) Adoptive father
b) Biological father
c) Foster father
d) Stepfather
e) Biological grandfather
f) Other male blood relative
g) Other male
h) No primary male guardian in the home 
9. Father or primary male guardian's age

$\square \quad$ Does not apply / No father or primary male guardian

10. Father or primary male guardian's highest level of education completed
a) Less than $7^{\text {th }}$ grade
b) Junior high school
c) Partial high school
d) High school or GED
e) Partial college or specialized training
f) College graduate
g) Graduate or professional degree
h) Does not apply / No father or primary male guardian

11. Relationship to your primary female guardian
a) Adoptive mother
b) Biological mother
c) Foster mother
d) Stepmother
e) Biological grandmother
f) Other female blood relative
g) Other female
h) No primary female guardian in the home

12. Mother or primary female guardian's age

$\square$ Does not apply / No mother or primary female guardian 
13. Mother or primary female guardian's highest level of education completed
i) Less than $7^{\text {th }}$ grade
j) Junior high school
k) Partial high school
I) High school or GED
m) Partial college or specialized training
n) College graduate
o) Graduate or professional degree
p) Does not apply / No mother or primary female guardian

14. Parent's or primary guardian's marital status [the person(s) whom you live with for the majority of the week, month, or year]
a) Cohabitating
b) Married
c) Remarried
d) Single
e) Single, never married

15. Grandparents living in your family home
a) No
b) Yes

16. Your own child(ren) or siblings' child(ren) living in your family home
a) No
b) Yes 
17. Number of siblings (in addition to you) in your family home
a) None
b) One
c) Two
d) Three
e) Four
f) Five
g) More than five 
Please choose from the following list of occupations when answering questions 18 and 19.

$1=$ Farm laborers, service workers, receiving welfare. Those not currently employed for wages and not receiving welfare or unemployment.

Examples: dishwashers, maids, teamsters, ushers. Housewives or househusbands.

$2=$ Unskilled workers.

Example: bartenders, cooks, dry cleaning operators.

$3=$ Machine operators and semiskilled workers.

Examples: guards, painters, health aides, childcare workers.

$4=$ Smallest business owners, skilled manual labor workers, craftsmen, tenant farmers.

Examples: carpenters, bakers, electricians.

$5=$ Clerical and sales workers, very small business owners.

Examples: bank tellers, bookkeepers, cashiers.

$6=$ Technicians, semiprofessionals, smaller business owners.

Examples: secretaries, draftsmen, teacher's aides.

$7=$ Small business owners, managers, professionals with Bachelor's level training.

Examples: social workers, real estate agents, elementary school teachers.

$8=$ Administrators, professionals, proprietors of medium-sized business, lesser commissioned officers. Examples: accountants, registered nurses, computer systems analysts, secondary school teachers.

$9=$ Higher executives, proprietors of large businesses or farms, professionals with advanced degrees, commissioned officers of Major or above in military service. 
18. Select the number of the occupation that best matches that of your father or primary male guardian
a) 1
b) 2
c) 3
d) 4
e) 5
f) 6
g) 7
h) 8
i) 9
f) Does not apply / No father or primary male guardian

19. Select the number of the occupation that best matches that of your mother or primary female guardian
a) 1
b) 2
c) 3
d) 4
e) 5
f) 6
g) 7
h) 8
i) 9
g) Does not apply / No mother or primary female guardian 


\section{Footnote}

${ }^{1}$ The pool of 310 parental monitoring items as well as information about their origination and reliability is available upon request. Please direct requests to Ryan Anderson, Department of Psychology, West Virginia University, 53 Campus Drive, PO Box 6040, Morgantown, WV 26506-6040. Electronic mail may be sent to ryan.anderson@mail.wvu.edu. 
Table 1

Number of Unique Scales Used to Measure Parental Monitoring

Constructs Across 29 Core Studies

\begin{tabular}{lc}
\hline Construct & Number of scales \\
\hline Parental monitoring knowledge & 12 \\
Parental monitoring behavior & 14 \\
Parental psychological control & 7 \\
Parent-adolescent relationship quality & 11 \\
Parent-adolescent communication & 5 \\
\hline Total & 49 \\
\hline
\end{tabular}


Table 2

Descriptive Statistics for the Demographic Characteristics of the Sample $(N=320)$

\begin{tabular}{|c|c|c|c|}
\hline Characteristic & Female & Male & Missing Values \\
\hline Sex & 248 & 71 & 1 \\
\hline$M$ age & $18.94(S D=.88)$ & $19.27(S D=1.08)$ & None \\
\hline Race & & & 2 \\
\hline Asian & 2 & - & \\
\hline Black/African American & - & 6 & \\
\hline Multiracial & 3 & - & \\
\hline White/Caucasian & 235 & 65 & \\
\hline Years of college & & & None \\
\hline One or two years & 214 & 53 & \\
\hline More than two years & 34 & 18 & \\
\hline Class in college & & & None \\
\hline Freshman & 129 & 33 & \\
\hline Sophomore & 76 & 21 & \\
\hline Junior & 31 & 14 & \\
\hline Senior & 12 & 3 & \\
\hline College residence & & & None \\
\hline On-campus housing & 141 & 36 & \\
\hline Greek housing & 2 & - & \\
\hline Off-campus alone & 11 & 2 & \\
\hline Off-campus family & 7 & 5 & \\
\hline Off-campus roommate(s) & 86 & 28 & \\
\hline Other & 1 & - & \\
\hline Primary male guardian & & & None \\
\hline Biological father & 214 & 61 & \\
\hline Stepfather & 14 & 6 & \\
\hline Other male guardian & 7 & 2 & \\
\hline No male guardian & 13 & 2 & \\
\hline
\end{tabular}

(Table 2 continues) 
(Table 2 continued)

\begin{tabular}{|c|c|c|c|}
\hline Characteristic & Female & Male & Missing Values \\
\hline Male guardian's education & & & 3 \\
\hline Less than high school/GED & 6 & 3 & \\
\hline High school/GED & 60 & 18 & \\
\hline Some college & 56 & 16 & \\
\hline College graduate or beyond & 117 & 31 & \\
\hline Unknown & - & 2 & \\
\hline Primary female guardian & & & None \\
\hline Biological mother & 242 & 68 & \\
\hline Stepmother & - & 1 & \\
\hline Other female guardian & 4 & 2 & \\
\hline No female guardian & 2 & - & \\
\hline Female guardian's education & & & 1 \\
\hline Less than high school/GED & 6 & 1 & \\
\hline High school/GED & 60 & 17 & \\
\hline Some college & 61 & 15 & \\
\hline College graduate or beyond & 120 & 37 & \\
\hline Guardians' marital status & & & 3 \\
\hline Cohabitating & 8 & - & \\
\hline Married & 176 & 58 & \\
\hline Remarried & 16 & 4 & \\
\hline Single & 46 & 8 & \\
\hline Siblings & & & None \\
\hline Only child & 48 & 12 & \\
\hline One or two & 182 & 51 & \\
\hline Three or more & 18 & 8 & \\
\hline
\end{tabular}


Table 3

Range of Possible Values, Means, Standard Deviations, Skewness, and Kurtosis for Parental Monitoring Variables (N = 320).

\begin{tabular}{|c|c|c|c|c|c|c|}
\hline Item & Minimum & Maximum & $M$ & $S D$ & Skewness & Kurtosis \\
\hline 66. Most important person & 1 & 6 & 4.71 & 1.18 & -1.23 & 1.67 \\
\hline 74. Comfort & 1 & 6 & 4.94 & 1.06 & -1.22 & 1.41 \\
\hline 71a. Give attention & 1 & 6 & 4.94 & 0.95 & -1.13 & 1.48 \\
\hline 72. Show affection & 1 & 6 & 4.89 & 1.10 & -1.20 & 1.36 \\
\hline 257. Love & 1 & 6 & 5.64 & 0.70 & -1.83 & 2.22 \\
\hline 208. Close or not close & 1 & 7 & 5.58 & 1.22 & -1.16 & 1.24 \\
\hline 64. Cheer me up & 1 & 6 & 4.69 & 1.15 & -1.08 & 1.14 \\
\hline 68. Often praise & 1 & 6 & 4.80 & 1.06 & -0.97 & 0.97 \\
\hline 70. Support and encourage & 1 & 6 & 5.23 & 0.99 & -1.39 & 1.60 \\
\hline 63. Enjoy doing things & 1 & 6 & 4.92 & 1.03 & -1.10 & 1.03 \\
\hline 195. Help with problem & 1 & 6 & 5.30 & 0.95 & -1.46 & 1.69 \\
\hline 83. Spend time with & 1 & 6 & 4.64 & 0.95 & -0.81 & 0.91 \\
\hline 61. Smile & 1 & 6 & 4.93 & 0.94 & -0.81 & 0.45 \\
\hline 71b. Listen & 1 & 6 & 4.94 & 0.95 & -1.13 & 1.48 \\
\hline 78b. Give guidance & 1 & 6 & 4.89 & 1.01 & -1.02 & 1.10 \\
\hline 69. Easy to talk to & 1 & 6 & 5.32 & 0.94 & -1.50 & 1.79 \\
\hline 78a. Give advice & 1 & 5 & 3.92 & 0.85 & -0.52 & -0.14 \\
\hline 209. Get along & 1 & 7 & 5.59 & 1.11 & -1.07 & 1.31 \\
\hline 260. Proud of me & 1 & 7 & 6.27 & 0.91 & -1.09 & 0.46 \\
\hline 88. Enjoy specific things & 1 & 6 & 4.23 & 1.13 & -0.82 & 0.72 \\
\hline 202. Just talking & 1 & 6 & 4.64 & 1.01 & -1.04 & 1.37 \\
\hline 270. I accept & 1 & 7 & 5.95 & 1.09 & -1.10 & 1.11 \\
\hline 269. Proud of parents & 1 & 6 & 5.11 & 0.87 & -0.88 & 0.59 \\
\hline 137. Know where night & 1 & 6 & 4.45 & 1.14 & -0.93 & 0.65 \\
\hline 286b. Know what school & 1 & 6 & 4.42 & 1.09 & -0.88 & 1.03 \\
\hline 249. Know what not home & 1 & 6 & 4.44 & 1.12 & -0.90 & 0.83 \\
\hline 136. Know whom not home & 1 & 6 & 4.44 & 1.11 & -1.01 & 1.18 \\
\hline 194. Know where school & 1 & 5 & 3.53 & 0.94 & -0.47 & -0.13 \\
\hline 247. Know where not home & 1 & 6 & 4.52 & 1.11 & -1.06 & 1.31 \\
\hline 294b. Tell where evening after & 1 & 6 & 4.52 & 1.07 & -1.04 & 1.52 \\
\hline
\end{tabular}

(Table 3 continues) 
(Table 3 continued)

\begin{tabular}{|c|c|c|c|c|c|c|}
\hline Item & Minimum & Maximum & $M$ & $S D$ & Skewness & Kurtosis \\
\hline 193. Know what free time & 1 & 5 & 3.47 & 0.87 & -0.66 & 0.43 \\
\hline 183. Tell what night after & 1 & 6 & 4.12 & 1.26 & -0.71 & 0.10 \\
\hline 138. Talk plans with friends & 1 & 6 & 4.56 & 1.04 & -0.73 & 0.47 \\
\hline 182a. Hide a lot & 1 & 6 & 4.06 & 1.37 & -0.37 & -0.73 \\
\hline 93. Tell where school before & 1 & 6 & 4.54 & 1.25 & -0.97 & 0.43 \\
\hline 188. Should know about friends & 1 & 7 & 4.78 & 1.16 & -0.63 & 1.06 \\
\hline 184. Should know where school & 1 & 7 & 4.88 & 1.33 & -0.61 & 0.43 \\
\hline 282. What money spent on & 1 & 6 & 4.16 & 1.13 & -0.67 & 0.38 \\
\hline 104. Know who friends are & 1 & 5 & 3.87 & 0.80 & -0.67 & 0.52 \\
\hline 173b. Tell whom Saturday before & 1 & 6 & 4.01 & 1.42 & -0.60 & -0.36 \\
\hline 173a. Tell where Saturday before & 1 & 6 & 4.17 & 1.35 & -0.73 & 0.07 \\
\hline 171b. If late, explain whom & 1 & 6 & 4.08 & 1.35 & -0.71 & 0.00 \\
\hline 172a. Tell where at night & 1 & 6 & 4.14 & 1.34 & -0.84 & 0.22 \\
\hline 171a. If late, explain what & 1 & 6 & 4.13 & 1.35 & -0.65 & -0.14 \\
\hline 172b. Tell whom at night & 1 & 6 & 3.90 & 1.34 & -0.47 & -0.37 \\
\hline 168. Interfere in free time & 1 & 7 & 5.00 & 1.51 & -0.60 & -0.05 \\
\hline 167. Want to know everything & 1 & 7 & 4.86 & 1.58 & -0.51 & -0.42 \\
\hline 57. Expect too much & 1 & 6 & 3.86 & 1.40 & -0.11 & -0.80 \\
\hline 16. Change think or feel & 1 & 6 & 4.58 & 1.28 & -0.86 & 0.00 \\
\hline 21. Alternate warm and critical & 1 & 6 & 4.25 & 1.38 & -0.44 & -0.77 \\
\hline 14. Act like they know & 1 & 6 & 3.66 & 1.33 & 0.13 & -0.86 \\
\hline 5. Want to control & 1 & 6 & 4.57 & 1.30 & -0.86 & -0.01 \\
\hline 41. Overboard in checking & 1 & 6 & 4.34 & 1.35 & -0.61 & -0.44 \\
\hline 18. Bring up past mistakes & 1 & 6 & 4.22 & 1.46 & -0.49 & -0.72 \\
\hline 44. Take action & 1 & 6 & 4.29 & 1.09 & -0.63 & 0.56 \\
\hline 43. Punish & 1 & 6 & 4.06 & 1.15 & -0.25 & -0.22 \\
\hline 45. Restrict privileges & 1 & 6 & 4.05 & 1.18 & -0.28 & -0.24 \\
\hline 42. Apply consequences & 1 & 6 & 4.20 & 1.10 & -0.38 & 0.16 \\
\hline 51. Enforce rules & 1 & 6 & 4.36 & 1.08 & -0.53 & 0.07 \\
\hline 46. Don't follow through & 1 & 6 & 3.74 & 1.34 & -0.07 & -0.65 \\
\hline 232. Lectured about alcohol & 1 & 6 & 3.93 & 1.37 & -0.45 & -0.33 \\
\hline 233. Dangers of alcohol & 1 & 6 & 4.33 & 1.20 & -0.77 & 0.48 \\
\hline 231a. Hints not to use alcohol & 1 & 6 & 4.17 & 1.26 & -0.51 & -0.08 \\
\hline
\end{tabular}

(Table 3 continues) 
(Table 3 continued)

\begin{tabular}{ccccccc}
\hline \multicolumn{1}{c}{ Item } & Minimum & Maximum & $M$ & $S D$ & Skewness & Kurtosis \\
\hline 231b. Hints not to use drugs & 1 & 6 & 4.48 & 1.24 & -0.89 & 0.80 \\
240. Thoughts and opinions & 1 & 6 & 3.41 & 1.43 & -0.03 & -0.70 \\
111. You criticize, they ignore & 1 & 6 & 4.09 & 1.20 & -0.17 & -0.72 \\
109. You discuss, they avoid & 1 & 6 & 4.15 & 1.34 & -0.29 & -0.77 \\
110. You nag, they withdraw & 1 & 6 & 4.30 & 1.24 & -0.30 & -0.77 \\
\hline
\end{tabular}


Table 4

Summary of Variables and Factor Loadings for Promax Oblique Seven-Factor Solution for the Parental Monitoring Variables $(N=320)$

\begin{tabular}{|c|c|c|c|c|c|c|c|c|}
\hline \multirow[b]{2}{*}{ Variable } & \multicolumn{7}{|c|}{ Factor loadings } & \multirow[b]{2}{*}{$h^{2}$} \\
\hline & 1 & 2 & 3 & 4 & 5 & 6 & 7 & \\
\hline $\begin{array}{l}\text { 66. My parents are people who make me feel like I am the most important person in } \\
\text { their lives. }\end{array}$ & .93 & -.18 & .11 & -.03 & -.03 & .01 & -.05 & .73 \\
\hline 74. How often do your parents comfort you? & .90 & -.07 & -.00 & .07 & .03 & .03 & -.14 & .79 \\
\hline 71a. How often do your parents give you attention? & .89 & .04 & .01 & .04 & .07 & -.09 & -.19 & .78 \\
\hline 72. How often do your parents show you affection? & .89 & -.06 & .05 & .04 & .02 & -.03 & -.09 & .78 \\
\hline 257. I feel my parents love me. & .85 & -.14 & .06 & -.06 & .04 & -.06 & .07 & .73 \\
\hline 208. How close or not close do you feel to your parents? & .82 & .11 & -.07 & -.04 & -.06 & -.01 & -.06 & .77 \\
\hline 64. My parents are people who cheer me up when I am sad. & .81 & .03 & -.07 & -.08 & -.04 & .06 & .07 & .77 \\
\hline 68. My parents are people who often praise me. & .81 & -.04 & -.02 & .05 & .03 & .06 & -.09 & .71 \\
\hline 70. How often do your parents support and encourage you? & .80 & -.04 & -.01 & .05 & .06 & -.05 & .04 & .73 \\
\hline 63. My parents are people who enjoy doing things with me. & .79 & .06 & -.01 & .00 & .04 & -.07 & .00 & .73 \\
\hline 195. I can count on my parents to help me out if I have some kind of a problem. & .75 & -.01 & -.06 & -.02 & .03 & .01 & .08 & .65 \\
\hline 83. How often do your parents spend time with you? & .74 & .08 & .15 & .06 & .01 & -.02 & -.14 & .75 \\
\hline
\end{tabular}

Note. Boldface indicates highest factor loadings.

(Table 4 continues) 


\begin{tabular}{|c|c|c|c|c|c|c|c|c|}
\hline \multirow[b]{2}{*}{ Variable } & \multicolumn{7}{|c|}{ Factor loadings } & \multirow[b]{2}{*}{$h^{2}$} \\
\hline & 1 & 2 & 3 & 4 & 5 & 6 & 7 & \\
\hline 61. My parents are people who smile at me very often. & .70 & -.06 & .06 & .09 & -.06 & .10 & -.01 & .67 \\
\hline 71b. How often do your parents listen to you. & .70 & .03 & -.07 & .05 & -.02 & .04 & .20 & .78 \\
\hline 78b. How often do your parents give you guidance. & .70 & .10 & .03 & .05 & .10 & .07 & -.09 & .74 \\
\hline 69. My parents are people who are easy to talk to. & .69 & .03 & -.07 & -.05 & -.08 & .01 & .21 & .73 \\
\hline 78a. How often do your parents give you advice & .66 & .10 & .02 & -.07 & .06 & .08 & .02 & .69 \\
\hline 209. How well do you and your parents get along? & .66 & .05 & -.01 & .04 & -.06 & -.05 & .04 & .66 \\
\hline 260. My parents are proud of me. & .66 & .07 & .01 & -.01 & .01 & -.13 & .14 & .67 \\
\hline $\begin{array}{l}\text { 88. How often do you and your parents do things together that you enjoy-like playing } \\
\text { sports or games, going somewhere together, or working on things together? }\end{array}$ & .65 & .16 & -.02 & -.06 & -.04 & .07 & -.07 & .64 \\
\hline 202. How often do your parents spend time just talking to you? & .65 & .16 & -.08 & -.07 & -.08 & .13 & .08 & .71 \\
\hline 270. I accept my parents the way they are. & .65 & -.04 & -.04 & .04 & .02 & -.05 & .16 & .63 \\
\hline 269. How often do you feel proud of your parents? & .63 & .05 & -.02 & -.09 & .03 & -.02 & .06 & .59 \\
\hline 137. How often do your parents know where you are when you go out at night? & -.10 & .96 & .11 & .03 & -.02 & -.06 & -.07 & .89 \\
\hline 286b. Do your parents know what you do after school? & -.06 & .92 & .01 & -.09 & -.03 & .03 & .05 & .83 \\
\hline
\end{tabular}

Note. Boldface indicates highest factor loadings. 


\begin{tabular}{|c|c|c|c|c|c|c|c|c|}
\hline \multirow[b]{2}{*}{ Variable } & \multicolumn{7}{|c|}{ Factor loadings } & \multirow[b]{2}{*}{$h^{2}$} \\
\hline & 1 & 2 & 3 & 4 & 5 & 6 & 7 & \\
\hline 249. When I am not at home, my parents know what I am doing. & -.04 & .91 & .06 & .05 & .05 & -.04 & -.06 & .85 \\
\hline 136. How often do your parents know whom you are with when you are not at home? & -.03 & .85 & .16 & .07 & .01 & -.01 & -.10 & .86 \\
\hline $\begin{array}{l}\text { 194. How much do your parents really know about where you are most afternoons after } \\
\text { school? }\end{array}$ & .00 & .84 & -.08 & -.07 & -.01 & .00 & .05 & .72 \\
\hline 247. When I am not at home, my parents know where I am. & .04 & .81 & .10 & -.05 & .01 & -.04 & .04 & .84 \\
\hline 294b. I tell my parents about where I went during the evening. & .05 & .81 & .09 & .00 & -.02 & -.05 & -.03 & .80 \\
\hline 193. How much do your parents really know about what you do with your free time? & .05 & .80 & -.13 & -.09 & .00 & .11 & .14 & .76 \\
\hline 183. When I get home after being out at night, I tell my parents about what I did. & .12 & .75 & .03 & .04 & -.06 & .02 & -.14 & .73 \\
\hline 138. How often do you talk with your parents about plans you have with your friends? & .14 & .74 & -.02 & -.04 & .01 & .00 & .03 & .73 \\
\hline $\begin{array}{l}\text { 182a. I hide a lot from my parents about what I do when I am out at night and on the } \\
\text { weekends. }\end{array}$ & -.20 & .74 & -.23 & .21 & -.03 & .06 & .07 & .59 \\
\hline 93. How often do you tell your parents where you are going after school? & -.02 & .68 & .06 & .02 & .04 & .02 & .08 & .65 \\
\hline 188. My parents should have knowledge about what things I do with my friends. & -.03 & .65 & .02 & .07 & .10 & .04 & .00 & .62 \\
\hline 184. My parents should have knowledge about where I am after school. & .01 & .60 & .12 & .08 & .09 & -.12 & -.01 & .63 \\
\hline 282. Do your parents know what you spend your money on? & .21 & .60 & -.07 & -.20 & -.03 & .08 & -.01 & .61 \\
\hline
\end{tabular}

Note. Boldface indicates highest factor loadings. 


\begin{tabular}{|c|c|c|c|c|c|c|c|c|}
\hline \multirow[b]{2}{*}{ Variable } & \multicolumn{7}{|c|}{ Factor loadings } & \multirow[b]{2}{*}{$h^{2}$} \\
\hline & 1 & 2 & 3 & 4 & 5 & 6 & 7 & \\
\hline 104. How much do your parents really know about who your friends are? & .26 & .57 & -.11 & -.04 & -.04 & -.07 & -.05 & .54 \\
\hline $\begin{array}{l}\text { 173b. Before I go out on a Saturday night, my parents require that I tell them whom I am } \\
\text { going out with. }\end{array}$ & .00 & .02 & .94 & .05 & -.03 & -.02 & -.01 & .87 \\
\hline $\begin{array}{l}\text { 173a. Before I go out on a Saturday night, my parents require that I tell them where I am } \\
\text { going. }\end{array}$ & .00 & .05 & .91 & .04 & -.04 & .00 & .03 & .86 \\
\hline $\begin{array}{l}\text { 171b. If I have been out very late one night, my parents require that I explain whom I was } \\
\text { with. }\end{array}$ & .04 & -.01 & .87 & -.06 & .02 & .05 & .02 & .90 \\
\hline 172a. My parents require that I tell them where I am at night. & .02 & .03 & .86 & -.02 & -.03 & .01 & .00 & .82 \\
\hline 171a. If I have been out very late one night, my parents require that I explain what I did. & .00 & .01 & .79 & -.06 & .05 & .06 & .06 & .84 \\
\hline 172b. My parents require that I tell them whom I am with when I am out at night. & -.05 & .18 & .73 & -.13 & -.04 & -.02 & .06 & .75 \\
\hline 168. I think that my parents interfere too much in my free time activities. & .02 & .06 & -.20 & .81 & .12 & -.09 & -.14 & .70 \\
\hline $\begin{array}{l}\text { 167. I feel as though I can't keep anything to myself because my parents want to know } \\
\text { everything. }\end{array}$ & -.10 & .02 & -.24 & .77 & -.02 & .11 & -.09 & .67 \\
\hline $\begin{array}{l}\text { 57. My parents are people who expect too much of me (for example, to do better in } \\
\text { school, or to be a better person). }\end{array}$ & .09 & -.04 & .12 & .66 & .06 & .08 & .00 & .53 \\
\hline $\begin{array}{l}\text { 16. My parents are people who are always trying to change how I feel or think about } \\
\text { things. }\end{array}$ & .25 & -.05 & .01 & .65 & .04 & -.01 & .02 & .66 \\
\hline $\begin{array}{l}\text { 21. My parents are people who go back and forth between being warm and critical } \\
\text { toward me. }\end{array}$ & .07 & -.01 & .14 & .61 & -.04 & .05 & .14 & .58 \\
\hline 14. My parents are people who act like they know what I am thinking or feeling. & -.13 & -.04 & .08 & .58 & .00 & .07 & .04 & .45 \\
\hline
\end{tabular}

Note. Boldface indicates highest factor loadings. 


\begin{tabular}{|c|c|c|c|c|c|c|c|c|}
\hline \multirow[b]{2}{*}{ Variable } & \multicolumn{7}{|c|}{ Factor loadings } & \multirow[b]{2}{*}{$h^{2}$} \\
\hline & 1 & 2 & 3 & 4 & 5 & 6 & 7 & \\
\hline 5. My parents are people who want to control whatever I do. & .27 & .00 & -.10 & .52 & -.17 & -.04 & .09 & .71 \\
\hline 41. My parents are people who go overboard in checking on my behavior. & -.05 & .02 & -.20 & .49 & -.16 & -.03 & .15 & .62 \\
\hline 18. My parents are people who bring up my past mistakes when they criticize me. & .28 & .06 & .11 & .48 & -.07 & -.12 & .06 & .63 \\
\hline 44. My parents are people who will take action if I don't follow the rules. & .01 & .10 & -.08 & .05 & .85 & .00 & -.05 & .69 \\
\hline 43. My parents are people who punish me when I do something they don't approve of. & .06 & -.03 & -.08 & -.16 & .80 & .02 & .00 & .70 \\
\hline 45. My parents are people who restrict my privileges when I don't follow the rules. & .01 & -.02 & -.03 & -.15 & .79 & -.01 & .02 & .71 \\
\hline $\begin{array}{l}\text { 42. My parents are people who apply consequences to me if I don't behave according to } \\
\text { their expectations. }\end{array}$ & .10 & -.04 & -.07 & -.13 & .78 & .06 & .06 & .69 \\
\hline 51. My parents are people who enforce the rules and regulations they have set. & .01 & .08 & .04 & .06 & .72 & .01 & .06 & .64 \\
\hline $\begin{array}{l}\text { 46. My parents are people who don't follow through on punishing me when I've done } \\
\text { something wrong. }\end{array}$ & -.16 & -.04 & .20 & .42 & .60 & -.01 & .05 & .50 \\
\hline $\begin{array}{l}\text { 232. At least one of my parents has lectured me or given me a speech about drinking } \\
\text { alcohol. }\end{array}$ & .10 & -.03 & -.02 & .00 & -.08 & .85 & .00 & .69 \\
\hline 233. At least one of my parents has warned me about the dangers of drinking alcohol. & .08 & .09 & .07 & .18 & -.05 & .79 & -.05 & .74 \\
\hline 231a. At least one of my parents has given hints that I should not use alcohol. & -.03 & -.07 & .06 & .04 & .04 & .78 & .01 & .67 \\
\hline 231b. At least one of my parents has given hints that I should not use drugs. & -.03 & .03 & -.05 & .06 & .15 & .63 & .10 & .56 \\
\hline
\end{tabular}

Note. Boldface indicates highest factor loadings. 


\begin{tabular}{|c|c|c|c|c|c|c|c|c|}
\hline \multirow[b]{2}{*}{ Variable } & \multicolumn{7}{|c|}{ Factor loadings } & \multirow[b]{2}{*}{$h^{2}$} \\
\hline & 1 & 2 & 3 & 4 & 5 & 6 & 7 & \\
\hline $\begin{array}{l}\text { 240. At least one of my parents asks about my thoughts and opinions about drinking } \\
\text { alcohol. }\end{array}$ & -.09 & -.04 & .05 & -.15 & .03 & .59 & -.09 & .58 \\
\hline $\begin{array}{l}\text { 111. During a discussion of a problem, how often do you criticize while your parents try to } \\
\text { ignore you? }\end{array}$ & .01 & .02 & .04 & .08 & .04 & -.02 & .67 & .57 \\
\hline $\begin{array}{l}\text { 109. During a discussion of a problem, how often do you attempt to discuss the problem } \\
\text { while your parents try to avoid the problem? }\end{array}$ & .11 & -.05 & .06 & -.05 & -.03 & .04 & .66 & .54 \\
\hline $\begin{array}{l}\text { 110. During a discussion of a problem, how often do you nag or blame while your parents } \\
\text { withdraw, become silent, or refuse to discuss the matter further? }\end{array}$ & -.01 & .03 & .06 & .13 & .12 & -.05 & .61 & .56 \\
\hline Eigenvalues & 22.81 & 8.91 & 4.66 & 2.77 & 2.27 & 2.06 & 1.55 & \\
\hline$\%$ Variance & 33.54 & 13.11 & 6.85 & 4.07 & 3.34 & 3.04 & 2.28 & \\
\hline Cumulative \% & 33.54 & 46.64 & 53.50 & 57.56 & 60.90 & 63.93 & 66.21 & \\
\hline Cronbach's alpha & .97 & .96 & .95 & .89 & .88 & .85 & .78 & \\
\hline
\end{tabular}

Note. Boldface indicates highest factor loading 
Table 5

Estimated Correlations between Parental Monitoring Factors $(N=320)$

$\begin{array}{lllllllll}\text { Factors } & 1 & 2 & 3 & 4 & 5 & 6 & 7\end{array}$

1. Quality Parent-Adolescent Relationships

2. Parental Monitoring Knowledge

$-$

3. Parental Knowledge Requirements

$.60 *-$

4. Feeling Controlled by Parents

$.27^{*} \quad .50 * \quad-$

5. Parental Enforcement of Expectations

$-.47^{\star} \quad-.23^{\star} \quad .25^{\star} \quad-$

6. Parent-Child Communication about Alcohol and Drugs $.15^{*} \quad .18^{*} \quad .37^{*} \quad .23^{*} \quad-$

7. Demand/Withdraw Communication

$.34^{*} \quad .27^{*} \quad .36^{*} \quad .09 \quad .33^{*}$

$\begin{array}{llllll}-.39 * & -.28^{*} & -.06 & .42^{*} & -.07 & -.05\end{array}$

${ }^{*} p<.01$ 
Table 6

Estimated Correlations between Parental Monitoring Factors and the Parent-Adolescent Communication Scale $(N=$

320)

\begin{tabular}{|c|c|c|c|c|c|c|c|c|}
\hline Scales & QPAR & PMK & PTC & CONT & ENF & CAD & DWC & PMT \\
\hline PACS Open Communication & $.83^{*}$ & $.54^{*}$ & $.15^{\star}$ & $-.53^{\star}$ & .05 & $.28^{*}$ & $-.37^{*}$ & $.61^{*}$ \\
\hline PACS Problem Communication & $-.56^{\star}$ & $-.41^{*}$ & .05 & $.73^{*}$ & .10 & -.05 & $.47^{*}$ & $-.28 *$ \\
\hline PACS Total & $.49^{*}$ & $.26^{\star}$ & $.23^{\star}$ & .05 & $.16^{\star}$ & $.31^{*}$ & .00 & $.49 *$ \\
\hline
\end{tabular}

Note. PACS = Parent-Adolescent Communication Scale; QPAR = Quality Parent-Adolescent Relationships; PMK = Parental Monitoring Knowledge; PKR = Parental Knowledge Requirements; CONT = Feeling Controlled by Parents; ENF = Parental Enforcement of Expectations; CAD = Parent-Adolescent Communication about Alcohol and Other Drugs; DWC = Adolescent-Demand/Parent-Withdraw Communication; PMT = Parental Monitoring Total score. ${ }^{*} p<.01$

John

$\mathrm{H}$.

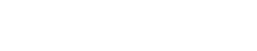

